\title{
What can I understand about children with special needs from the musical offerings that emerge in the music therapy process?
}

\begin{abstract}
A thesis presented in partial fulfilment of the requirements for the degree of
\end{abstract}

\author{
Masters in Music Therapy
}
at New Zealand School of Music, Wellington, New Zealand.

Shane Cammell

2008 


\begin{abstract}
This arts-based research thesis sought to understand two children with special needs, through their musical offerings within the context of their music therapy sessions. The process of understanding the children came through firstly listening to and extracting meaningful musical data from recordings of their sessions. This data included both actual excerpts of the musical interplays between the child and music therapist (myself), and more broadly, underlying themes drawn from the recorded session material. The data was then creatively 'melded', resulting in two original instrumental works, herein referred to as 'songs'. Before, during and after writing the songs, rigorous analyses were undertaken utilising both a formal approach, via the use of a contextual question framework, and two creative approaches: free-form narration and data-led imagery. The contextual question framework, involving the repetitive use of two key questions - where? and why? - sought to understand the data's context, its purpose for inclusion, and its influence on the respective song. One of the creative approaches, that of free-form narration, sought to, rather than analysing the song through formal structures, instead 'tell the song's story', narratively conveying the experience of being with the child in his music. The other creative approach, that of data-led imagery, involved creating images during and after being 'immersed' in the musical data, employing instinctive or subconscious means to further develop the therapist's understanding of the child's musical offerings, and moreover, the child himself. Upon completion of the two songs, it was discovered that clinical themes present from the sessions strongly influenced the song creation process. Results also strongly supported the validity of arts-based research as a viable means of analysing music created with children with special needs.
\end{abstract}




\section{Acknowledgements}

I gratefully acknowledge the support and encouragement I received from countless people during my research journey and over the years of my Masters study:

- My wife Elisabeth, for proofreading, photocopying, listening, for putting up with countless late nights and a rather absent husband, even when I was in the same room.

- My Family, for listening to countless music therapy activity role plays and endless editions of the final songs.

- Daphne Rickson, for shaping my thoughts and channelling my energies in constructive directions.

- Sarah Hoskyns, for teaching me that 'good enough is good enough'!

- Ruth Armstrong, for proof reading expertise

- $\quad$ Bridget Roche, for proof reading expertise

- and most importantly, the two boys within this research, whose musical voices became everything.

\section{Thank you all}

This research received ethical approval from the Central Regional Ethics Committee (Ref No: CEN/07/32/EXP). 


\section{Table of Contents}

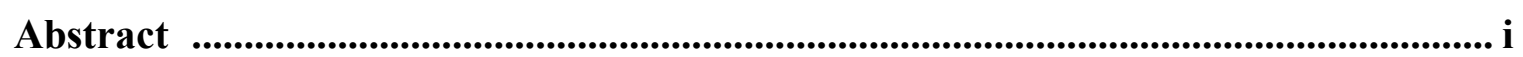

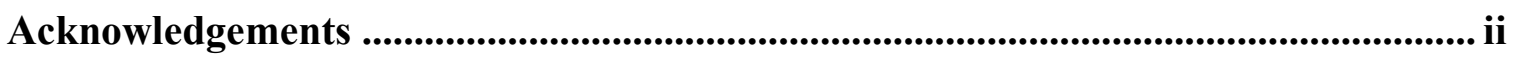

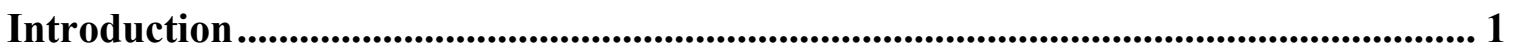

Central Proposition ................................................................................... 1

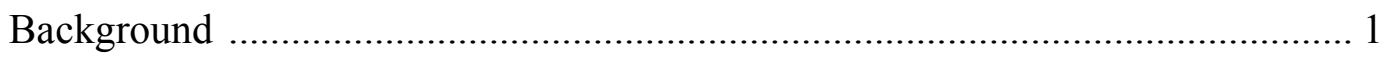

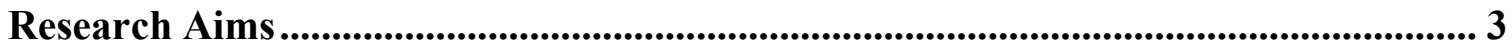

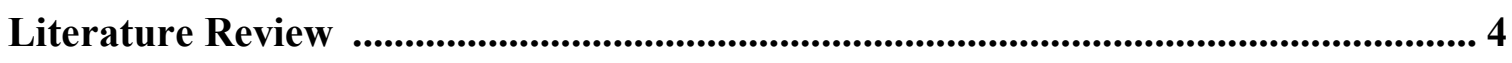

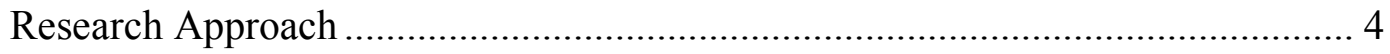

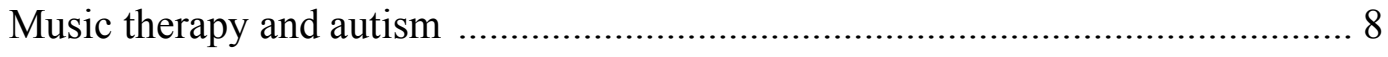

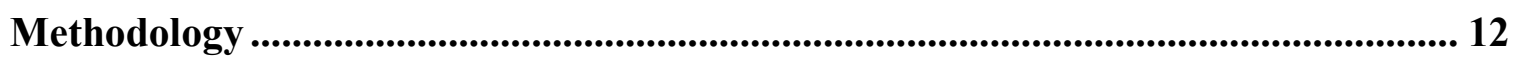

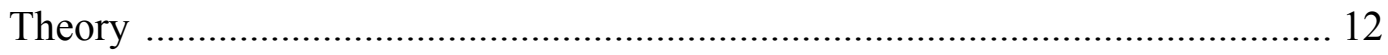

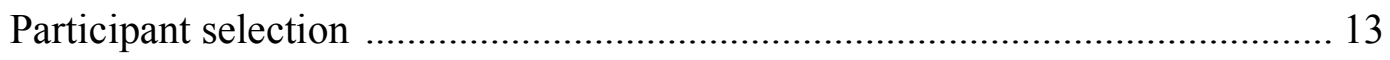

Method …...................................................................................... 14

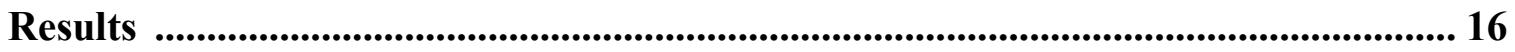

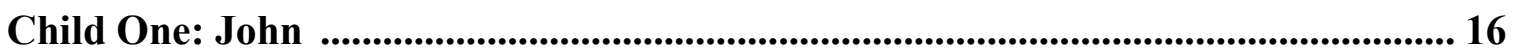

A creative description of the child ............................................................ 16

A short clinical description of the context ............................................... 16

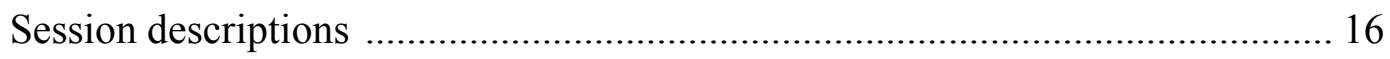


The song - 'Life is Good'

Song Analysis

Child Two: Robert

A creative description of the child

A short clinical description of the context

Session descriptions

The song - The Journey

The boys

John - 'Life is Good'

Robert - 'The Journey' 
References

Appendix A: John - 'Life is Good' - Garageband representation of sequential instrumentation

Appendix B: John - Classical Guitar Score 69

Appendix C: John - Distortion Guitar Score

Appendix D: John - Keyboard Score

Appendix E: John - Drum Score

Appendix F: Robert - 'The Journey' - Garageband representation of sequential instrumentation

Appendix G: Robert - Grand Piano Score 93

Appendix H: Robert - Xylophone Score

Appendix I: Robert - Marimba Score. 96

Appendix J: Robert - Jazz Bass 1 Score 99

Appendix K: Robert - Jazz Bass 2 Score 103

Appendix L: Robert - Maraca Score

Appendix M: JEX15 - John . 108

Appendix N: JEX15 - MT

Appendix O: REX06 - Robert - Xylophone

Appendix P: REX06 - Robert - Voice. 
Appendix R: REX06 - MT - Voice........................................................................................ 123

Appendix S: Robert's excerpt chart................................................................................... 124

Appendix T: Research Information Form for participant's parents......................... 127

Appendix U: Participant Consent Form ........................................................................ 129

Appendix V: CD Track List................................................................................................ 130 


\section{What can I understand about children with special needs from the musical offerings that emerge in the music therapy process?}

\section{Central Proposition}

'All behaviour is communication' (Watzlawick, Bavelas \& Jackson, 1967) and accordingly, musical behaviour can be musical communication. Through a rigorous examination of the musical interplays between the therapist and a child with special needs, this research's purpose was, by learning to listen to the child's communication, to contribute to a better understanding of the child. Furthermore, the research re-presents the themes, drawn from the clinical sessions, through song structures, gifting a musical voice back to the child.

\section{Background}

This research project arose from my work as a music therapy student, alongside children with special needs, who have been placed into mainstream school classes.

There were four key ideas that arose from the afore-mentioned clinical work and lead to the development of this research. Firstly, I believe that understanding a child's personality, pathology and presentation can enhance a clinician's ability to shape appropriate musically therapeutic interventions. This adds value to the accumulated understandings and effectiveness of the multi-disciplinary team assigned to the care of the child.

Secondly, the process of rigorously examining musical data produced from clinical practice has benefited my professional skills as an emerging music therapy 
professional.

Thirdly, although the results of this arts-based research are not able to be generalised, music therapists may benefit from the findings and from examining the research process that was undertaken.

Finally, the output of this research, offering a musical experience to recreate the child's musical voice, is innovative and unique within both a New Zealand, and more broadly an international context. The process of presenting research findings as an art form (in this case: songs, drawings and narrative text) is encompassed within two very similar research approaches: practice-led and arts-based research. Both practice-led and arts-based research employ creative mechanisms to approach and process the raw data, and then to understand the research findings. For simplicity's sake, I will use these terms interchangeably.

Whilst arts-based research originates in the qualitative rather than quantitative orthodoxy, some purport that a third paradigm be embraced (Haseman, 2007), allowing for sufficient departures from the qualitative 'camp':

$\ldots$ in this third category of research - alongside quantitative [symbolic numbers] and qualitative [symbolic words] - the symbolic data, the expressive forms of research work performatively (p. 150).

The findings are not able to be generalised nor are they empirically driven, as in quantitative research. The findings are analysed and communicated through ways departing from pure academic narration, as in qualitative research. This third paradigm involves steps additional to describing the data. Within arts-based 
research, the method and / or results are respectively experienced and portrayed actively. The researcher employs any number of creative arts, which become filters, through which the raw data is gathered, analysed, and presented as findings. Likewise, in this thesis, rather than the 'audience' of the research being given only a written interpretation of the findings, the reader will 'experience' the findings themselves. This research approach is new and still being developed (and defended) within the music therapy research community and other academic communities.

\section{Research Aims}

The first aim was to learn more about each child's personality, pathology and presentation by analysing rigorously both the music they created during their music therapy sessions, and the music drawn from me during the sessions and afterwards in the research process.

Secondly, by studying the musical material, I aimed to recreate the child's observable behaviour, musical or otherwise, through the creation of individualised songs. These songs attempt to help the listener come to an understanding of the particular children who participated in the music therapy sessions. Through this process, I hope to contribute to the body of research on the use of music therapy with children with special needs. 


\section{Literature Review}

\section{Research Approach}

Arts-based research is still in its early stages of development within the music therapy profession. While few examples exist in music therapy literature, one valuable example is that of Austin and Forinash's chapter in Wheeler (2005), which reviews the limited literature currently available at the time of printing. They describe quite accurately how, just "as we hold music and other art forms at the center of our clinical practice, it follows that music can also be the foundation of our research methods" (p. 458). This chapter includes the theoretical premises for arts-based research, reveals the historical background to this research approach with music therapy, and then elaborates on the potential methodologies available in using this approach. The chapter then catalogues important contributions from music therapy researchers that currently exist, describing also several examples from other arts-based therapies.

Indeed, more examples are found in other arts-based therapies, for example, dance (Olsen, 1995) and art (McNiff, 1998). There is a call however for a greater acceptance of, and growth within this area of music therapy research. Haseman (2007) states that:

...central to the argument for an alternative methodology for the creative arts [research] is an insistence by practice-led researchers, that research outputs and claims to knowledge be reported through symbolic language and forms specific to their practice (p. 148). 
Such a thought challenges conventional methods of presenting research findings. Arts-based researchers such as Haseman (2007), believe it to be foolish to seek only to:

...'translate' the findings and understandings of practice into the numbers [quantitative] and words [qualitative] modes as favoured by time-honoured research models ... [as it can only result in the] ... dilution and ultimately the impoverishment of the epistemological content embedded and embodied in practice (p. 148).

One arts-based research example, mentioned in Austin and Forinash (2005), is a review on Jenoure's (2002) 'Sweeping the Temple: A Performance Collage', where a series of research interviews gave rise to a performance of spoken words, sung vocals and violin playing. In the process of creating the performance work, Jenoure confessed to struggling to make the performance as accessible to the 'audience' as possible and yet still remain true to her original data, not embellishing for artistic sake alone. Jenoure also strove to avoid imposing any particular art forms on her work. She acknowledges that the research process had gifted her a new appreciation for the ways her biases affected so many aspects of her work. Even more so, she desired to remain true to the memories of her friend Patti, the key figure represented in the performance, who died of cancer before the performance was delivered. Jenoure states “... at some point, I realised that I simply wanted people to know Patti better" (p. 78). By putting her research results into an 'active voice', she hoped a wider population might experience what Amir (1990, p. 65) describes as going "beyond physically observable reality to intuition, emotions, feelings, 
thoughts, and kinaesthetic sensations".

Another example mentioned by Austin and Forinash (2005) is that of Austin's multi-layered research into Alcoholic's Anonymous (1998), which also utilised music (among other art forms), culminating in a musical play called 'Grace Street'. As part of the research process, Austin attended four months of AA meetings to explore their appeal and success. She initially processed her thoughts and reflections (including self-reflexive) via creative mechanisms, such as writing poetry and keeping a reflective diary. Dunn (2006) describes how this play, performed at an American Music Therapy Association conference, was "not presented dryly with a great deal of professional jargon". Rather, the audience could "see, hear and experience an AA meeting". Austin's research study results "came to life" (p. 18).

In yet another example of arts-based research Blumenfeld-Jones and Barone (1997) reproduced an analysis of their research interview data, in terms of its musical qualities, such as pitch, tempo, rhythm and harmony, to examine outcomes of teacher preparation that focused on diversity issues.

This current research dissertation explored new territory, using arts-based research to gain understanding of two children with special needs who have individual music therapy sessions. It consists of two components. Firstly, from improvisational 
(referential ${ }^{1}$ and non-referential ${ }^{2}$ ) activities within clinical sessions with the aforementioned children, musical data was gathered and rigorously analysed.

Bruscia (1987) and Wigram (2000a) both describe how musical material, such as tempo changes, rigid or flexible rhythmic patterns, phrasing, changes in intensity and general variability in style, can be analysed and measured. Analysing musical improvisations as the 'raw data' of the therapy in order to identify, compare, interpret and reach conclusions about a child's personality, pathology and presentation is an important procedure of music therapy assessment (Wigram \& Gold, 2006). Several authors, including Nordoff \& Robbins (1977, 2007) and Wigram (2000b) have published assessment models suitable for children with special needs. However, Wigram, Pederson \& Bonde (2002) also note that despite the many formal assessment models available, clinicians have often chosen instead to develop their own very effectual and suitable ways of examining and recording change in music therapy.

In music therapy, the client in the music "sounds his Self, how he behaves, how he feels, and how he expresses his conflicts ... the music sounds as the client's psyche" (Smeijsters, 2005, p. 72). Smeijsters goes on to state how the client "expresses himself in the music in the same way he expresses himself in other contexts and by other media of expression ... unhealthy thoughts, feelings, and behaviours come to sound in the musical play and musical choice of a client" (p. 89). Understanding the

\footnotetext{
${ }^{1}$ referential improvisations derive from a premeditated source or idea. A prearranged theme 'colours' the context of the improvisation.

2 non-referential improvisations do not derive direction from a specific theme. Also known as 'free' improvisation.
} 
client's music greatly enhances the clinician's ability to understand the client's pathology and therefore to shape and offer therapeutic activities.

Secondly, and specific to arts-based research, the data and moreover the 'experience' of capturing the data is re-presented, using personalised songs to portray the experience for the 'audience' of this research. While the songs are analysed using words in the discussion section, the primary motive for this research was that the major output transcends words, putting that which cannot be described by words into a format that has no need for words. Priestley suggests that music and words are two distinct forms of communication, and that a translation between these two languages is problematic, moreover that "the interpreters are few and far between" (1994, p. 28). She also notes however that there is an attraction for the music therapist to let the music, created from the therapeutic process, have its own veiled denotation. So while it may have been simpler to write the songs, and let them stand alone as the output, I decided instead to discuss the songs in their context as representations of the experience of 'musically being' with the two respective children.

\section{Music therapy and autism}

The two children whose musical material this research focused on are both diagnosed with ASD (autistic spectrum disorder). Autism is currently defined at the behavioural level, on the basis of impairments in socialisation, communication and imagination, with stereotyped repetitive interests taking the place of creative play (American Psychological Association, 2000). Wing \& Gould (1979) describe how impairments present in the autistic condition can be visually explained using a 
'triad of impairment' with social, intellectual and communicative aspects situated respectively at each corner.

Individuals on the autistic spectrum often have sensory integration difficulties (SID). Jacobs (1999) cites Ayres' (1968) seminal work on SID that explained two inherent problems: difficulties with the perceiving and sensing and the modulation of incoming stimuli. One consequence of inadequate perception of proprioceptive sensory input is difficulties found in managing motor challenges. Additionally, Nicholas et al. (2007) describes how in screening high-functioning autistic progeny and their parents for "clock' genes that are associated with temporal synchrony, sleep and memory, etiologically significant anomalies were found. These anomalies are suggested as causative factors in autism.

One of the first documented examples of music therapy being used as an intervention with autism is Nordoff \& Robbins $(1977,2007)$, who while developing 'Creative Music Therapy', describe autistic children, previously 'unreachable' becoming animated and 'extending' outside their supposed boundaries when placed in a musically inviting environment. Trevarthen (2002) describes how these pioneers of 'Creative Music Therapy' discovered that by emulating the foundational desires of motivation and emotional states, offering "rhythmic coherence, continuity and balance of emotional change and a 'narrative' of feeling, ... [the music therapist] ... can reach the sensibilities of an autistic child and give form and consistency to motivation" (p. 87).

3 Clock genes encode proteins that regulate circadian rhythm; the 'clock proteins' affect both the persistence and length of the circadian cycle (Wimpory, Nicholas \& Nash, 2002). 
Since these initial findings, music therapy has become increasingly accepted as a positive intervention for clients with ASD. Wigram (2002) describes how music therapy is a worthwhile intervention for children with ASD for its ability to "engage and nurture their capacity for flexibility, creativity, variability and tolerance of change" (p. 11). Music making that occurs in music therapy, specifically improvisation, can also offer an autistic child a 'safe' construct, while still stretching their rigid boundaries to realise greater emotional and communicative flexibility.

Stable and recognizable musical frameworks ... can provide security, and at the same time allow creative improvisation within ... [a structure which should] ... include repetition of ideas, sequences and repeated phrases to ensure that there is some direction and familiarity in the musical material (Wigram \& Gold, 2006, p. 537).

As those with ASD struggle in areas of communication, a musical relationship between the music therapist and themselves can provide a space or a transitional bridge (Winnicott, 1971) through which relational contact can be made, unhindered by verbal limitations. Within the sessions, the communicative emphasis is through the music; therapeutic goals are achieved through this focus. For example, the client may be encouraged in the music to offer musically sympathetic responses to the tempo and dynamic range of the therapist's musical interactions (Trevarthen, 2002). He also describes how:

The same rhythmic sense and self-expression in narrative as infants show in protoconversation remains as a receptive resource inside the 
confused consciousness, wayward emotions and impulsive motility of autism. Improvised musical engagement stimulates episodes of concerted activity and brings this receptivity to life, regulating anxiety, aiding coherent awareness and memory and helping the child to enjoyable contact with persons and more comprehensible communication (p. 86).

However, Alvin (1975) does identify several contraindications in working with individuals with autism. She explains that music can in fact become a fixation, which unfortunately can aid in withdrawal and self isolation. Music can sometimes hypnotize autistic individuals into lassitude and focus them inward, making them unaware of their environment.

Nonetheless, a musically therapeutic relationship can still enhance reciprocity and ameliorate deficiencies in sharing and turn-taking (Aldridge, 1996; Bunt \& Hoskyns, 2002; Davis, Gfeller \& Thaut, 1999; Wigram 2000a; Wigram \& Gold, 2006). Music therapy can offer opportunities for meaningful connection when the client is non-verbal, as well as regulating emotion and mood expression, particularly anxiety. It has also been used in the reduction of echolalic responses which impede functional language use (Bruscia, 1987). 


\section{Methodology}

\section{Theory}

This research, whilst containing hermeneutic and naturalistic influences, is nonetheless essentially arts-based research.

The primary hermeneutic aspect was that of an interpretive nature to the analysis of the musical data. Hermeneutics is the "art and science of interpretation" (Kenny, Jahn-Langenberg \& Loewy, 2005, p. 335). It is important to acknowledge a hermeneutic influence, as the way in which the children's musical offerings were interpreted and notated was influenced by how meaning is derived by the researcher.

The naturalistic aspect of this research was the context, in that the music therapy sessions being 'observed' were not altered in any way due to undertaking of the analysis (Aigen, 2005, p. 355). The clinical work remained the priority, and the therapy was client focused.

However, despite these borrowed aspects from other research methodologies, this research thesis was essentially arts-based research. Arts-based research, as mentioned earlier, is a relatively new research approach, and has much to offer music therapy with its stress on utilising music and other art forms as the research mechanism. Austin and Forinash (2005) describe how by "following the creative process and letting it unfold", what results is not only an "artistic artifact but also a research outcome" (p. 460).

Arts-based research uses the arts (for this thesis, songs, drawings and narrative text) 
as a response to the raw data produced by the music therapy clinical practice, for the purpose of creating new data. This approach allows me to communicate, through auditory means, statements too difficult to convey only through words. Arts-based research can also best describe subtleties and enhance the portrayal of experiences in ways that do justice to the intricacies of the research subject (Knowles \& Thomas, 2002).

Furthermore, artistic forms are closer to the "irrational world of the unconscious and the source of creativity" and thus closer approach rendering experience than the more "rational world of words" (Austin and Forinash, 2005, p. 470). Sandelowski, Trimble, Woodard \& Barroso (2006) describe how when working with stigma in HIV-positive women, "the process of transformation entailed bringing together the norms and imperatives of scientific research, clinical practice, and artistic presentation" (p. 1367).

\section{Participant selection}

All children currently undergoing music therapy at the school were invited to participate in the research. Information and consent forms (see Appendix T and $U$ ) were sent to parents, and both parents and children were offered opportunities to ask any questions at any stage of the research process

From the consent forms received back, two children were randomly picked, using a lottery-based system of 'names in a hat'. It was specified within the information and consent form, that those children not chosen, and their parents, would be informed of the outcome and that they might be used in the future due to one of the participants not being able to take part in the research. 


\section{Method}

Over the period of data collection, six sessions for each child were audio recorded using a Belkin TuneTalk Stereo Voice recorder attached to an Apple iPod. The recording device was placed on a shelf at one end of the room, closest to where most of the musical activities took place.

Each week:

$\# 1$. Each session was listened to once, and then one sentence or phrase was written to describe the overall impression of the session.

\#2. Each session was listened to again, and excerpts marked that seemed meaningful.

\#3. Each excerpt (or musical phrase) was listened to again, and 'categorised' with an impressionistic title.

\#4. The musical extract was notated, where possible, and the activity that occurred in each excerpt was described in detail.

Outputs - After all data had been collected:

\#5. A personal description of each child was written, and excerpts were chosen to be used in each composition.

\#6. A song was written for each child. The purpose was to communicate an overall impression of the respective child using data from specific excerpts to represent particular aspects of their respective clinical presentations. The aim, if possible, was to demonstrate contrasting mood or presentations observed during clinical work. 
\#7. The output of each child was discussed, in relation to the clinical description of the child and where possible, in the context of their specific diagnostic condition.

Whilst writing the song for each child, it should be noted that I decided against using voice, as the listener would be hearing mine, not the boys'. However, as the children's respective musical offerings were balanced, excerpts containing both instruments and voice, and for ethical reasons being unable to include vocal excerpts in the research songs, I decided to notate some of the vocal excerpts and include them instrumentally. 


\section{Results}

The process discussed in the previous Methods section involves first describing the sessions, and successively analysing them, leading further on to a description of the child. However, for reasons of logical presentation order, this Results section starts appropriately with the child, as this thesis is still essentially client-focused research.

\section{Child One: John}

\section{A therapist's personal description of the child}

Delightful, semi-chaotic warmth; a rambunctious smile.

\section{A short clinical description of the context}

Music therapy sessions were held over a period of ten months, but the research period was over six weeks, one session per week (S1 - S6) with John, who has fragile $\mathrm{X}$ disorder, dyspraxia, and is behaviourally on the autistic spectrum. John, who attends a mainstream primary school, presents as a socially communicative child with speech difficulties, a tendency to display repetitive behaviours and a sensitivity to sensory input, specifically auditory.

\section{Session descriptions}

S1: $\quad$ The session was exciting; full of nervous energy and exploration.

S2: $\quad$ The session was exploratory with more structure.

S3: The session contained moments of humour; an adventure in semiorganised chaos.

S4: The session was busy, challenging limitations - his and mine. 
S5: The session was all about singing and other vocalisations - much laughter.

S6: $\quad$ The session was steadily paced with much talking and playing; I felt a little sad, it being our last session.

\section{The song - Life is Good}

\section{Song Analysis}

John's song was written with two major aims in mind. Firstly, to present behavioural themes, musical or otherwise, that emerged from his sessions. And secondly, to express specific moments that particularly personified John as a musical individual. Excerpts are located on the disc accompanying this thesis. Excerpts are labelled JEX (J Excerpt) plus the number, for example JEX01, JEX02, JEX03 etc.

Each portion of the song analysis is broken down into important questions:

Where? Where is this motif, melodic or rhythmic, from? Describe its context. Is it an actual transcription from an excerpt? If so, is it melodically and/or rhythmically identical? Or have I transposed it? If it isn't drawn from an excerpt, is it thematic? Is the theme drawn from John's music? Or is it more behaviourally driven / inspired?

Why? Why did I include this motif? Why put it at this point in the song? Why use this particular instrument? Why are the characteristics of the instrument important or pertinent? 
The song, broken down into each instrumental contribution, is analysed below:

Time Instruments - as introduced sequentially.

00:00 Drums - D01 - '3, 2, 1, Hit it!'

Where: The rhythmical motif, which starts this song, is drawn from JEX01. It is not an actual transcription, as the original is spoken; this adaptation is percussive. It mimics the vocal start to an improvisation we created in Session 1 (S1). John announced, unrequested, at the start of the improvisation: "Three, Two, One, Hit it!!"

Why: I included this motif as it felt a natural way to start the song, being a count-in. The tom-tom drum used in this phrase is an instrument John enjoyed using. I also chose to use this particular drum for its 'attack' (sound quality), as in JEX01, John's speech is clear and staccato in pronouncing the words, similar to the drum.

00:02 Distortion Guitar - DGT01 - 'Joy’

Where: This melodic motif, drawn from JEX21 is an approximate transcription of a delightful laugh, an outburst of joy that John expressed during S6. Melodically and rhythmically, it is a close representation, and dynamically, it is animato (animated).

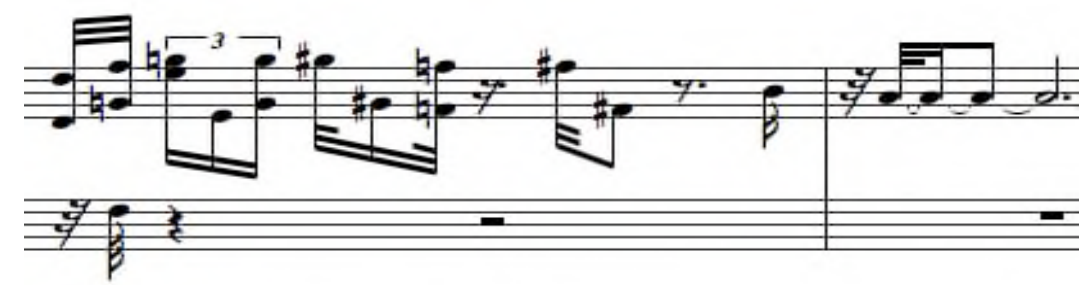

Figure 1: Transcription of John's laugh from JEX21 
Why: This motif expresses thematically the enjoyment John expressed during his music therapy sessions. In JEX28, he is captured becoming excited, to the point of perseveration.

\section{0:05 Classical Guitar - GT01}

Where: This motif has a step up / step down quality to it, and is rhythmically syncopated. It is thematically based on a number of levels. It draws on John's behaviour, whilst music making or otherwise. It is based upon excerpts JEX29 and JEX30.

Why: While the step up / step down motif represents the exploratory nature of John's keyboard playing, as captured in JEX29 and JEX30, I did choose to however not directly transplant the excerpts at this point in the song, though samples from these excerpts are represented later in the song. The up and down nature of the phrase is also analogous to how I often felt with John. In a session, after participating enthusiastically in a song containing distinct vocal phrases, John would speak the pertinent phrase slowly and clearly and present as behaviourally calm. In the following session, he would exhibit great difficulty in pronouncing the same phrase and become agitated at the effort. Progress is a relative description.

Additionally, the guitar is used in this phrase, as in a direct reference to my style of therapy, as I used guitar a great deal in containing John's music. The idea that the phrase is the backbone of the song is parallel to the amount of guitar usage in our sessions. 
Finally, the syncopated nature of the second half of the phrase intends to infer a sense of off-balance; a lack of rhythmical awareness, which was prevalent in much of John's playing and singing. Finally, there is a lot of space in the phrase. This was characteristic of our sessions, as John would often display perseveration, becoming fixated on a note or rhythmical motif and repeating it multiple times - musically, perseveration itself is represented later in the song. This is a common trait of autistic individuals. When he presented as such, my first reaction was sometimes to pause, giving him space, as he would often laugh with glee, caught up in the moment. Perhaps I was also 'caught up' or 'stuck'?

\section{0:05 Guiro - G01 and G02}

Where: Several guiro samples were included at this point, not transcribed from particular excerpts, but rather for the purpose of developing several themes that emerged from particular excerpts. One of the samples used, G02, is shown below:

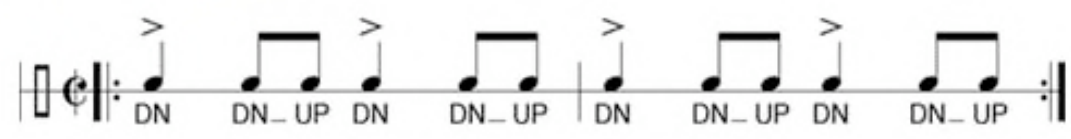

Figure 2: Charanga rhythm: $D N=$ Down stroke; $U P=U p$ stroke (Gajate-Garcia, 2002).

Why: This instrument was used only on occasion in our sessions. However, in writing this song, I considered it firstly as an analogous reference to John's stuttering, especially G01, due to the drawn out percussive character of the instrument's sound. An example of John's stuttering is found in JEX31. 
It further linked to John's musical behaviour, as the traditional Charanga rhythm employed at this point in the song (G02]) is an inversion of his 'beatboxing' rhythm, as found in JEX05 and JEX06.

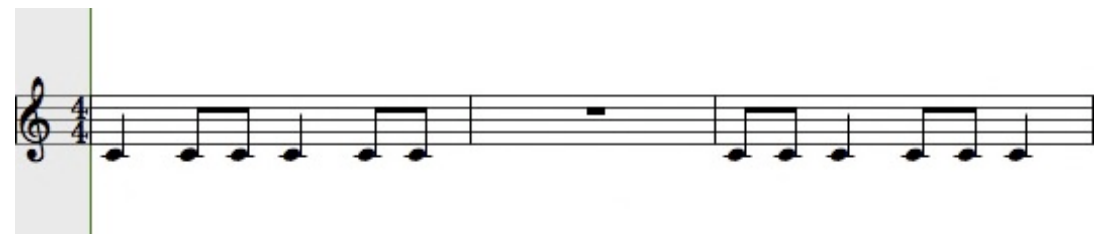

Figure 3: Charanga rhythm \& John's 'beatbox' rhythm respectively.

Additionally, the guiro samples were placed whereby the rhythm patterns phased in and out of time with the guitar rhythm. This characterised many of John's musical interactions during our sessions. For example within JEX15 (see Appendix M and N), during his 'Hello Song', bars 4, 18, 21 and 31 show how he is most probably aware of the song structure, but rushes ahead in his phrasing, despite having heard and sung the song in many previous sessions. Within bars 15 and 16 , he appears almost to be matching me, with only a slight echo. He is able to sing along with me rhythmically at bars 7, 11, 25, 26 and 30 .

\section{0:21 Drums - D02}

Where: These drums were added for thematic reasons, rather than being inspired by a particular excerpt. The drums are used to convey excitement, with a tempo of 120 beats per minute.

Why: Being with John, musically or otherwise, was exhilarating. There is energy to his presence that pours into his music. From his excited 
vocalisations and xylophone playing in JEX28 to the 'guttural' speech he employed (JEX14 and JEX19) with his cheeky sense of humour, our sessions never lacked 'movement'!

00:23 Keyboard - K01

Where: John often enjoyed improvising on the keyboard. The keyboard motif provides a stylised and shortened representation of John displaying perseveration whilst playing this instrument.

Why: The repeated notes symbolise his repetitive musical behaviour that was common during improvisations. Perseveration occurs when an individual gets 'locked into' repetitive behaviours. Kanner (1943; cited in Trevarthen, 2002) described this as an 'insistence of sameness'. Some excerpts embodying this presentation include JEX25, JEX26 and JEX27; a consequence of this behaviour is a gradual loss in engagement.

\section{0:26 Distortion Guitar - DGT02 - 'Joy'}

Where: The expression of joy returns. It is placed within the phrase representing perseverative playing on the keyboard.

Why: This embodies the pleasure John displayed playing rapid notes, as shown in JEX28. 


\section{0:31 Guiro - G03}

Where: This motif uses the same Charanga rhythm as G02, though slightly faster. The motif starts in time but ends out of time with the guitar track.

Why: This motif suggests John showing a reduced awareness or ability to be with others in the music. It represents John's difficulty playing in the same rhythm with another person. Normally in a music therapy session, when John would initiate a rhythmical pattern, I would adapt what I was playing to accommodate and contain his pulse and / or dynamic range.

00:39 Beatbox - B01

Where: This motif is a stylised representation of John's enthusiastic 'beatboxing' vocalisations. JEX06 shows how in the middle of the xylophone improvisation, he puts down the beaters and places his hand over his mouth and using forceful expulsions of air, creates a strongly percussive-sounding rhythm. The motif is in synchrony to D02, with the heavy down stroke mostly on the crotchet beat, as opposed to the quaver off-beat.

Why: The 'beatbox' samples were included to capture the enthusiasm John displayed during improvisational activities. He expressed a consistent desire in our sessions to explore musical experiences. The motif was synchronised with the other tracks to represent the occasional moments where John played in time with the containing rhythm. 
00:40 Keyboard - K02

Where: This motif shows John beginning to explore the range of the keyboard. There is a playful quality to the execution of the notes.

Why: The main purpose for using this phrase was to express the playfulness John often displayed in his music.

00:47 Distortion Guitar - DGT03 - 'Joy'

Where: The joyful expression returns yet again. It is placed this time directly in proximity to $\mathrm{K} 02$ and $\mathrm{B} 01$. It is also a shorter phrase than the previous joy motifs.

Why: It is placed at this point in the song as John has started to open up in his exploration of the keyboard and in performing his beatbox skills. Its shorter length represents more of a 'woohoo' than an actual laugh.

00:49 Keyboard - K03

Where: This motif is more tonal than K02. It contains octaves and some repetitive note playing.

Why: John showed the capacity to play tonal melodies, for example in JEX20 with his 'Hello Song'.

00:49 Guiro - G04

Where: This motif involves slow deliberate scraping across the guiro with a crisp attack. The time between strikes gets progressively shorter. 
Why: This motif revisits John's stuttering, a clinical presentation of his dyspraxia. This sample of the guiro is similar to G01, though more pronounced in quality.

\section{0:53 Classical Guitar - GT02}

Where: GT02 possesses a similar rhythm to GT01. The syncopated nature is maintained through the passage. Melodically however it deviates. Whilst the second half of GT01 moves in an ascending and then descending direction, the second half of GT02 is predominantly descending, ending on the dominant of the key (E). Dynamically, this phrase gradually becomes quieter in a diminuendo, then in the second half returns to full volume suddenly.

Why: The melodic stepping up, but mostly down between notes is again reminiscent of John's exploratory musical behaviour on the xylophone and keyboard. In juxtaposition to the descending direction of the second half, the last note steps up. This has a questioning quality to it, as verbally a raised inflection would normally indicate a question. A purpose of John's music therapy sessions was to support him in language and pronunciation exercises. This included certain question phrases. Additionally, the guitar phrase changed here, in terms of volume, to represent an approach I used often in our improvisations. I would alter dynamics, asking him musically "are you listening to me?" Other variations included altering tempo or suddenly stopping again musically asking "Hello? Are you listening? 
00:55 Keyboard - K04

Where: Melodically, this motif is simpler. Fewer notes are used though there is still a playful quality. It is also an answering phrase to the second half of K03. Melodically, this motif steps down and up, like an inversion of K03.

Why: This simplification of the melody represents John's reaction to the introduction of the new musical idea. Whilst I don't have a particular excerpt example, I did observe in earlier sessions, a hesitation when a new activity was introduced.

\section{0:57 Beatbox - B01}

Where: This is the same sample that appeared earlier at 00:39. Its placement however is shifted so as to be rhythmically opposing the D02 beat. The heavy down stroke lands mostly on the quaver off-beat, whereas earlier it sounded on the crotchet beats in the bar. However, this sample, whilst playing 'offbeat' still complements this portion of the song.

Why: This is another example of the theme already explored, John's difficulty in acknowledging another person's part in the music. The oppositional quality to the motif symbolises John's musical 'path', which would only sometimes converge with others' paths. Sometimes I would alter my playing to match his rhythm, though it was also beneficial to persist in rhythmical opposition, even exaggerating it to capture his attention; this worked, at times. 
01:09 Classical Guitar - GT01

Where: GT01 returns at this stage of the song after GT02 introduced new melodic material.

Why: This motif, that represents my containment of our sessions, returns representing coming back to 'the familiar'. Our sessions were framed and interspersed with regular activities; predictability gave John structure to create within. A 'Hello Song' and 'Goodbye Song' respectively started and finished each session. By the end of the ten months of working with him, he was singing along with most of the words, though quietly - see JEX15.

01:09 Distortion Guitar - DGT04 - 'Joy'

Where: DGT04 returns, this time directly preceding K05.

Why: Its expression of joy or 'woohoo' announces John's growing freedom in his musical creativity.

01:09 Distortion Guitar - DGT05 - 'Joy'

Where: DGT05 arrives at the top of John's first keyboard 'climb'.

Why: Like in previous appearances, it is symbolic of John's infectious laugh see JEX21.

01:10 Keyboard - K05

Where: As mentioned previously, K05 appears after another symbolic 'woohoo' from the Distortion Guitar. It is also situated at the return of GT01. 
Why: With the return of GT01, John's playing of the keyboard is 'unleashed'. John's music, contained and supported by the guitar playing, becomes more experimental and spans a wide range of the keyboard. Tonally, it is reminiscent of the theme explored by GT01, stepping up and down. The keyboard moves directionally up then accelerates downward, ending with a 'last minute' rapid ascending glissando, similar to JEX30.

\section{1:25 Classical Guitar - GT03}

Where: This motif contains new melodic material for the classical guitar. Like GT01 and GT02, space is still present. A glissando is placed early in this motif, echoing the glissando at the end of K05. Dynamically, this motif features a diminuendo.

Why: The new melodic material indicates a change in direction, or at least a metaphorical pause in my playing; John's heightened energy feels overwhelming. The space in this motif represents me 'standing back' as John becomes ever increasingly absorbed in his keyboard creativity. The diminuendo is actually representative of John, not myself; it shows him becoming increasingly disengaged with our musical relationship.

\section{1:25 Drums - D03 - 'Losing him?'}

Where: This drum motif is new and a lot less 'busy', defined perhaps as a 'half-time feel'. Unlike D02, D03 does not use the snare drum, which featured prominently in D02. It cuts off abruptly, at approximately the same time that GT03 has finally faded. 
Why: The impressionistic title for this motif is 'Losing him?' Arriving at the same time as GT03, the laid back character contains space and a simplification in presentation. With the loss of the snare, D03 starts to fade away. It is representative of a gradual loss, like GT03, in connection between John and myself due to perseveration.

\section{1:26 Distortion Guitar - DGT06 - 'Joy'}

Where: DGT05 arrives at the top of John's glissando at the end of K05.

Why: Like in previous appearances, it is again symbolic of his triumphant joyful outburst. - see JEX28 (00:19 - 00:23).

\section{1:28 Keyboard - K06}

Where: K06 arrives on the tail of K05's enthusiastic 'glissandic explosion' which culminated in the outburst of joy in DGT06. K06 is characteristically similar to K03, with octaves and repetitive playing, though much longer. John launches into a perseverative scalic run up the keyboard, closing with broken octaves. As he plays the closing octaves, all other instruments gradually stop.

Why: This feeling that was inferred from K05, that is, the captivation of his playing drawing him away from our musical dialogue, becomes a reality in the monologue of K06. This is an inference of a less engaged therapeutic situation. The slowing down of the broken octaves may symbolise John beginning to recognize his self-imposed 'musical aloneness'. And then there is silence... 


\section{1:41 Distortion Guitar - DGT07 - 'Joy'}

Where: DGT07 occurs at the peak of John's perseverative scalic run, as he moves into the decelerating broken octaves. It occurs four times in a row to emphasise its thematic purpose.

Why: Persistently, this motif has symbolised John's joy and enthusiasm. However at this point in the song, further musical encouragement or stimulation from myself could have been detrimental. In these types of situations, I was cautious of him becoming over stimulated. A basic premise of my music therapy work with John was to provide pleasurable musical engagements. This over stimulation would foster disengagement and could lead to agitation.

\section{1:53 Classical Guitar - GT03}

Where: GT03 returns again after the period of silence that followed his perseverative outburst.

Why: GT03 was paused from re-entering, to evoke a response from John, to break him out of his repetitive behaviour. Wigram, Pedersen \& Bonde (2002, p. 185) discuss how, among other techniques, pausing or 'freezing' is an effective way to elicit a response; in this circumstance, from a perseverative client. The reintroduction is an invitation to John: "Let's continue!" 


\section{1:54 Keyboard - K07}

Where: K07 occurs as an answer to the invitation just presented by GT03. It starts with a descending glissando, an answer to the build-up throughout the K06 motif. The chords vary between tonal and atonal, and are strongly syncopated. The phrase ends with yet another upward glissando.

Why: This motif starts where K06 ended. John stopped playing upon realizing that GT03 had stopped. The silence I offered captured his attention, reengaging him and drawing him back to the musical dialogue. The reintroduction of GT03 gives John 'licence' to resume playing. John appears to become more attuned to my musical frame during this time. This is evidenced through his use of the tonal open fifths.

\section{1:56 Drums - D02 - 'And he's back!' ('Excitement')}

Where: D02 comes in after John has finished his 'glissandic' answer to K06.

Why: This motif, familiar due to its presence throughout the song, represents John's energy, moreover his contained energy. His period of perseveration 'caused' the drumbeat to change and ultimately cease. Its return symbolises the re-initiation of our dialogue.

\section{1:57 Beatbox - B01}

Where: John's ‘beatboxing' also returns. It is in synchrony with D02.

Why: The return of B01 signals John's enthusiasm is still present, but as the motif is in synchrony to the song, it represents his ability to, on occasion, match the pulse of the musical activity. 
02:05 Beatbox - B01

Where: This is essentially a continuation of the previous B01 motif. However, it becomes asynchronous to the surrounding music.

Why: This motif's purpose juxtaposes the previous B01 motif to demonstrate that even while John is engaged, he still has difficulty playing in time with another persons' music.

02:09 Classical Guitar - GT01

Where: This motif occurs after GT03, bringing back the original musical idea that 'contains' this song.

Why: The GT01 motif has threaded through the song, creating a containing structure. As mentioned earlier in this analysis, specific familiar songs were used to communicate the start and finish of John's sessions. GT01, returning once again, thematically reminds the listener / reader of that concept.

\section{2:11 Keyboard - K08}

Where: This motif is not a direct transcription from an excerpt. However, it is thematic of John mostly 'moving' in musical synchrony with me.

Why: Like B01 at 01:57, this shows that there are moments when John is able to sing or play rhythmically with me. Excerpt JEX15 (Appendix M and N) contains examples of John matching my singing. 


\section{2:24 Keyboard - K09 - 'Goodbye Shane'}

Where: This motif was appropriately placed at the end, as it was John's personal 'Goodbye Song' to me in our last session. The first four notes of this motif were taken directly from JEX20, though positioned so as to be in approximate time to the accompaniment. The remainder of the motif was transposed down a minor third. The timing was left unchanged.

Why: JEX20 was extracted from S6 as a unique musical moment. I had reminded John that I usually play a 'Goodbye Song' to him at the end of every session; how about he play a 'Goodbye Song' for me?! He acquiesced, and with a xylophone, played me his 'offering'. Whilst I extracted it for this research, perhaps for sentimental reasons, it is still nonetheless, an accurate portrayal of John's musicality.

However, after writing John's song for this thesis, I returned to the excerpt, wistfully wondering whether I still might be able to use it, perhaps just to honour my memories of our relationship. What I discovered was, for me, astonishing. Apart from some small adjustments, with regards to key in one portion, and timing in another, JEX20 was able to be inserted directly into the song without any major manipulation. The excerpt essentially fits perfectly within this song. It provides a counter-melody to GT01 and as John's 'goodbye' to me, it is the ideal way to sign off this song, alongside DGT08 (to be discussed below). 
02:26 Distortion Guitar - DGT08 - 'Peace out!'

Where: This motif is a stylised representation of John's final words to me in numerous sessions: "Peace out!!!"

Why: This motif is included as, like K09, it signals the end of my time with John. This was commonly expressed at the end of our sessions including the last session. 


\section{Child Two: Robert}

\section{A therapist's personal description of the child}

Warmth with shiny, smiling eyes; prone to spilling over with chaotic wild abandon.

\section{A short clinical description of the context}

Music therapy sessions were held over a period of ten months, with an autistic child who attends a mainstream school. Robert presented as a 'bubbling pool of energy', his behaviour chaotic at times, calmer and more interactive at others. He is verbal, but has limited language and displays periodic echolalia. His ability to interact with others, on the whole, is extremely limited.

\section{Session descriptions}

S1: The session was changeable, from laughter to agitation, from moments of engagement to disengaged vocalisations.

S2: $\quad$ The session was a playground - an adventurous child-led 'romp' with occasional responses to therapist-led direction.

S3: The session was full of joy; semi-chaotic connections with busy positive musical energy.

S4: The session contained peals of laughter, busyness and moments of appropriate musical conversation.

S5: $\quad$ The session was a casserole of laughter with meandering threads of engagement and disengagement.

S6: The session was all about connection, amusing communication 
and goodbyes.

\section{The song - The Journey}

Robert's song - "The Journey", like John's, was written to communicate the experience of 'being in the music' with this particular child. Themes drawn from the sessions and excerpts extracted were again, the raw musical data. However, it was necessary to utilise differing mechanisms and presentations to analyse this song. Rather than taking an inventory of Robert's song, like the process with 'Life is Good', by breaking it down into components, the process undertaken instead involved impressionistic drawings and a free-form narrative. These were both created after writing "The Journey". References to excerpts, located on the disc accompanying this thesis, are labelled REX [R Excerpt] and a classification number, for example REX01, REX02, REX03 etc. It would be beneficial for the reader to refer to Appendix F during the narrative of the song, to follow the parallel pictorial flow of the sequential instrumentation. These arts-based analyses take the reader on a expedition through "The Journey" that Robert's music enabled me to create. Below are the thoughts and impressions created from the musical data and the song, given form in symbolic illustrations. 


\section{Impressionistic Drawings}

\section{The Caterpillar:}

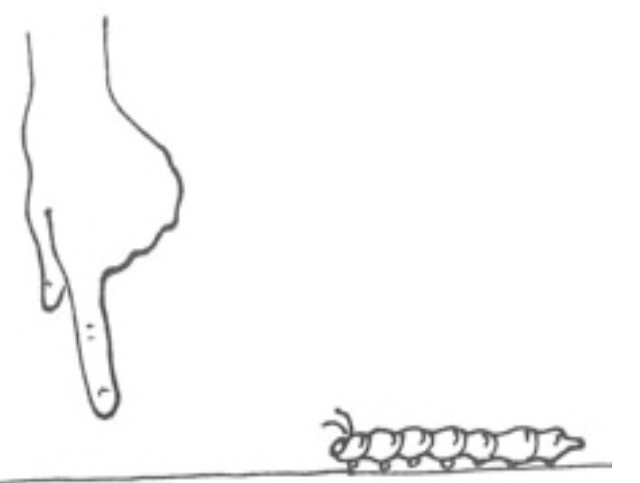

The caterpillar, symbolising Robert, seems to be a busy insect. At least that's how cartoons portray them. With their many legs moving independently and at speed, it would seem like, in personifying the insect, one could imagine it being very occupied in its action, concentrating on its own journey and not very aware of too much else. Robert presents also as a child 'in his own world'. His nearly constant vocalisations are like a language that at face value I don't understand. It seems like his own private narration, a commentary of what is happening around him.

Then, into the image comes the hand and the extended finger, representative of myself musically reaching out to Robert.

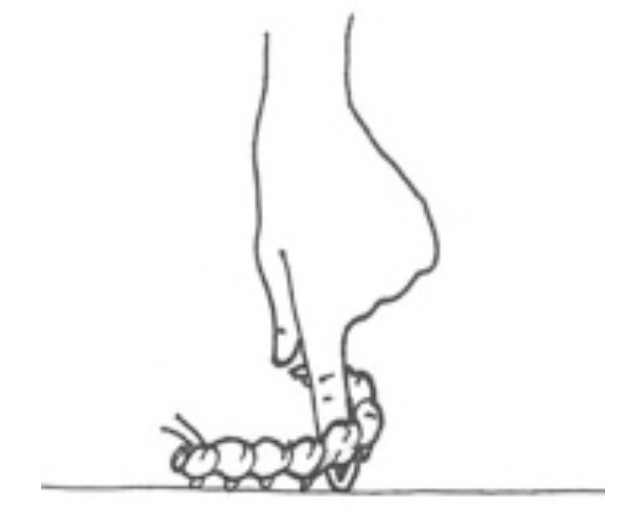

Whe

$\mathrm{n}$ the caterpillar reaches the finger, it stops to investigate this new phenomenon. It then winds itself around the finger, exploring this new 
'event' in its world. This attitude of exploration is evident in Robert's music in his sessions and symbolically through his song. In, for example REX06, there are passages of exploratory music, initiation of an independent musical narrative, within which I am given some room to interact. Yet there is also purpose in the caterpillar's movements, a deliberate state of enquiry. It is open to new experiences; although it wouldn't have sought out the finger to explore, it does interact with it: "Is this safe? Will it nourish me?"

Having inspected and so interacted with the finger, it moves on. Perhaps the hand had some food morsels, perhaps it was just a new surface to experience and perhaps learn from. What could the hand have done differently to alter the caterpillar's experience? Perhaps place down two fingers; perhaps one finger moving to simulate a changeable surface. In parallel to Robert and myself, the question consistently facing me was "how can I shape this activity to engage the most with Robert - how can I 'speak his language'?” If the hand was to place the finger one inch above the ground, it would be choosing to communicate in a contextually different language than that of the caterpillar. All that the caterpillar knows is in front of it, on the surface that it is traveling over. Communicating with Robert required using the language he seemed most comfortable with: music. Having said that, it was difficult to match many of his vocalisations as they were quick and quiet. Attempts at duplicating or responding to them rarely brought any reaction.

Another aspect of these images is that the hand and the caterpillar are worlds apart, obviously being different species. After reflecting on these images, I do 
admit remembering feeling like Robert and I were worlds apart. Feelings of sadness remain that the many meaningful moments of connection, perceived at least by myself, will not translate into any major shift in Robert's clinical conditions, in the short term anyway. 


\section{The Drive through the Jungle}

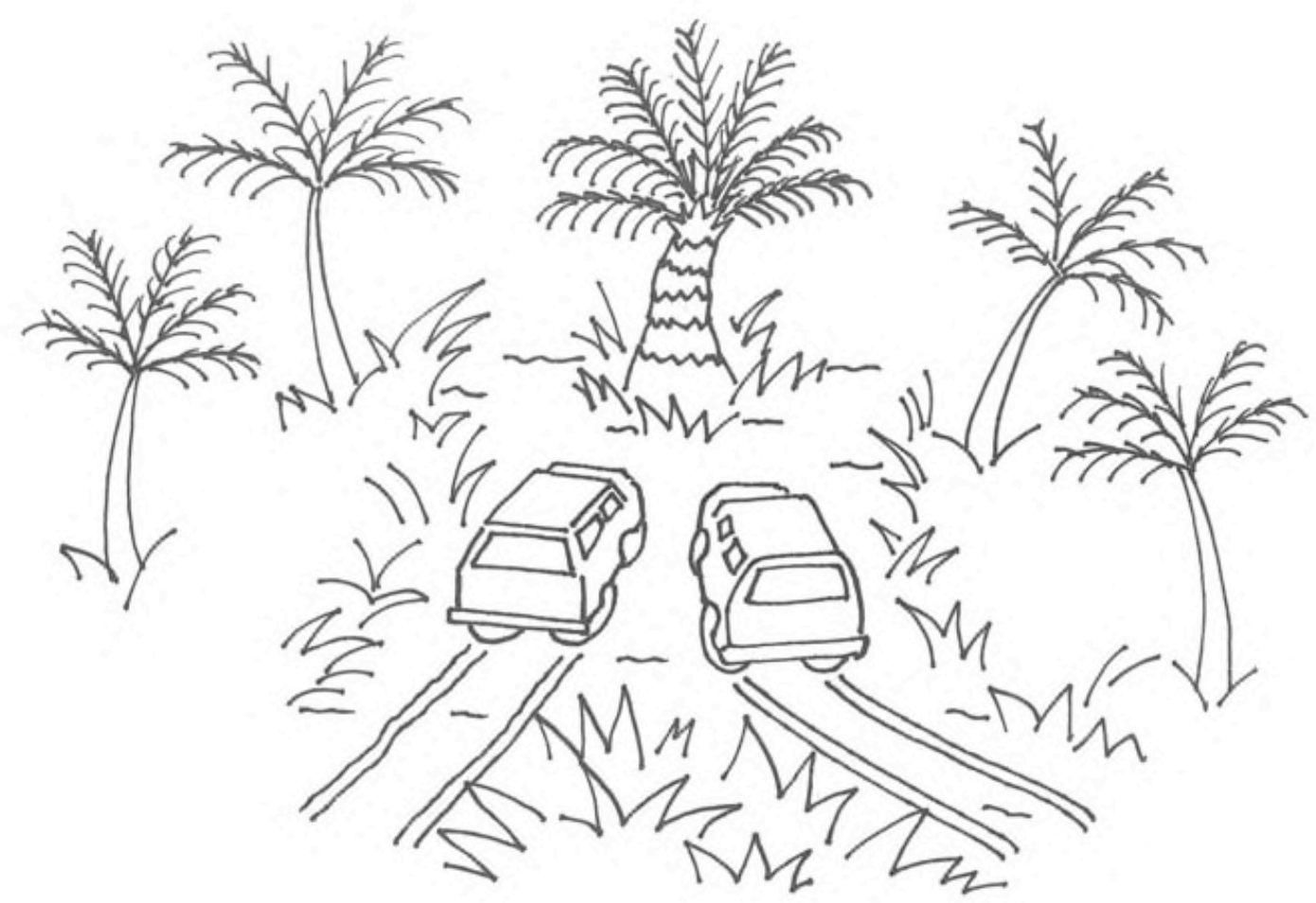

This image was formed after listening to the constant to and fro between Robert and myself; engagement which normally presented through participation in the referential musical activities, and disengagement, where Robert would be vocalising, exploring the music therapy room and unable or unwilling to interact. This image contains two vehicles that are on a journey through a jungle. Robert is in one car and myself in the other. At various points in the journey, as portrayed in this image, our paths meet. As Robert's music therapist, I am navigating this jungle for the purpose of finding those pathways that allow me to draw alongside Robert and interact with him. The 
jungle is symbolic for the challenges that autism asks that we face in communicating with each other. In the image, it is my car that must purposefully navigate the trees, such as the one ahead of us, to maintain moments of 'communication'. Robert is happy in his car, meandering through this landscape, aware of my musical outreaches, involved at varying levels during them, but not independently seeking to experience them.

This metaphor is also expressed outside the music therapy room where, according to his multi-disciplinary team, Robert does not initiate social interaction, an aspect common to autism. This image is also relevant, as the jungle symbolism connects to why I chose the 'exotic style' drumbeat to represent Robert. Jungles are unexplored; jungles contain unexpected noises; jungles take some effort to navigate. Yet in jungles, fables describe that treasure exists, and scientists continue to discover new, rare plants and animals - a menagerie of unique wealth. I feel this is a rich and accurate representation of Robert, and of being with him in his music. 


\section{Narrative Analysis}

\section{The Song: The Journey}

Robert's song starts with a fanfare (GP01):

\section{... a building in intensity ...}

in anticipation of him entering the room. This was an appropriate introduction to the song, as I would often hear Robert before I saw him. The pedal note within the fanfare motif was symbolic of him running to the classroom ahead of his teacher aide, crashing into walls or doors, squeezing the horn on a bike in the corridor outside the music therapy room. At the peak of the fanfare occurs the four cymbal crashes (C01):

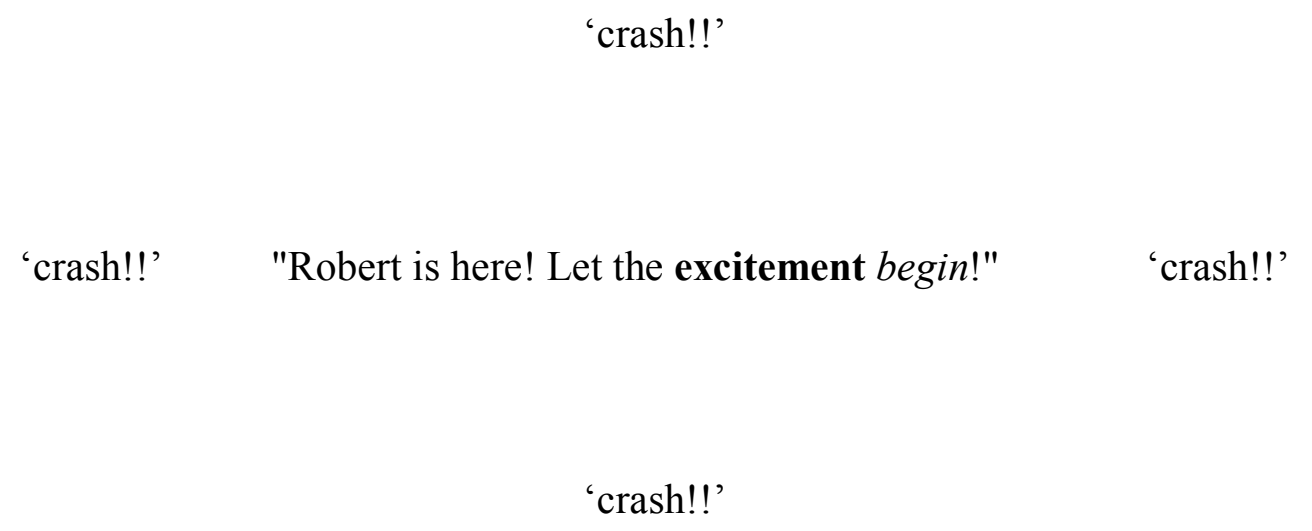

The cymbals are both symbolic and literal in their sense of crashing. Robert will at times display an unawareness of objects and people around him. One of the 
Individual Education Plan (IEP) goals that his music therapy sessions focused on was to develop his spatial awareness. The drumbeat that runs through the majority of the song has energy and an exotic feel to it; an apt description of Robert. It starts at a consistent volume, symbolising an energetic 'sensory equilibrium'.

The first instrumental symbol for myself is the jazz bass (JB01). There is a calling quality to this motif. The intonation of the notes infers the phrase "Ro - bert, R-, R-, R-, Ro - bert", centring around a C bass. The call is repeated; this second time employing the third and fifth ( $\mathrm{E}$ and $\mathrm{G}$ ) above the $\mathrm{C}$ root from first calling phrase. This represents my invitation for Robert to 'take up that harmony' by adding his 'voice' to the music, his contribution. As the jazz bass is calling Robert, the drums (ED01), representative of Robert's 'state of being'/ sensory equilibrium, are cycling up and down in volume. This cycling stylistically represents Robert's sensory system attempting to regulate the sensory input I am offering. While he has not been diagnosed with Sensory Integration Disorder, it has a high co-morbidity with Autistic Spectrum Disorders. As his therapist, I was aware at times of a delay between a spoken or musical instruction from myself and his response. I wondered what impact sensory difficulties were having on his interaction abilities. A negative impact, that of agitated behaviour, was captured in REX01; the cause was not known, but he was drawn out from that agitation through being musically matched with a familiar song.

The next element to appear is a motif (JB02) centred around a C bass, still played by the jazz bass, and is transcribed from the introduction to his Hello Song. It is placed deliberately out of time and at a slower tempo to represent the exploratory 
nature I needed, to attempt to meet Robert 'where he is at.' The timing and tempo of this motif clash with the drums (ED01) and show at this stage of the song that I have not yet engaged Robert through the music-making process.

Robert's first symbolic contribution to this song appears in the form of a melodic motif (X01) drawn from REX19. In the actual session, I asked Robert "How are you today" within lyrics to his 'Hello Song'. He responded with the vocalisation that was transcribed and inserted at this point of the song. Whether the motif is a response to what I just played or a disengaged private musical moment is not known at this point in the song. I repeat my bass line, only a little faster (JB03). He again plays X01, this time interrupting the end of JB03. It is feeling more like a call and response moment.

Thematically speaking, JB02, JB03, JB05, JB06 and JB07 progressively accelerate to symbolise a growing engagement, a mounting awareness of how to meet Robert 'where he is at'. That he repeats the motif again (X02) encourages me that his response could be just that; not a disengaged musical moment, but rather an acknowledgement that he has heard my playing and is 'speaking' back to me. In our improvisational activities, it was often difficult to ascertain whether Robert was initiating musical conversation or experiencing 'private' musical moments. An assessment technique I used in our sessions, represented in this song by JB04, involved mirroring, either melodically or rhythmically what Robert expressed. How he responds to that mirroring was a diagnostic factor in determining our level of engagement. When his X01 phrase is mirrored back to him in JB03, his response (X02) comes rapidly and louder. 
There is an issue however that needs to be considered in employing mirroring. For an autistic child, it would not be therapeutic to be encouraging echolalic behaviours, musical or otherwise. Therefore, when Robert plays X02, I alter the motif two times (JB04 - bars 23 - 27). In bars 23 and 24, I play the motif as an echo of him, ending on the note D. In bars 25 and 26, I subtly alter the melody, ending it on E flat. Finally in bars 26 and 27, the revised motif is played up one octave. Robert's response is then to follow this revised motif. He copies, repeating the revised motif three times. Changing the motif gave him an opportunity to not repeat X02 again. He instead responds musically by repeating the altered motif (X03), perhaps to the point of perseveration. However it could also be simply representative of him enjoying the new musical idea suggested to him. At a more thematic level, the sense of engagement between Robert and myself is growing as JB05 and JB06 are accelerating. I am becoming aware of the 'speed of his drums', that is to say, what music he is most engaging with. There is a shared musical connection - it was Robert's motif originally, but I have altered it and he has given me 'permission', repeating it back to me. Additionally, as mentioned earlier, the jazz bass motifs are accelerating, finally becoming synchronous with ED01:

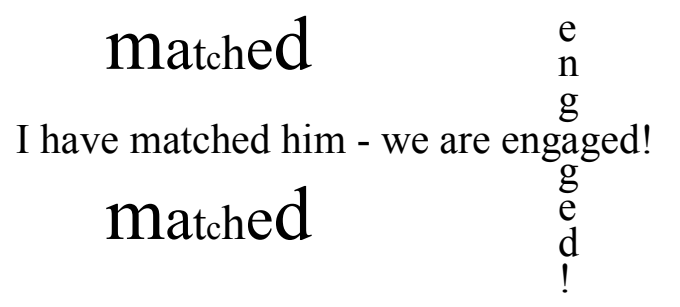

Yet even as the music celebrates our connection, our engagement, culminating in JB07, it all fades in volume as X04 appears. This simple motif heralds a new chapter in this melodic story, and was stylistically transcribed from Robert's 
answering phrase in REX05. During that excerpt, I played a glissando run on the xylophone and he responded with two accented notes on his xylophone. I played another glissando and he responded with another two notes. It was a moment of calling and answering, pertaining to him initiating further musical expression. Many of the excerpts drawn from the six sessions, including REX05, REX06 and REX19 are suggestive of Robert's independent musical thought, either in melodic or rhythmic form.

This new movement was created from 'sub'-excerpts within REX06. There was an incredible amount of meaningful musical data, initiated entirely by Robert. The first forty-one bars transcribed are found in Appendix O, P, Q and R.

Robert shares first in this new movement. The notes have a hypnotic swing feel, of a haunting quality. X05 represents his xylophone and rocks between G down to middle $\mathrm{C}$ and back up to the $\mathrm{G}$ several times. M01, played on the marimba and symbolising his voice, uses the same notes, but sustains the $\mathrm{C}$ pedal note longer. It is also out of synchrony to his xylophone (X05). I answer on the jazz bass (in JB08), using the same tonal centre.

Robert then plays an answer phrase (X06) and M02), still centred around $\mathrm{C}$ but now adding an $\mathrm{E}$ flat to bring a minor sense to his phrase. I respond adding a new element, lowering the supertonic to D flat, thus inferring C Phrygian - the third mode of the A flat major scale. The Phrygian aspect is commonly found in Spanish music and possesses an exotic 'aroma', connecting perhaps back to the jungle imagery. 
In X06 and M02, Robert continues with the $\mathrm{C}$ minor tonal centre. The rhythm is more arrhythmic. My response on the jazz bass runs from the A flat down the Phrygian scale to C. At this time (M03), Robert rests from the xylophone and issues a vocal chant (REX06: 01:07). He starts the chant on the last two notes of my scalic run with fairly perfect timing! I echo it back to him (JB10). He then alters it slightly and I again echo it. The song then recapitulates, repeating X05, M01 and JB08. Hearing such beauty in this dialogue, I felt compelled to again draw attention to it. I then use some 'artistic licence', swapping the Phrygian scale from the jazz bass to the marimba, symbolising turn-taking.

M04 signals another change in direction. Thematically, after so much engagement and sensory input, Robert's playing becomes less calm, building through M04 to eventually enter a phrase of agitation. During M04, the jazz bass is quietly containing with sustained root notes (JB11). M04 starts with another motif drawn from REX06 (00:36) though the timing has been altered slightly. This motif repeats, accelerating through into a new motif, drawn from REX01 (00:08). Underneath, the jazz bass echoes the REX06 motif (JB12), though in its original swing rhythm. The REX01 motif that follows was included to symbolise agitation, as it did during the actual session. Supporting it is the introduction of the maraca (Mc01) that also appeared in the original excerpt.

The drums also return now, though are distorted (DD01), bringing a more urgent sense to the agitation build-up. Symbolised are the sensory difficulties Robert presents at times, with delays in response to requests. 
In M04 when the REX06 motif changes to the REX01 motif, the jazz bass - myself - pauses: "He's getting agitated... What shall I do? Robert! What's wrong? Why are you getting agitated? Robert? Robert? Ro - bert." Now is when JB01 makes a brief return, calling, seeking to break into the perseverative playing that Robert is displaying. That pause gives me time to reflect and attune myself to the rhythm of his agitation.

JB14 instinctively appears, played on the jazz bass at a slower and accented beat. Robert's response to JB14 is the last mention of the agitated motif in M04. This last mention is affected by JB14 and slows to match its pace; the agitation has been dispelled. Engagement has resumed. JB14 contains the bass line introduction to Old McDonald. This was the actual tune I used to break Robert out of an agitated period, as captured in excerpt REX01. Like in this song, the introduction of Old McDonald, in a strong, deliberate tempo, was able to musically reach Robert.

In response to JB14's playful introduction, Robert is challenged to respond instrumentally with "E-I-E-I-O" in the gap that's been left for him at the start of JB15. He does so in M05. I then match him as he repeats the phrase twice more. The last time shows us playing in synchrony. Thematically this is reinforcing that Robert is again engaged. Underpinning this Old McDonald phrase are a number of instruments that all mean to communicate the excitement that occurs when as a therapist you know that you are 'in the moment' with the child. JB07 returns, fading in and continuing until the end of the song. When JB07 first featured it symbolised the culmination of a number of trials to engage Robert at the start of the song. Appearing here it is an echo of the original engagement, and still represents the 
feeling of discovering 'just the right phrase', just the right key to open the door to musical communication.

Also reappearing is ED01 fading in and reinforcing JB07 in a synchronous relationship. The cymbals also reappear, reminding us of Robert's passage at the end of our session, out of the music therapy room, down the corridor, and on to his next activity. In the final moments of the song, the fanfare that heralded Robert's entry to my room also contains his exit. At the start of the song it symbolised my excitement at his entry; at the end of the song it symbolises the excitement I hope and believe Robert feels, off on his 'big adventure', 'the journey' awaiting him. 


\section{Discussion}

\section{Research process}

John Anthony Ciardi (n.d.) once stated:

A good question is never answered. It is not a bolt to be tightened into place but a seed to be planted and to bear more seed toward the hope of greening the landscape of ideas.

The original research question asked and will always ask me: "What can I understand about children with special needs from the musical offerings that emerge in the music therapy process?" I believe this question can never be fully answered. Individuals are unique, in that differing circumstances produce different responses. Music, as used in music therapy, can provide myriads of meaningful moments, creating countless contexts and evoking a range of different feelings.

This research was a snapshot of six sessions, a vignette in the wider context of the research participants' long term music therapy program. Both boys are on the autistic spectrum and both have as one of their IEP goals, through the use of music, to engage with their music therapist, becoming better communicators, to whatever extent that may imply.

The premise upon which this thesis is based is choosing to see all behaviour as communication, and all musical behaviour potentially as musical communication. If all speech and communication have a measurable pitch and / or rhythm, then potentially it could be seen that life is really one extensive song, a symphony perhaps, made up of trillions of movements. Every conversation is a movement. 
These movements can communicate the complete range of human emotions. We write or improvise a song with every new interaction. Songs, in the more traditional understanding of the word, are therefore simply framed moments of communication. Adopting this notion changes how we perceive our interactions with those we meet who have verbal communication difficulties.

However, not all communication is pleasing to the senses; "music therapy is not an aesthetic affair" (Smeijsters, 2005, p. 71). Within the boys' communications were atonal 'crashings' on the xylophone, drums resonating aggressively and a keyboard being played more as a percussion instrument than as a tonal instrument. Nonetheless, and perhaps even because of such a variety of expressions, I did hear these boys communicate through their music. Amir (1990, p. 65) describes that "the created product [the music] is a concrete symbol of validation, reflection, and affirmation of the self". Communicating can hold such risk; emotional and social influences can often hinder genuine sharing. Within the music therapy room, there too, limitations can apply. However, this research was based within a context that enhanced the probability of a 'smooth flow' of musical communication. The two research participants had been attending music therapy sessions for over eight months when the research period was initiated and musical data collected. The preexisting therapeutic relationship was highly beneficial in framing the aims of this research.

And yet there is a threatening 'counter-balance' to such familiarity. Objectivity could have become less obtainable during the research analysis stage, as whilst my ears had become attuned to hearing the boys' music, perhaps they had also become 
dulled or biased in what I was perceiving during the stages of data analysis. Sandelowski and Barroso (2007) suggest that:

Data generation is inseparable from the: (a) researchers who decide what will become data for their projects; (b) specific and irreplaceable encounters between researchers and the people and events that are the subjects and objects of study that together produced those data; and, (c) researchers' interpretations of these subjects and objects of study and, in a reflexive move, of themselves and the research process itself.

So, it was a quite deliberate strategy to encompass and direct this research through arts-based mechanisms. Within the creation of art, there is premeditation; pondering over purpose, deliberating over design and wondering over execution. However, beneficial to this research, there are also more intuitive aspects of the arts. It is important to realise that "we have in the arts a tool that can break through, uncover, penetrate, and reveal while at the same time supporting, containing, sustaining, and nourishing" (Estrella \& Forinash, 2007). The creation of an art form may have a plan but there are also surprises. Songwriters through to dance therapists may strike upon a connection between two aspects of their work that was never intended. Imagery and metaphors contain multiple contextual significances that empower them beyond their original usage. Intuitively, the artist may impose upon their canvas more than just paint. Dreams, prejudices, instincts all emerge when the creator approaches the research process less cognitively and more intuitively. 
This arts-based research gave me the ability to elevate the boys' communication beyond their sessions. Yet within that process of elevation, limits were drawn. How could I choose what would be a 'good enough' representation of the boys?

Everything has the potential to be data, but nothing becomes [italics in original] data without the intervention of a researcher who takes note and often makes note - of some things to the exclusion of others (Wolcott, 1994, pp. 3-4).

Due to the risks mentioned regarding subjectivity and premeditation, the research process thus embraced the strengths possessed within song writing, a structured song analysis, creative drawings and a more free form of narrative writing.

Songwriting, as the encompassing tool for this research, offered me qualitative devices beneficial in understanding the boys' communication. Literary devices such as imagery and analogy enabled me to see the boys as more than their clinical condition. Autism, defined within certain behavioural aspects, infers a predictability about the individual. Instead, the imagery and metaphorical descriptive capacities of creating songs allowed me to shut my eyes, for a period, and let my intuition listen and then speak.

Structured song analysis, as used with John's song, provided constructs in which to channel my understandings of what came about in his song. Two key questions where? and why? - shaped how I interpreted the song. In choosing two particular questions, I of course neglect the myriad of other questions possible, but for reasons of textual conciseness, I believe they were adequate. 
Drawing, as used with Robert's material, allowed me to communicate metaphors intuitively sourced from the child's music. Listening for nuances in how he presented in the music [or "how he was 'in the music"'], how he reacted to interaction and how he explored the musical relationship gave me 'fodder' to focus on, delve into and turn over in my mind. The resulting images were simple but communicative.

Free-form narration involved me removing certain literary structures from the analysis. Applied to 'The Journey', it allowed me to describe without conforming to particular questions, to express without pausing, sometimes for breath! While it still contains much descriptive terminology, the writing of it contained a momentum. I didn't need to clarify whether a thought was specifically answering a set list of analytical questions. It was rather like telling a story. And in telling the song's story, I intended hopefully to share an aspect of Robert's story.

The notion of diving into the data, being surrounded by it, not attempting to describe it immediately in words, and so not quantifying the experiences within the sessions is risky. It might seem easier to objectively describe how "the child then hit the drum three times with his right hand". What if instead, the therapist heard from the drums a 'battle cry'? The boy could be communicating despair and frustration at a circumstance in his life. What if in hearing 'beyond the sound', the therapist can understand intuitively the child's need for containment, for safety that the child is really crying out for. Smeijsters asks "how can we discuss music therapy if words ... distract us from its essence? ... do not write about music 
therapy, but join the session and experience the music therapy process yourself else you risk reducing what 'it' is all about" (2005, p. 53).

When the research process started to meander, I asked myself the foundational question: "What can I learn?" A passage from some of my reflective notes describes how:

Reflecting about the ability to shape and be shaped with these children. How do they shape me? How has their music shaped me? What impact has it had on me? Did it have? Is it having? Definition that's what I'm working so hard on now, assessing myself, them, and the environment - maybe not even just the therapy room environment in which the sessions took place (although I know my project is about the music arising out of those sessions) but somehow also assessing their school environment, their social environment, their mental environment, etc... and this idea of transcending the limitations that appear to exist - the boys' own limitations in their disabilities, my limitations in my training and / or perception of them, the limitations of the room, the time, the sessions, the words and eventually the song design ... to somehow still create something performance-worthy here...

As part of the research process, whilst collating Robert's excerpts, I created a chart (see Appendix S), documenting the contexts of the excerpts as I found them. I also applied, where possible, impressionistic titles or images to each excerpt. It was beneficial to keep these titles or images in my thoughts as I shaped the song. I 
chose to not use the same approach with John's excerpts, keeping any detailed analysis to a minimum, prior to finishing "Life is Good".

It should be recognised however that one aspect of the research I'd alter in future research would be the placement of the iPod, as it was nearer where I usually sat due to space restrictions of the room - thus my voice is dominant in the recordings and hearing all the nuances of the boys' music was sometimes difficult.

\section{The boys}

The children, both having autism, collectively present with standard autistic symptomology. Perseveration, echolalia, sensory integration and communicational difficulties were all present in our clinical sessions and in the resulting musical data. Nonetheless, they are individuals, and the musical data suggested as much. The key results of this research are contained within the two songs written. Just as the song for each boy is more than just excerpts pieced together like a musical jigsaw, each boy is more than just the sum of his 'parts' - his clinical labels - he is a "gestalt": where "the whole is greater than the sum of the parts" (Hodges, 1996). The musical data collected from the children's sessions was rich and unique to each child. While some excerpts from the sessions contained clinically predictable musical behaviours, other captured moments were inimitable, surprising and enthralling both their respective teacher aide and myself. In reflection, it may have been easier to "play puppeteer and pull the strings in order to make the data dance in ways that best suit me" (Rasberry, 2002, p. 113). But by employing these artsbased mechanisms, I was able to, in some small part, remove the temptation to simply create a song that would be a 'promotional tool' for the benefits of music 
therapy with autistic clients.

\section{John - 'Life is Good'}

John's song was written, at least partly, quite early in the research process. Having worked with him all year, it felt natural for me to start listening for themes and forming them into musical ideas. I had to weigh up what portion of the song would be thematically influenced versus what portion of the song would be created directly from excerpts. The excerpts were derived from clinical symptomology, whereas the themes were more objectively based. Excerpts contain for example, samples of stuttering and perseveration, whereas themes pertain to painting a bigger picture of what it is really like to be in the music with John. The guitar motif and drums were created almost instantaneously based on my impressions of John, grown over the eight months of previous music therapy sessions. These impressions could be best described as that of exploration and of excitement. Other aspects of the song came later, after more listening and re-listening to the raw musical data had occurred.

An interesting revelation during John's analysis was that when transcribing his 'Hello Song' excerpt (JEX15, Appendix M and N), I realised that rather than separating the speech from the singing, I could in fact keep them as one track, as speech obviously has tonal qualities. Also of note was an observation I made in my clinical notes that during a session:

He played the piano very percussively - no real melody. In fact, predominantly one note, just rhythm and driving rhythm at that... racing! competing! volume! Maybe because a lot of our music therapy 
time was spent on percussion instruments, when moving to the piano, he plays the piano the same way he plays the drum. Everything at one speed, one volume (fast and loud); doesn't perceive that the piano is a different instrument with a different voice to be played differently... Perhaps somewhat akin to his ability to cope in varying social situations; his adaptability, one speed in all situations???

\section{Robert - 'The Journey'}

A first impression of Robert's song is that it doesn't centre around one motif and extrapolate. It contains, rather, a variety of ideas that emerge then disappear, only to emerge again. Instruments appear, then are discarded for new exploratory activities. I don't have all the answers in the song and sometimes become 'stuck' in the process of searching for answers. An aspect included in Robert's song was that of change, of extremes. There were periods during our sessions where he was completely disengaged ... and yet other times he was completely engaged in the music making process. It was possible to include examples of engagement and disengagement, yet it was also possible to inject a feeling of change thematically through bringing in new musical ideas and letting others fade away. A challenge in Robert's song was to not make everything 'neat' - coming in 'on time'. Robert isn't neat! I had to fight my instinct to make everything aesthetically pleasing. A sample from my clinical notes describes how:

Robert was ... a 'menagarie'(?) of sound today. His vocalisations ranged from animal noises to partially formed words to infant-like babble. His movements so extreme, from quiet drumming motions to 
flying leaps into my arms (and the teacher aide's!). How do I channel such unpredictability?

\section{Additional Thoughts}

A limitation on this research was using GarageBand (Apple recording software) in the editing of the excerpts. The software was unable to print out musical scores of all the instruments. This limitation was only discovered late in the research process.

Future research could more rigorously analyse the musical data, perhaps utilising musicology analysis tools or frameworks. 


\section{Summary}

In many ways these songs were confessional in their approach. I inquire, I seek to listen and understand, I learn and I make mistakes. The songs communicate the two children to the listener, but the music, the children and I are all wrapped up in the context, in the process. I sought to draw on feelings evoked in the sessions, abstract concepts not recordable by the iPod. To really communicate what it is like to 'be' with the boy; not just in the same room, but in the same space, the musical space. To enable the audience of this research to gain an impression of encountering the clients. Another passage of reflective diary concludes with this desire:

I want an audience to experience a performance... yes, I am documenting the data, talking about what the child presented, and what he presented musically. I'm recording the data faithfully, and transcribing each note as carefully as I can... but ultimately I want people to EXPERIENCE a PERFORMANCE of the boys - something that can be felt, heard, even enjoyed. To hear the boys beyond their and my music. To really capture of glimpse of who they are. That these songs would resonate! 


\section{References}

Aigen, K. (1996). Being in music: Foundations of Nordoff-Robbins Music Therapy, 1. St. Louis, Missouri: MMB Music, Inc.

Aigen, K. (2005). Naturalistic Inquiry. In Wheeler, B. (2005) (Ed.). Music Therapy Research: Quantitative and Qualitative Perspectives (2nd ed.) (pp. 352 - 364). Barcelona: Gilsum.

Aldridge, D. (1991) Physiological change, communication and the playing of improvised music: some proposals for research. The Arts in Psychotherapy, 18, 59-64.

Aldridge, D. (1996). Music Therapy Research and Practice in Medicine: From Out of the Silence. London: Jessica Kingsley.

Alvin, J. (1975). Music Therapy for the Autistic Child. London: Oxford University Press.

Amir, D. (1990). A song is born: discovering meaning in improvised songs through a phenomenological analysis of two music therapy sessions with a traumatic spinalcord injured young adult. Music Therapy, 9 (1), 62-81.

Austin, D. (1998). Grace Street: A qualitative study of Alcoholics Anonymous. Presentation at the Inaugural Conference of the American Music Therapy Association, Cleveland, $\mathrm{OH}$.

Austin, D. \& Forinash, M. (2005). Arts-Based Research. In Wheeler, B. (2005) (Ed.). Music Therapy Research: Quantitative and Qualitative Perspectives (2nd ed.) (pp. 458 - 471). Barcelona: Gilsum. 
Berger, D. S. (2002). Music Therapy, Sensory Integration and the Autistic Child. London: Jessica Kingsley.

Blumenfeld-Jones, D. S. \& Barone, T. E. (1997). Interrupting the sign: The aesthetics of research texts. In J. Jipson \& N. Paley (Eds.), Daredevil research: Recreating analytic practice. New York: Peter Lang Publishers.

Brophy, T. S. (2001). Developing Improvisation in General Music Classes. Music Educators Journal, 87 (6), 34-41, 53.

Bruscia, K. E. (1982). Music in the assessment and treatment of echolalia. Music Therapy, 2 (1), 25-41.

Bruscia, Kenneth E. 1987. Improvisational Models of Music Therapy. Springfield, IL; Charles C. Thomas Publications.

Bunt, L. and Hoskyns, S. (2002). The Handbook of Music Therapy. Hove and New York : Brunner-Routledge.

Ciardi, J., A. (n.d.). Good questions should begin good research. Retrieved March 10, 2008, from http://www.teachers.ash.org.au/researchskills/questions.htm.

Davis, W. B., Gfeller, K. E. \& Thaut, M. H. (1999). An Introduction to Music Therapy : Theory and Practice. Dubuque, IA : McGraw-Hill.

Denzin, N. (2003). Performance Ethnography: Critical Pedagogy and the Politics of Culture. Thousand Oaks, CA: Sage.

Dunn, B. (2006). Accents on Music Therapy: Arts-Based Research. Victory Review: Acoustic Music Magazine, 31 (6), 18, 21. Retrieved March 10, 2008, from 
http://www.victorymusic.org/pdfs/2005-6/vr_jun06.pdf.

Estrella, K. \& Forinash, M. (2007). Narrative Inquiry and Arts-Based Inquiry: Multinarrative Perspectives. Journal of Humanistic Psychology, 47 (3), 376-383.

Exegesis. (n.d.). Dictionary.com Word of the Day. Retrieved March 08, 2008, from Dictionary.com website: http://dictionary.reference.com/wordoftheday/archive /2001/07/17.html.

Frith, U. \& Happe, F. (1994). Language and Communication in Autistic Disorders. Philosophical Transactions: Biological Sciences - The Acquisition and Dissolution of Language, 346 (1315), 97-104.

Flohr, J. (1985). Young Children's Improvisations: Emerging Creative Thought. Creative Child and Adult Quarterly, 10, 79-85.

Gajate-Garcia, R. (2002). Play Bongos \& Hand Percussion Now: Basics and Beyond. Miami, FL: Warner Bros Publications.

Haseman, B. (2007). Rupture and Recognition: Identifying the Performative Research Paradigm. In E. Barrett \& B. Bolt (Eds.). Practice as Research - Approaches to Creative Arts Enquiry. London: I. B. Tauris.

Hodges, D. (Ed.) (1996). Handbook of Music Psychology. San Antonio: IMR Press.

Jacobs, K. (Ed.). (1999). Quick Reference Dictionary for Occupational Therapy (2 ${ }^{\text {nd }}$ ed). Thorofare, NJ: Slack Inc.

Jenoure, T. (2002). Sweeping the Temple: A Performance Collage. In C. Bagley \& M. B. Cancienne (Eds.), Dancing the data (pp. 73 - 89). New York : Peter Lang Publishers. 
Kenny, C., Jahn-Langenberg, M. \& Loewy, J. (2005). Hermeneutic Inquiry. In Wheeler, B. (2005) (Ed.). Music Therapy Research: Quantitative and Qualitative Perspectives (2nd ed.) (pp. 335 - 351). Barcelona: Gilsum.

Knowles, G. \& Thomas, S. M. (2002). Artistry, inquiry, and sense of place: Secondary school students portrayed in context. In C. Bagley \& M. B. Cancienne (Eds.), Dancing the data (pp. 121 - 132). New York : Peter Lang Publishers.

Kratus, J. (1991). Growing with Improvisation. Music Educators Journal, 78 (4) 3540.

Lefevre, M. (2004). Playing with sound: The therapeutic use of music in direct work with children. Child and Family Social Work, 9, 333-345.

McNiff, S. (1992). Art as Medicine. London: Shambala.

McNiff, S. (1998). Art-based research. Philadelphia: Jessica Kingsley Publishers.

Nicholas, B., Rudrasingham, V., Nash, S., Kirov, G., Owen, M. J. \& Wimpory, D. C. (2007). Association of Per1 and Npas2 with autistic disorder: support for the clock genes/social timing hypothesis. Molecular Psychiatry, 12 (6), 581-592.

Nordoff, P. \& Robbins, C. (1977). Creative Music Therapy. New York: John $\quad$ Day Company.

Nordoff, P., Robbins, C., \& Marcus, D. (2007). Creative music therapy: a guide to fostering clinical musicianship (2nd ed.). Gilsum, N.H. : Barcelona Publishers. (Original work published 1977).

Olsen, A. J. (1995). Moving the question: Authentic movement as research. A Moving Journal, Fall-Winter, 7-8. 
Priestley, M. (1994). Essays on Analytical Music Therapy. Phoenixville, PA: Barcelona Publishers.

Rasberry, G. W. (2002). Imagine, Inventing a Data-Dancer. In C. Bagley \& M. Cancienne (Eds.). Dancing the data (pp. 105 - 117). New York : Peter Lang Publishers.

Saffran, E. M. \& Schwartz, M. F. (1994). Impairments of Sentence Comprehension. Philosophical Transactions: Biological Sciences - The Acquisition and Dissolution of Language, 346 (1315), 47-53.

Sandelowski, M. \& Barroso, J. (2007). Handbook for Synthesizing Qualitative Research. New York: Springer Publishing Company.

Sandelowski, M., Trimble, F., Woodard, E. K. \& Barroso, J. (2006). From synthesis to script: Transforming qualitative research findings for use in practice. Qualitative Health Research, 16 (10), 1367.

Shields, A. \& Robbins, A. (1994). Music in expressive therapy. In: A Multi-modal Approach to Creative Art Therapy (ed. A. Robbins), pp. 239-257. London.: Jessica Kingsley.

Smeijsters, H. (2005). Sounding the Self: Analogy in Improvisational Music Therapy. Gilsum, N.H.: Barcelona Publishers.

Trevarthen, C. (2002). Autism, sympathy of motives and music therapy. Enfance, 54 (1), $86-99$.

Watzlawick, P., Bavelas, J., \& Jackson, D. (1967). Pragmatics of human communication: A study of interactional patterns, pathologies, and paradoxes. New York: Norton. 
Wheeler, B. (2005) (Ed.). Music Therapy Research: Quantitative and Qualitative Perspectives (2nd ed.). Barcelona: Gilsum.

Wing, L. \& Gould, J. (1979). Severe impairments of social interaction and associated abnormalities in children: Epidemiology and classification. Journal of Autism and Developmental Disorders, 9, 11-29.

Wigram, A. (2000a). Contact in music: The analysis of musical behaviour in children with communication disorder and pervasive developmental disability for differential diagnosis. In T. Wigram and J. De Backer (Eds.), Clinical Applications in Developmental Disability, Paediatrics and Neurology. London: Jessica Kingsley. 69-92.

Wigram, T. (2000b) A method of music therapy assessment for the diagnosis of autistic and communication disordered children. Music Therapy Perspectives, 18, 13-22.

Wigram, T (2002). Indications in Music Therapy: evidence from assessment that can identify the expectations of music therapy as a treatment for Autistic Spectrum Disorder (ASD); meeting the challenge of Evidence Based Practice. British Journal of Music Therapy, 16 (1), 11-28.

Wigram, T. (2005) 'Survey Research'. In B. Wheeler \& K.Bruscia (Eds.) Music therapy research: qualitative and quantitative methods (2nd ed.). Phoenixville: Barcelona Publishers.

Wigram, T \& Gold, C. (2006). Music therapy in the assessment and treatment of autistic spectrum disorder: Clinical application and research evidence. Child: Care, Health and Development, 32, 535-542. 
Wigram, T., Pederson, I. N., \& Bonde, O. L. (2002). A Comprehensive Guide to Music Therapy. London: Jessica Kingsley Publishers Ltd.

Wimpory, D., Nicholas, B. \& Nash, S. (2002). Social timing, clock genes and autism: a new hypothesis. Journal of Intellectual Disability Research, 46 (4), 352 - 358.

Winnicott, D.W. (1971). Playing and Reality. London: Tavistock Publications.

Wolcott, H. F. (1994). Transforming qualitative data: Description, analysis, and interpretation. Thousand Oaks, CA: Sage. 


\section{Appendix A: John - 'Life is Good' - Garageband representation of sequential instrumentation}
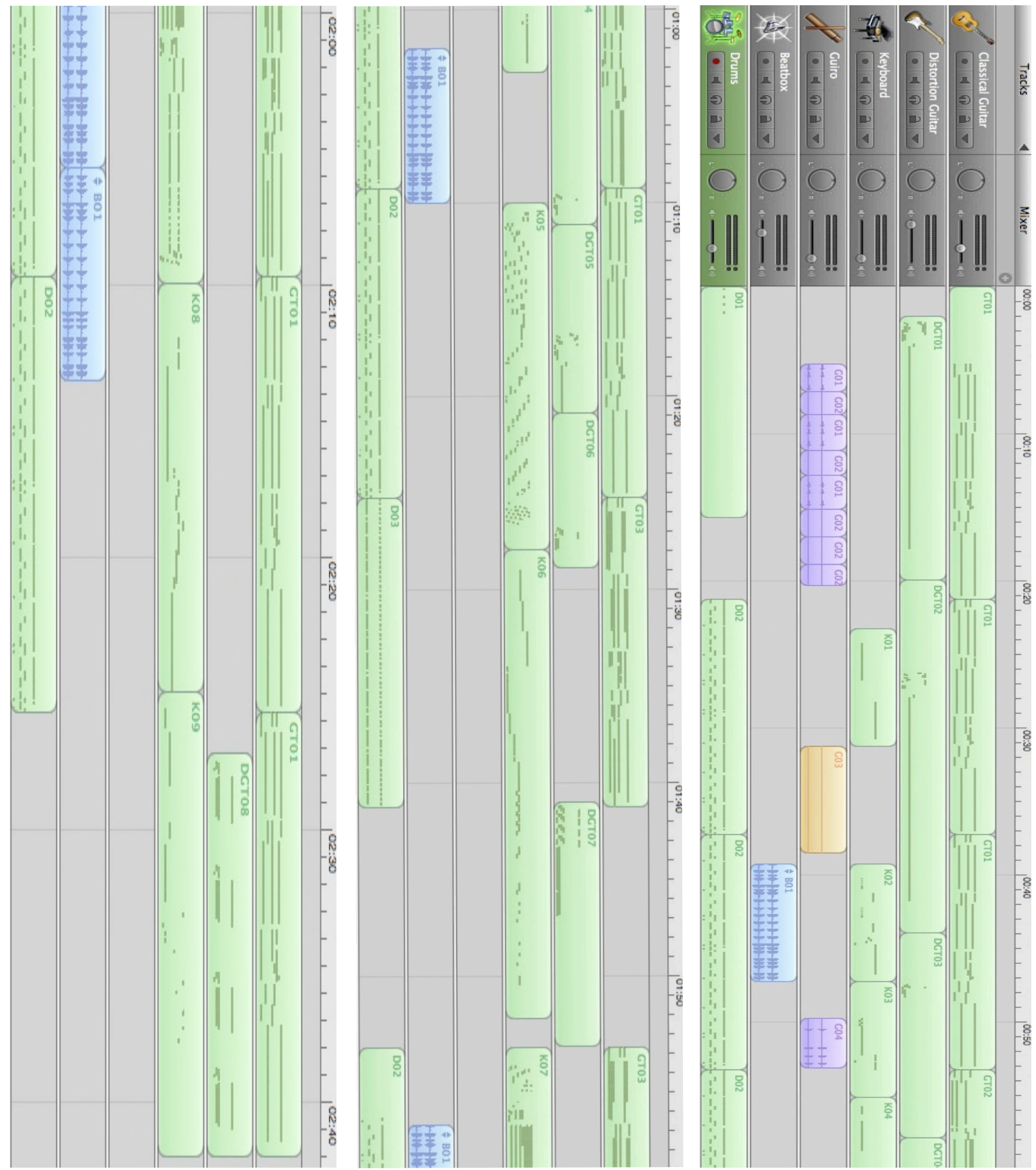
Appendix B: John - Classical Guitar Score

Life is good

Classical Guitar
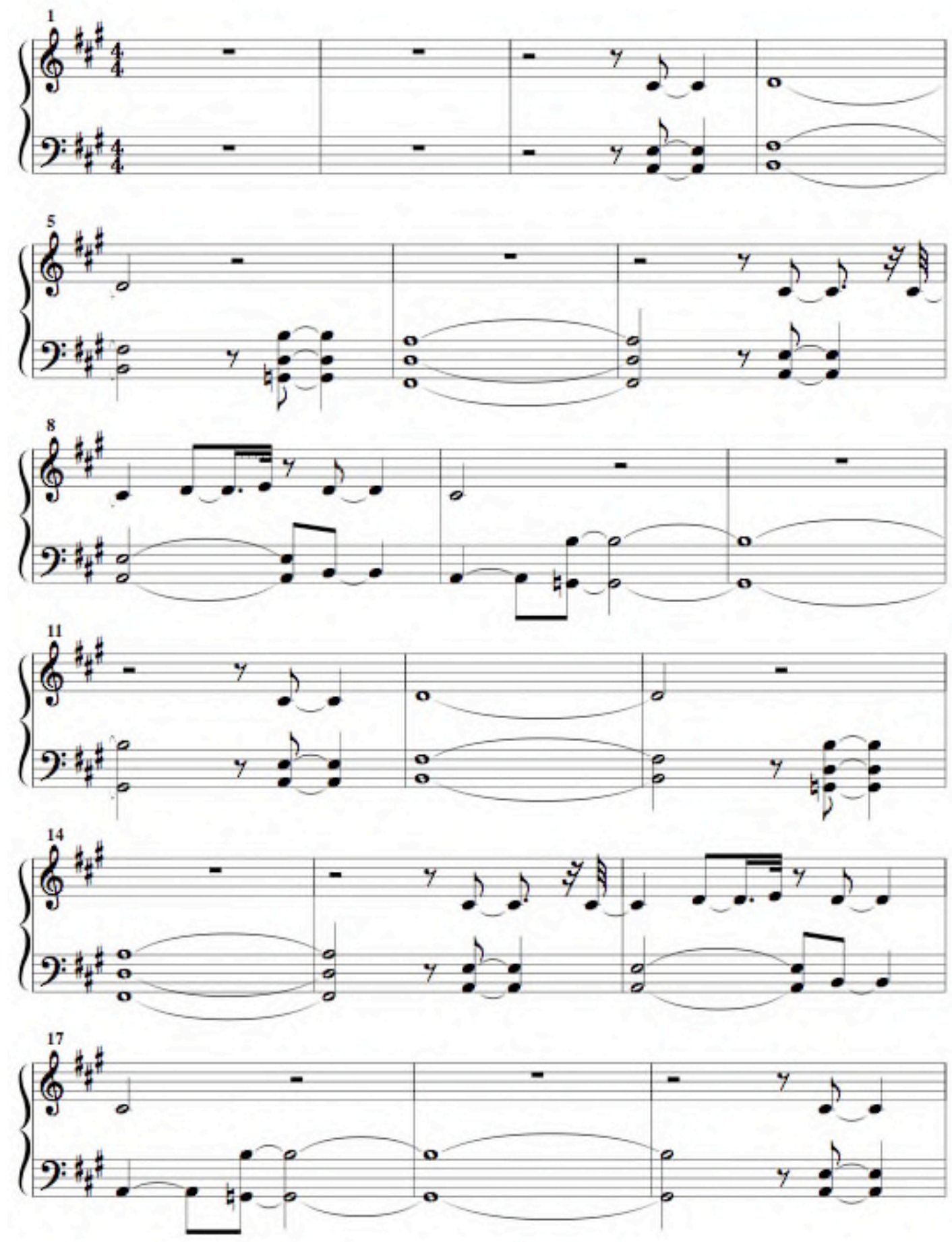

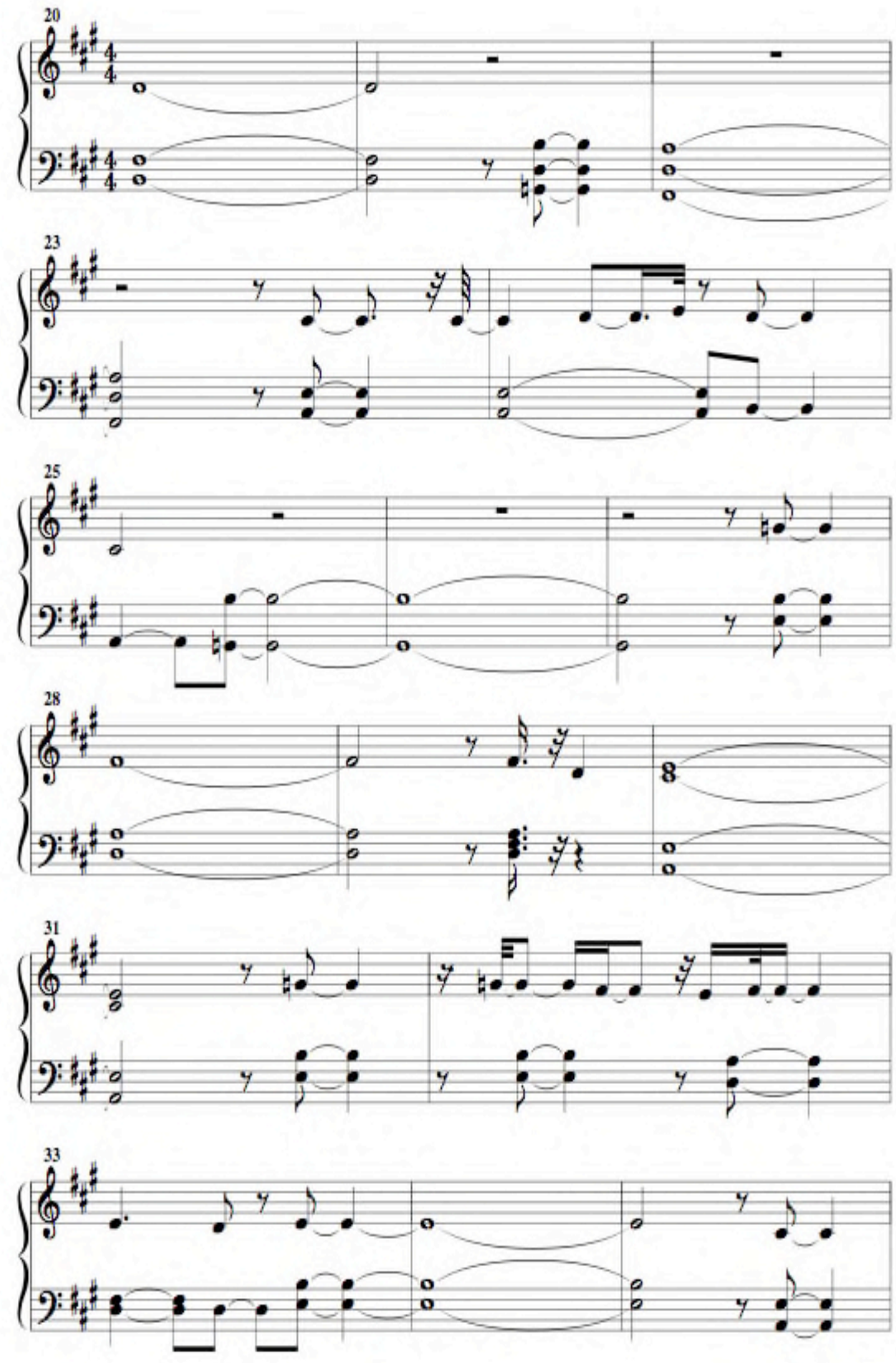

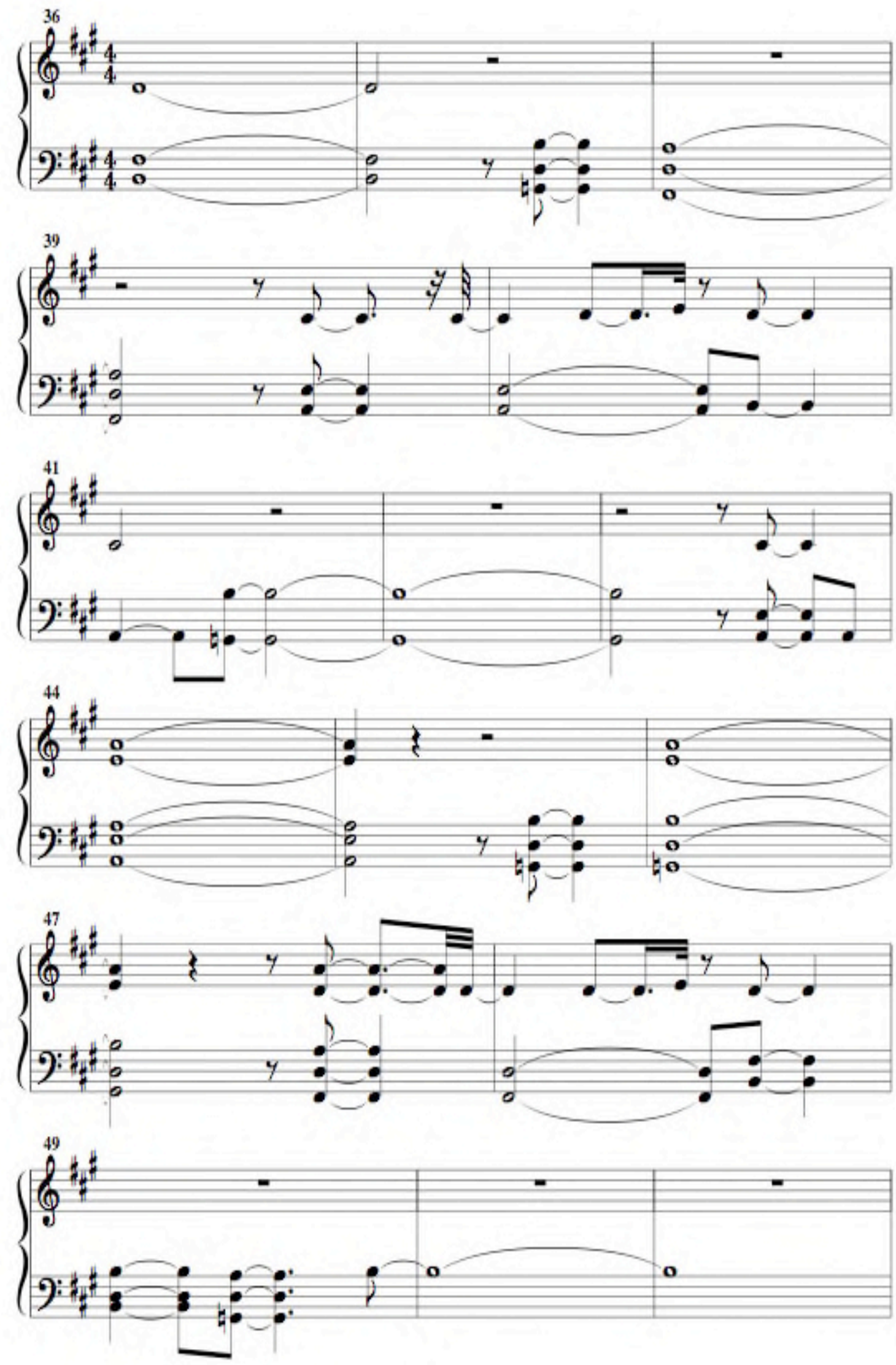

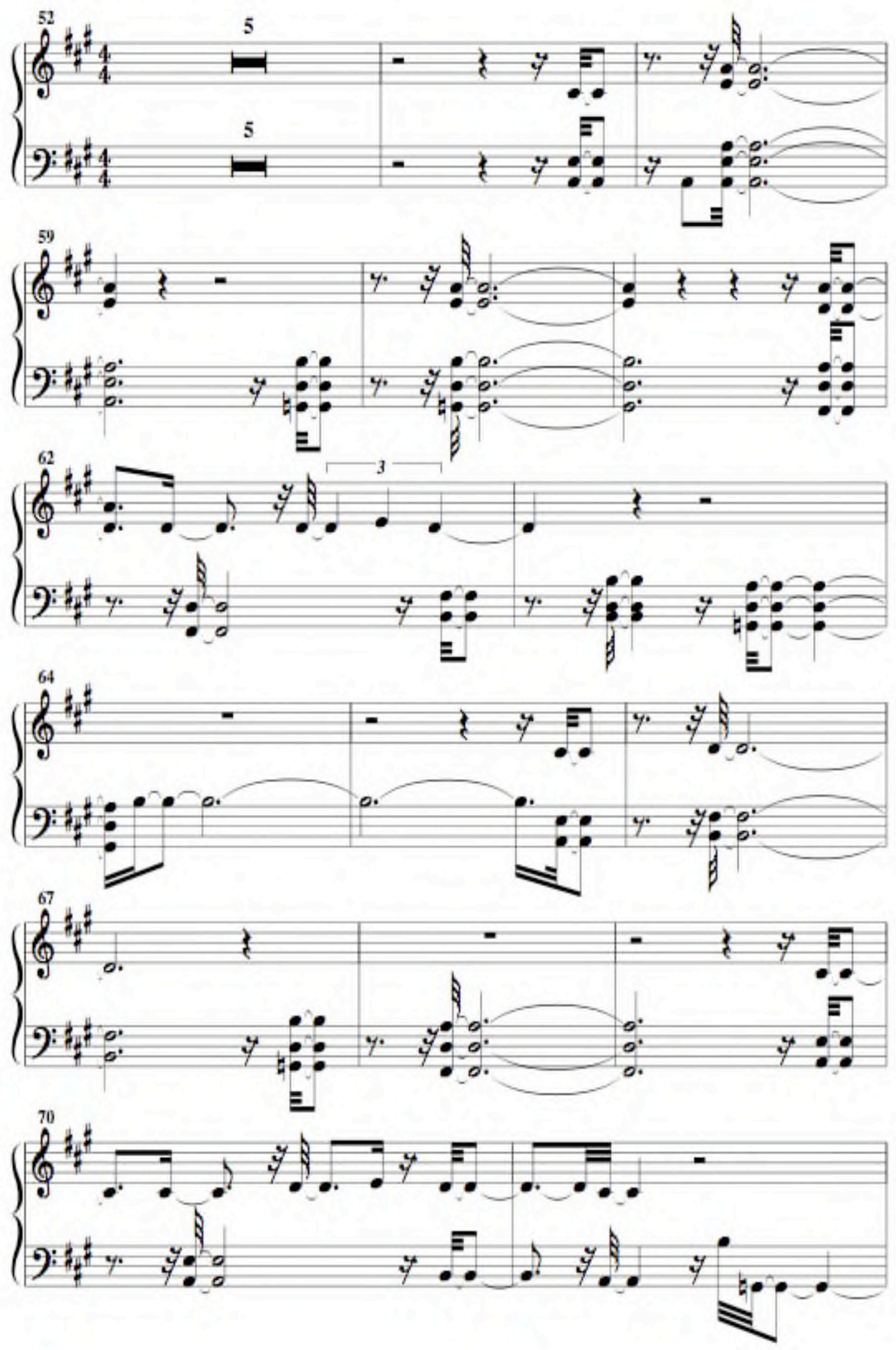

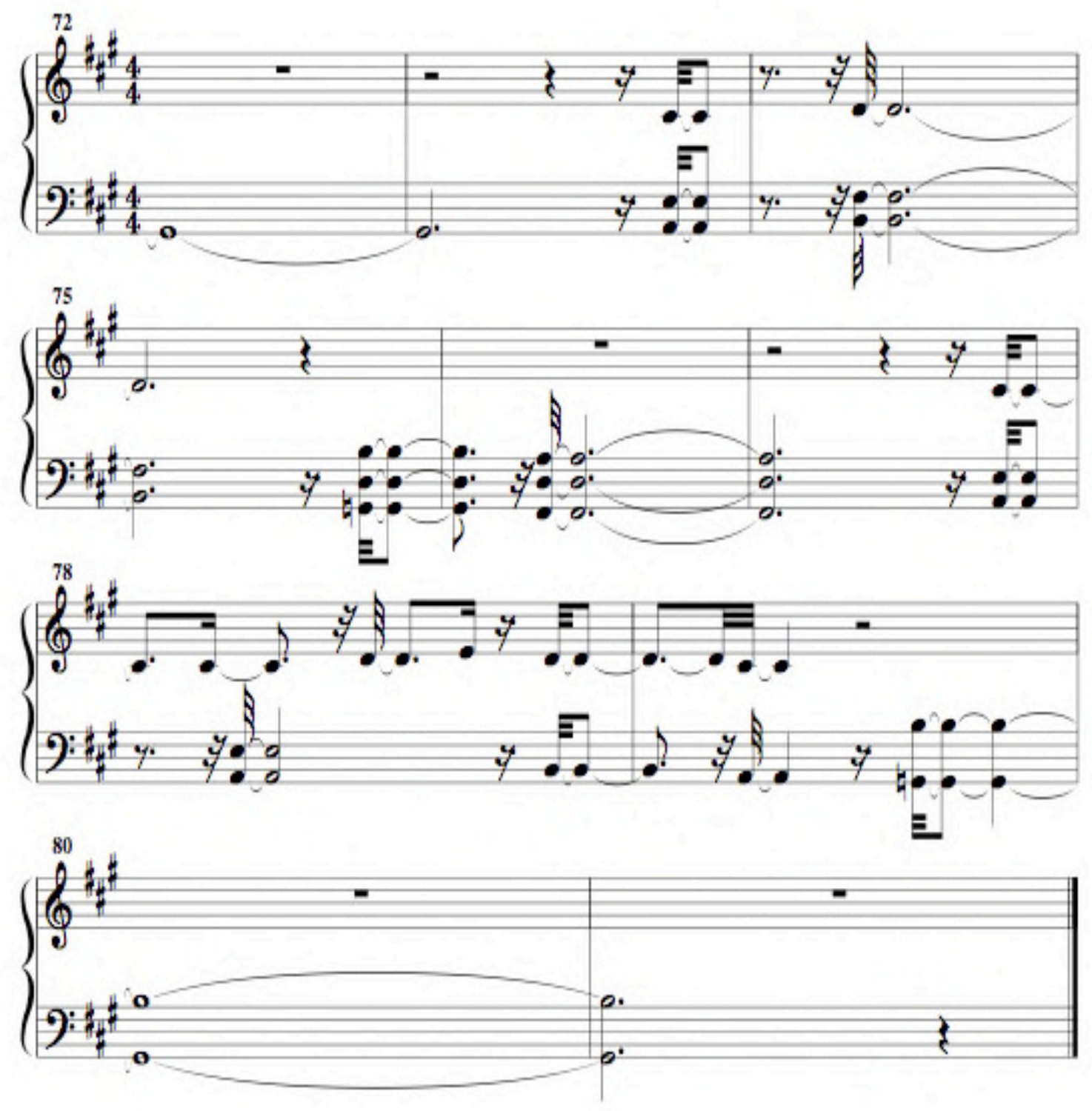


\section{Appendix C: John - Distortion Guitar Score}

\section{Life is good}

\section{Distortion Guitar}
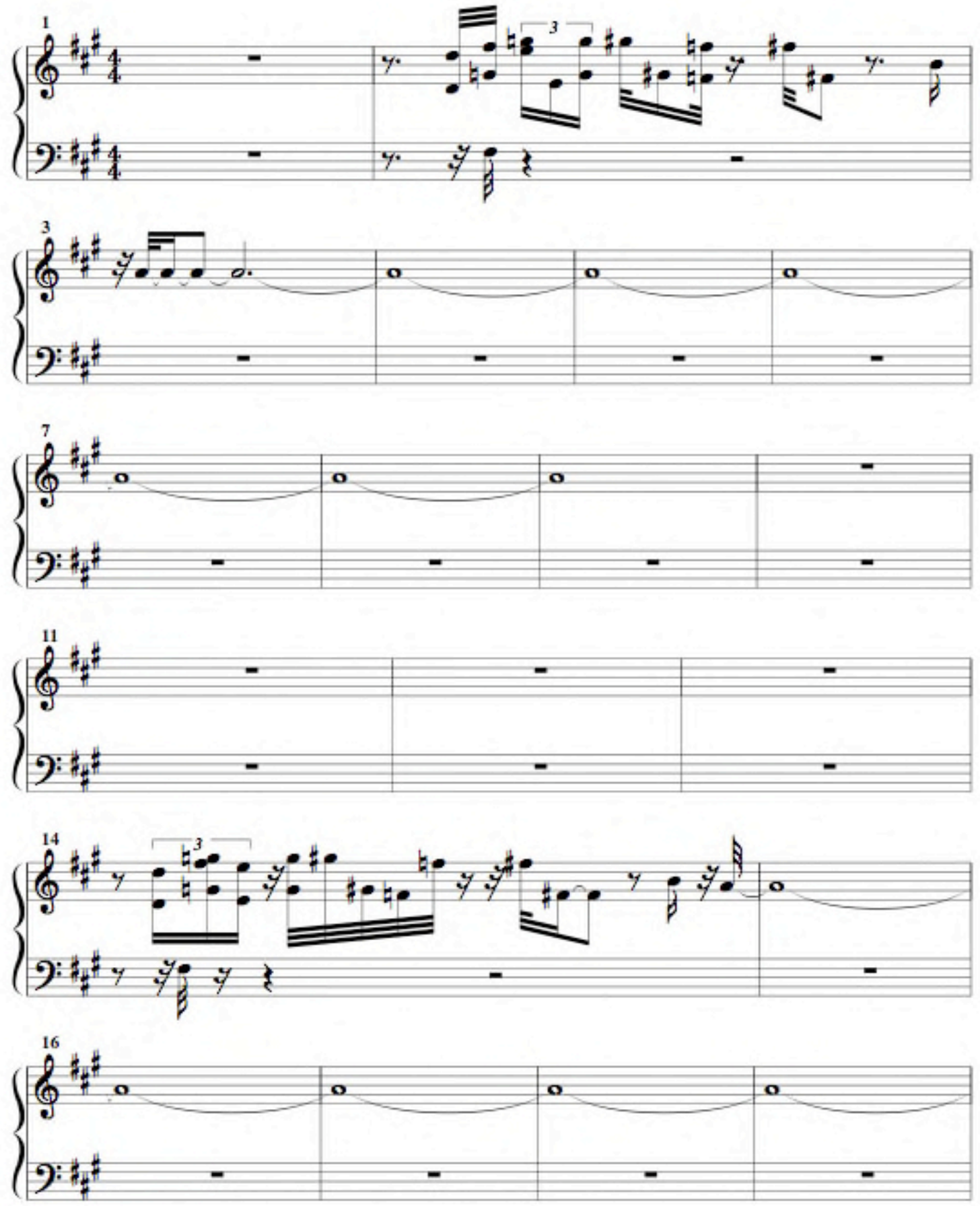

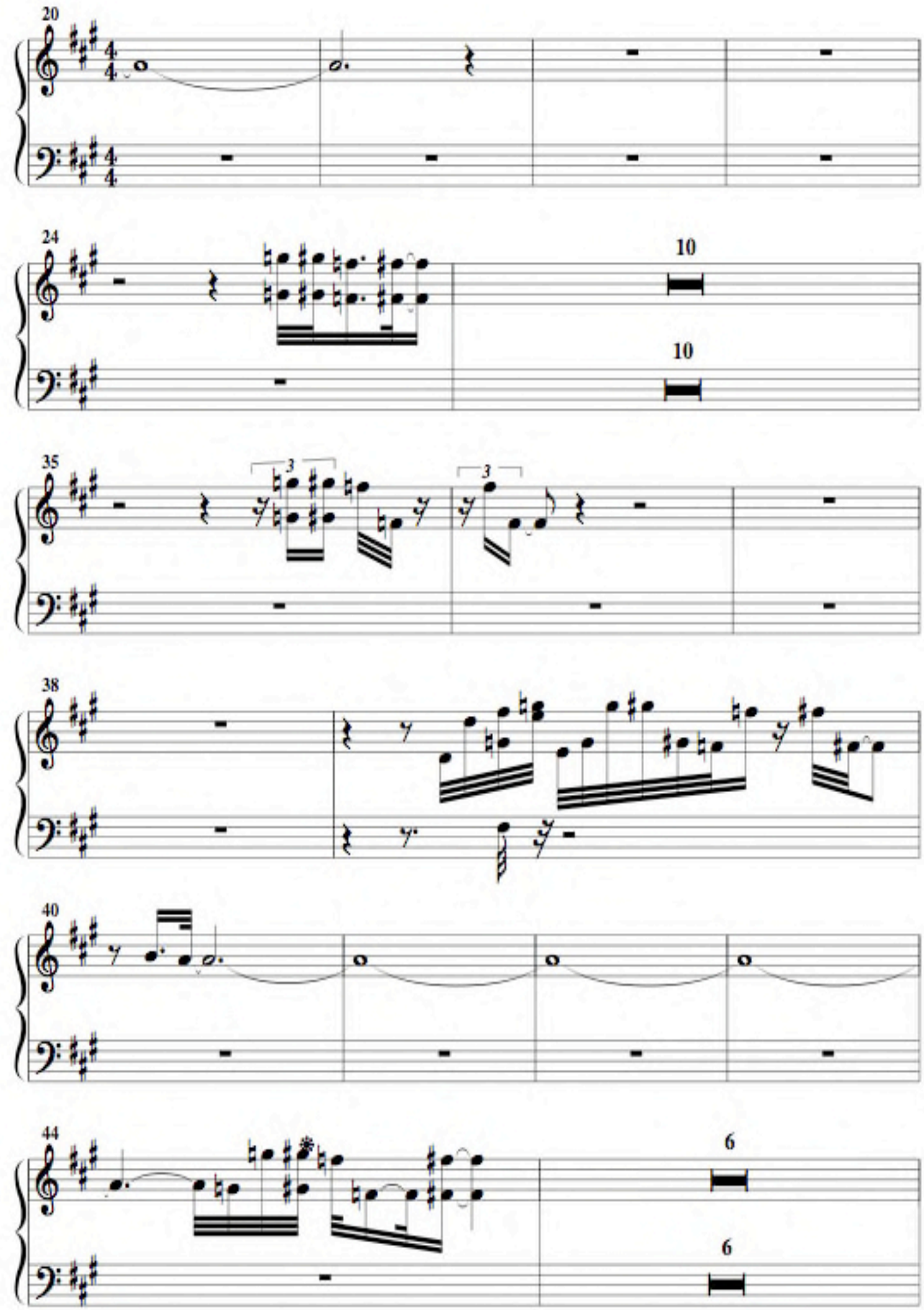

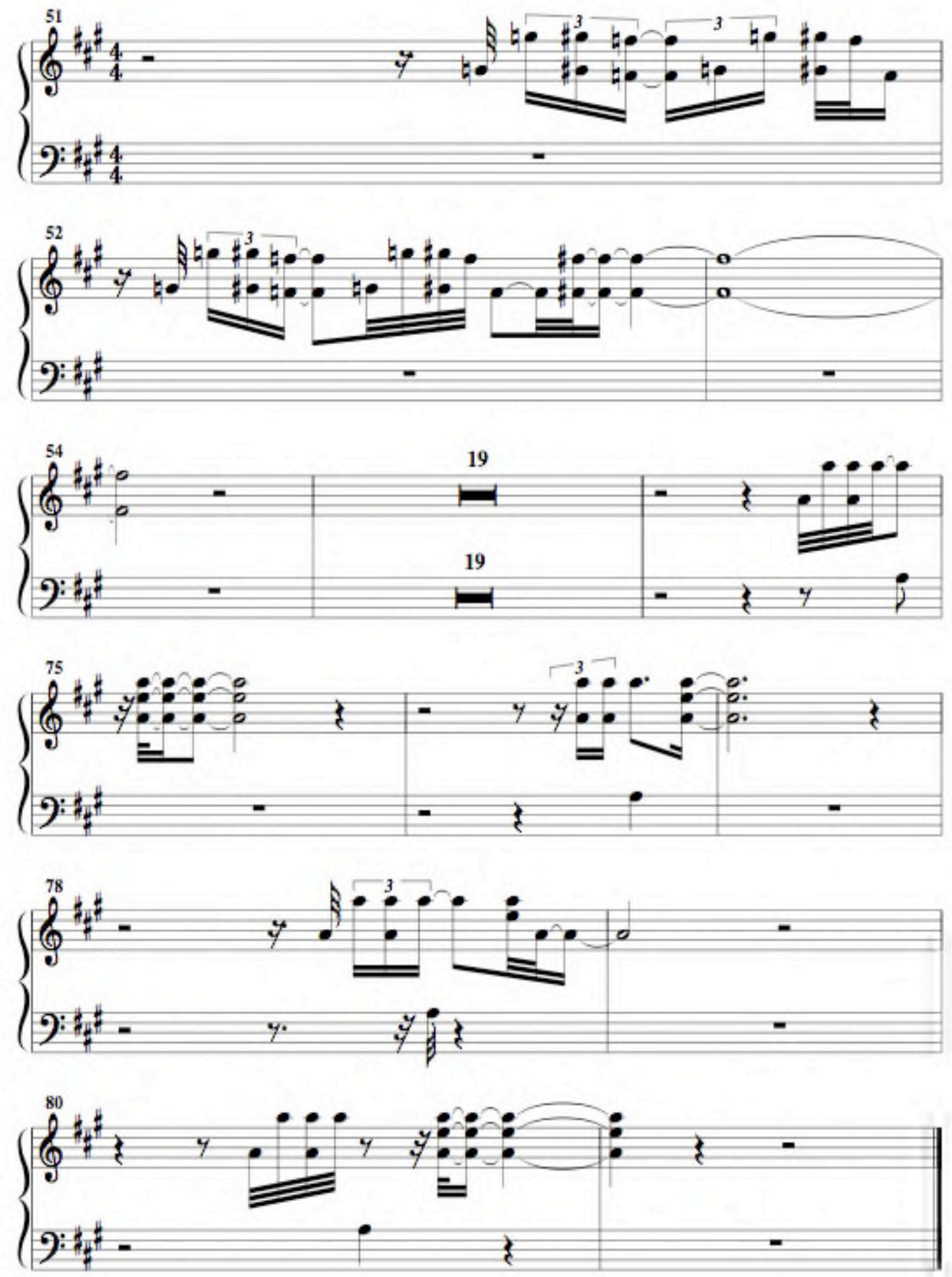
Analysing children's offerings in music therapy

77

Appendix D: John - Keyboard Score

Life is good

Keyboard
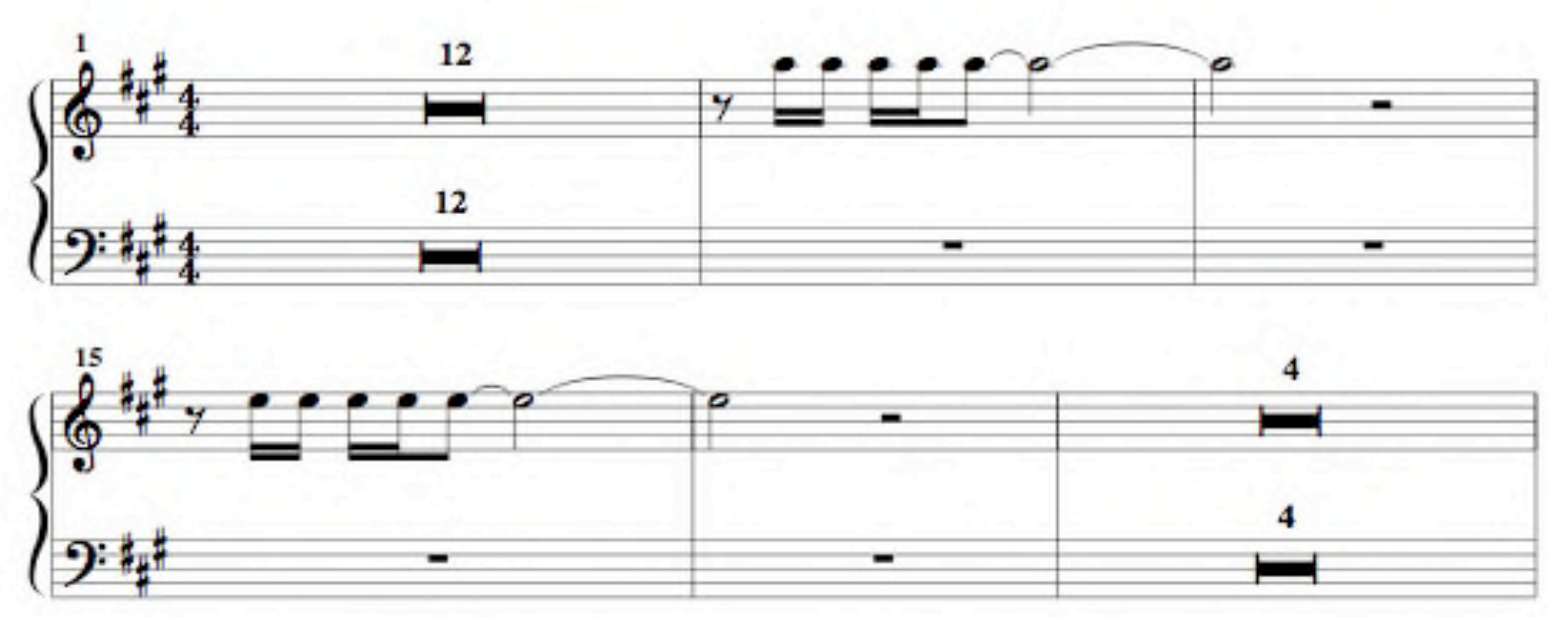

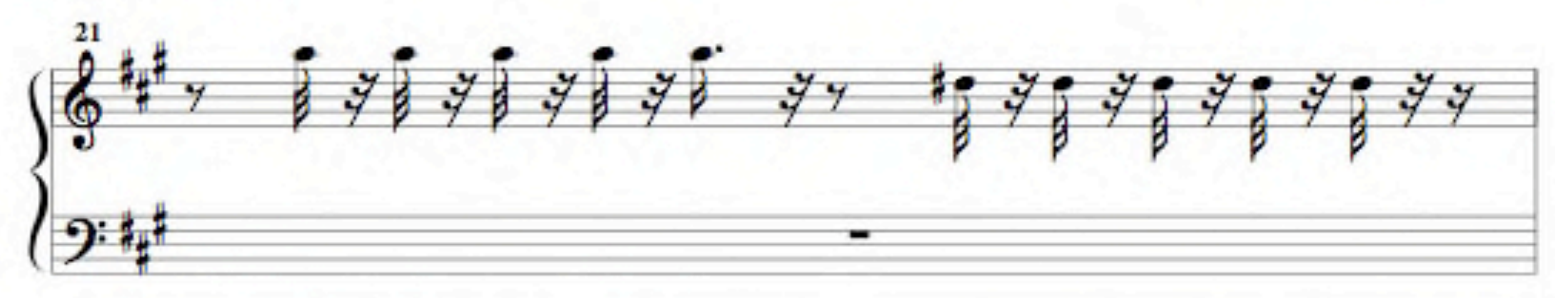

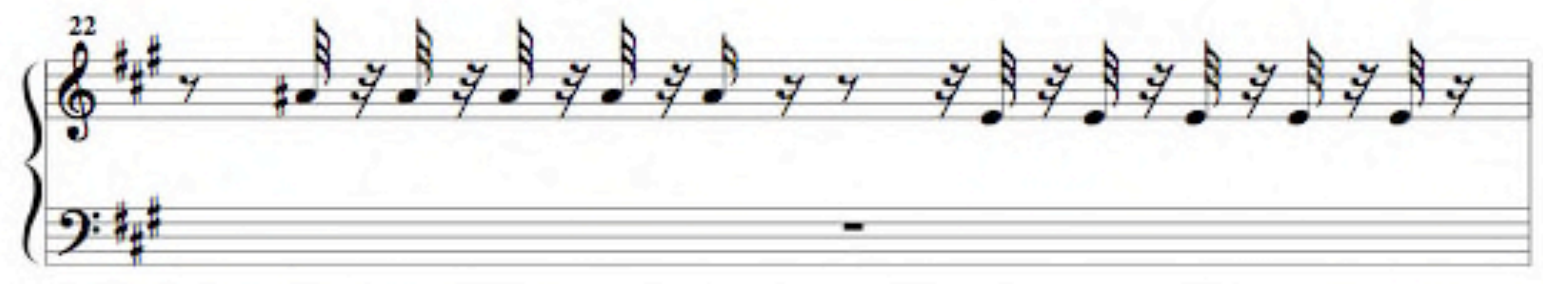
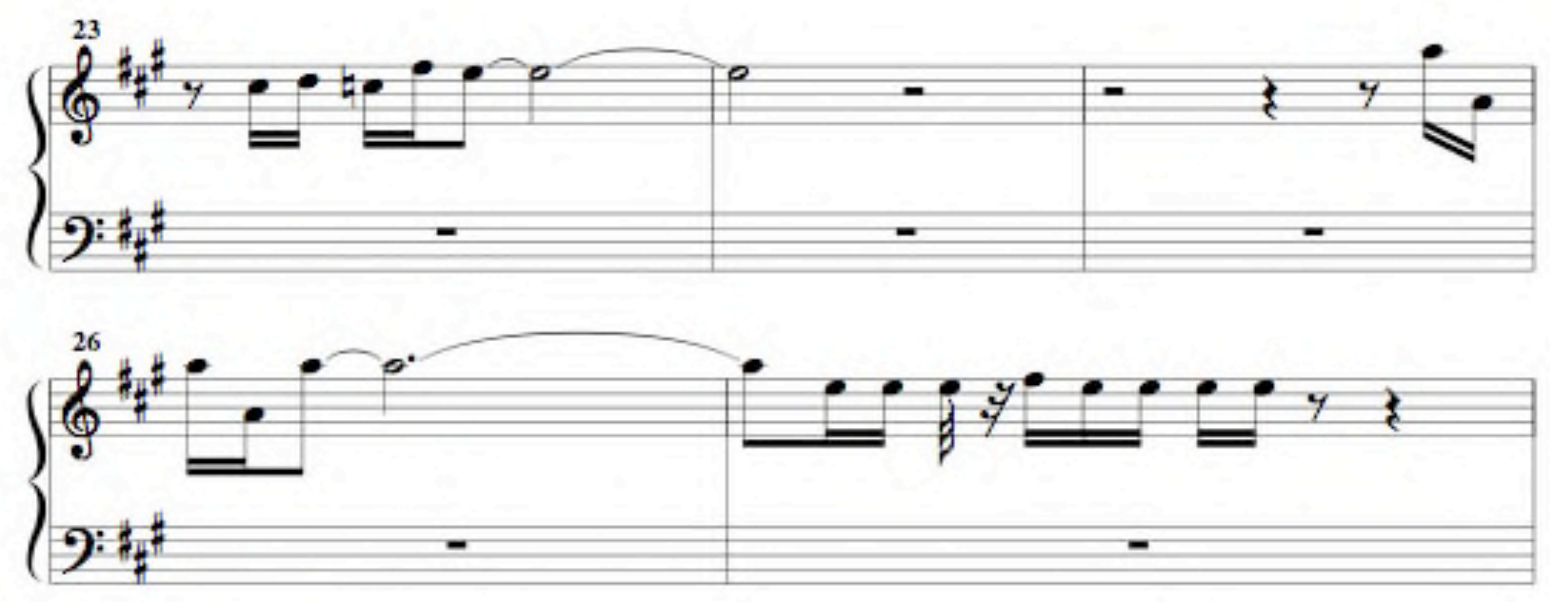

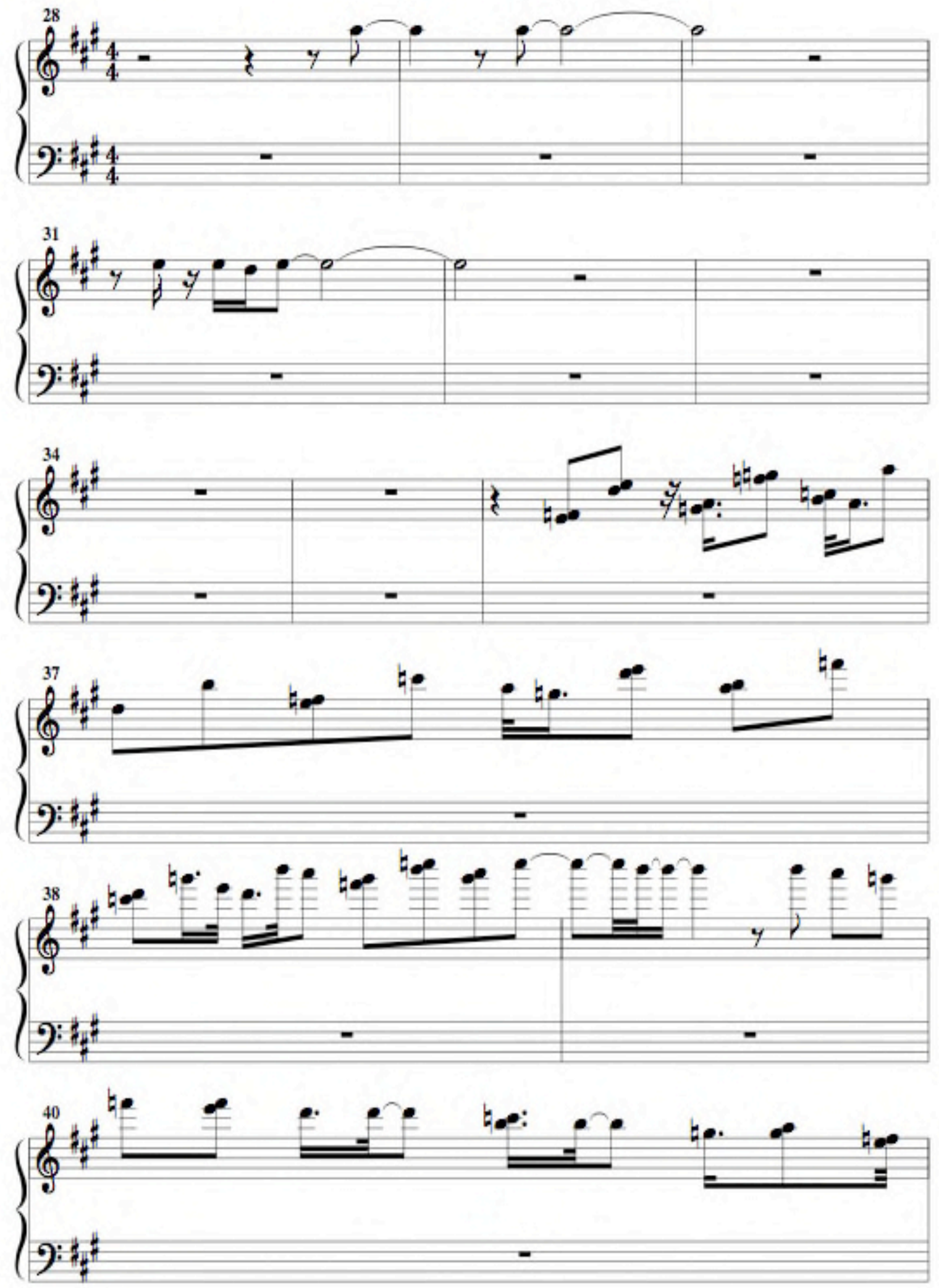

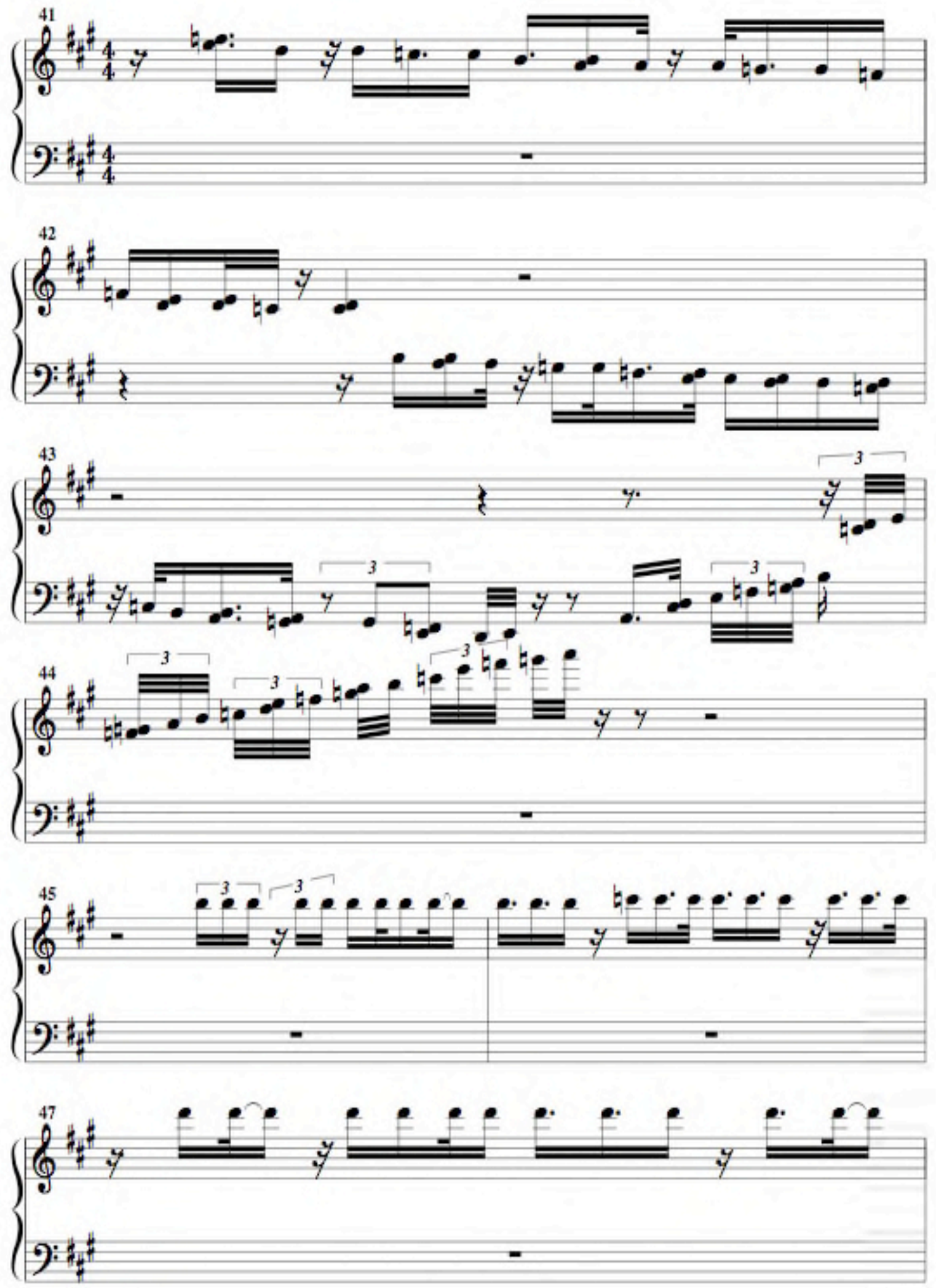

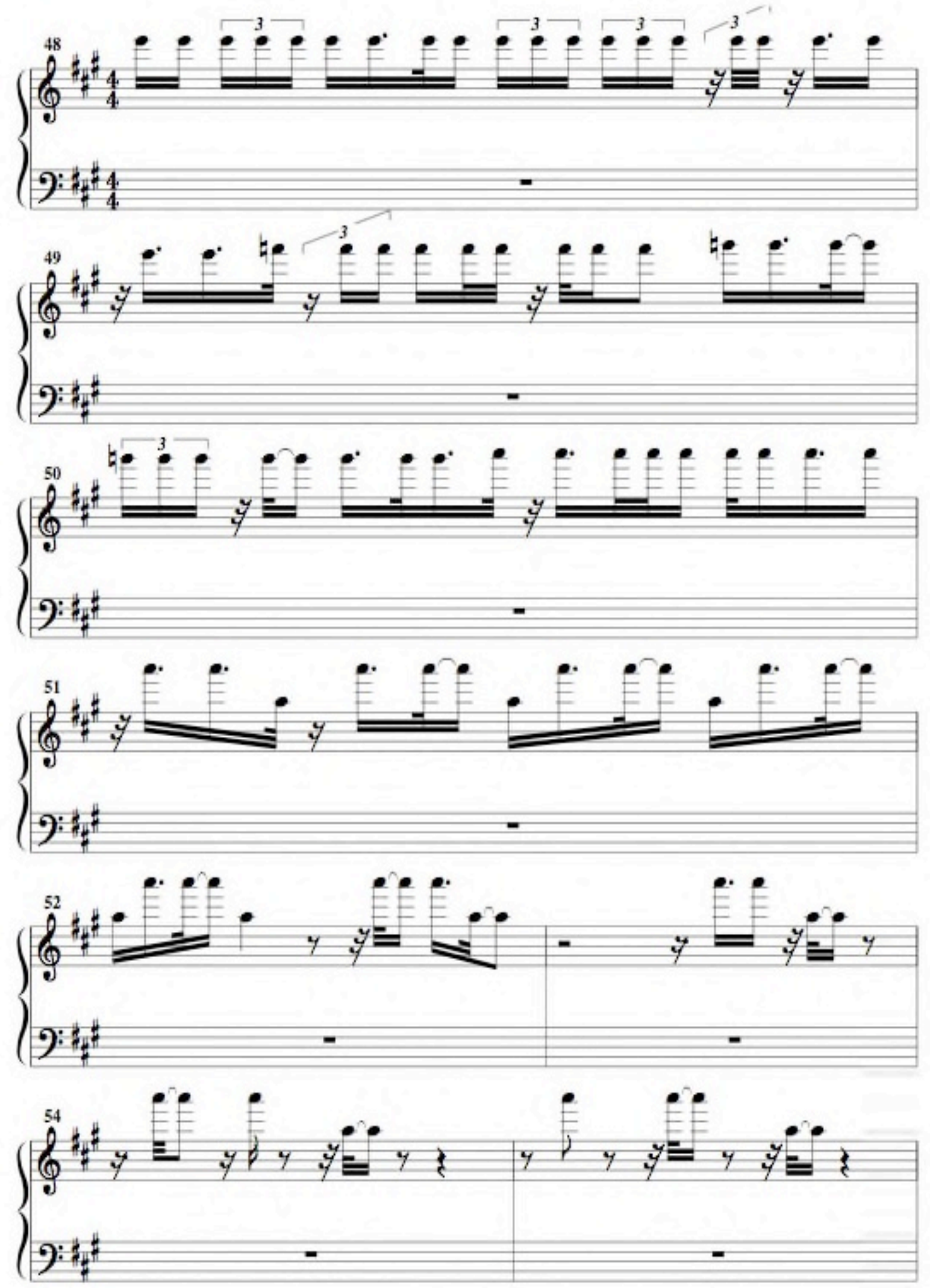

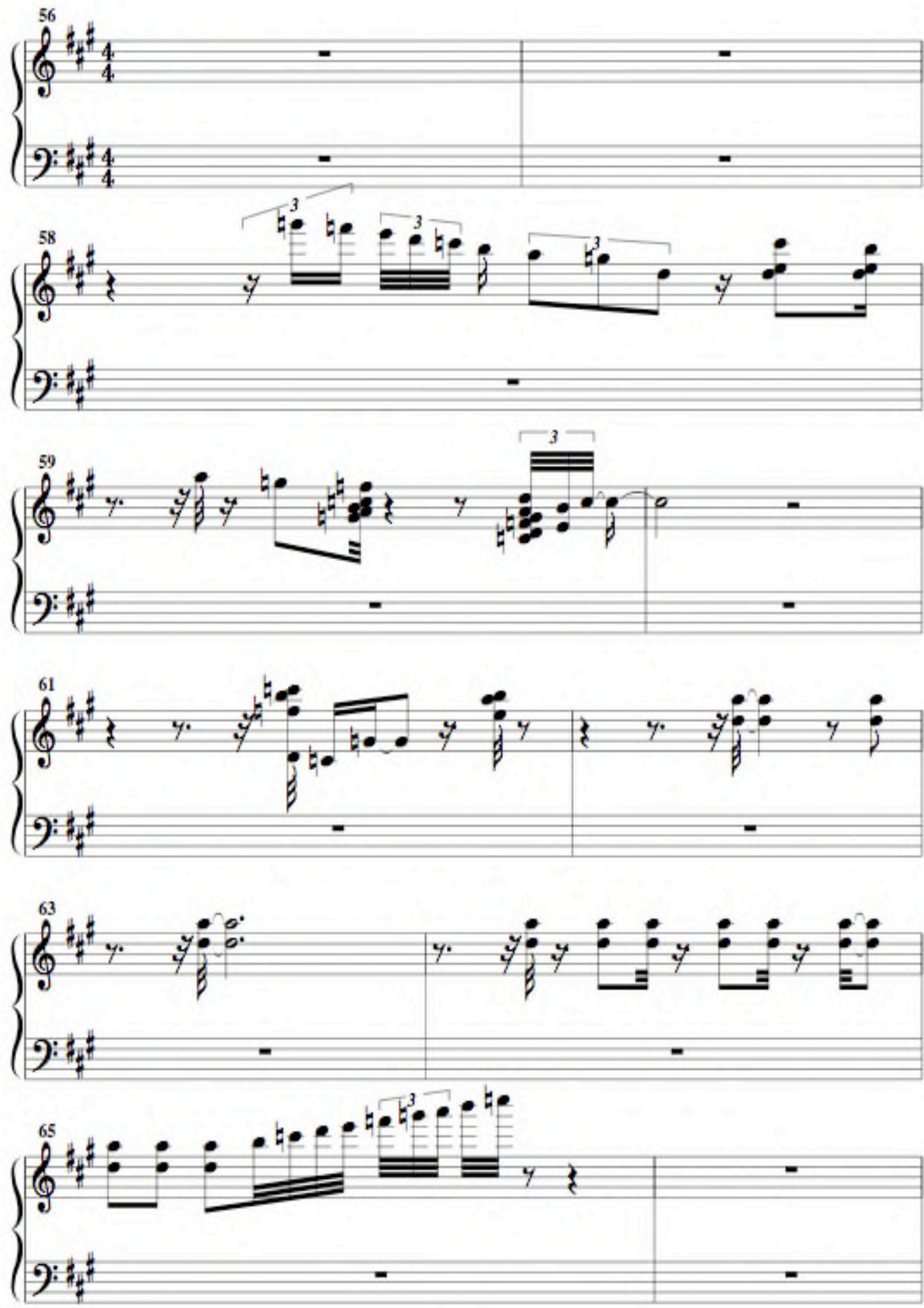

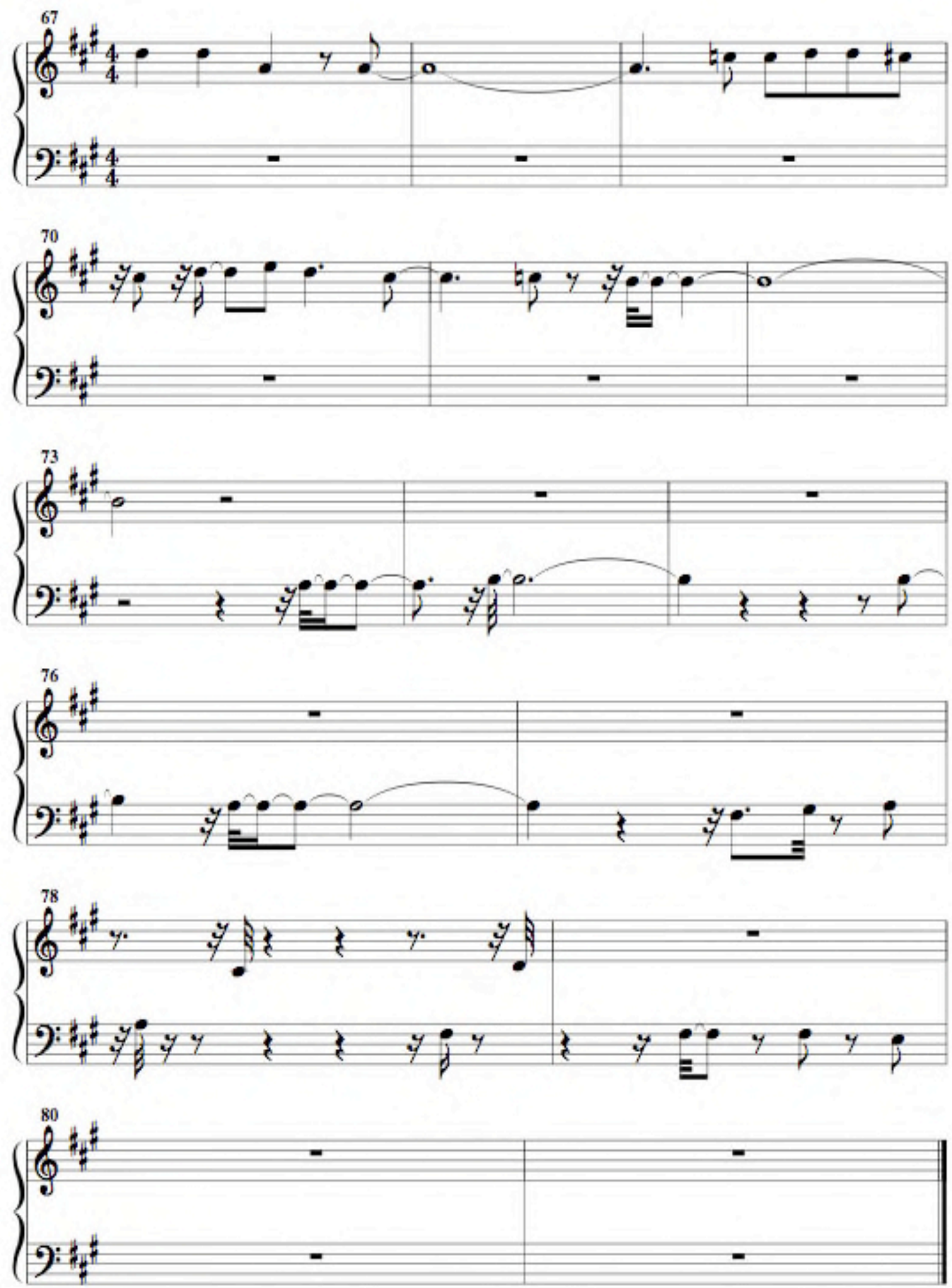
Appendix E: John - Drum Score

Life is good Drums
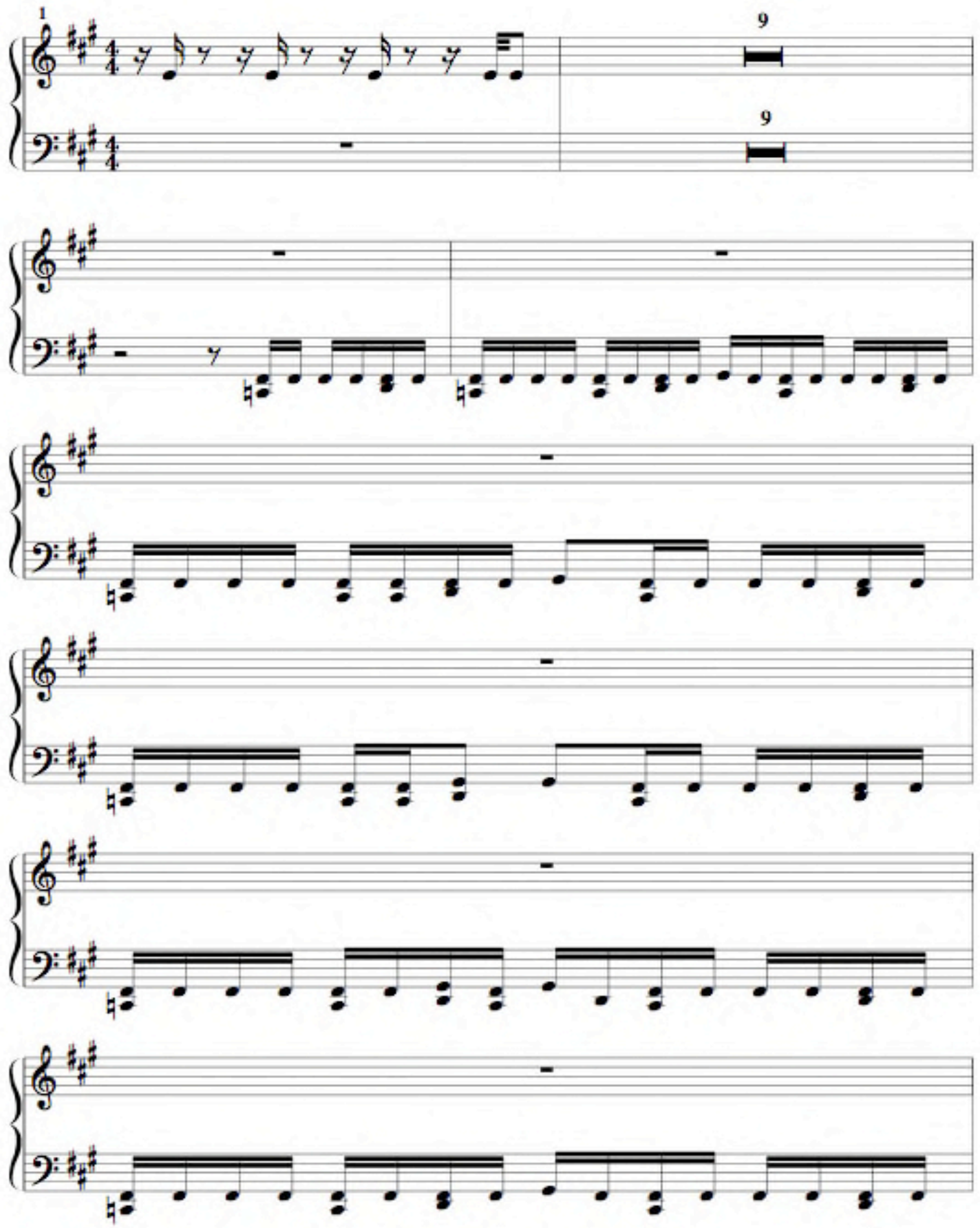

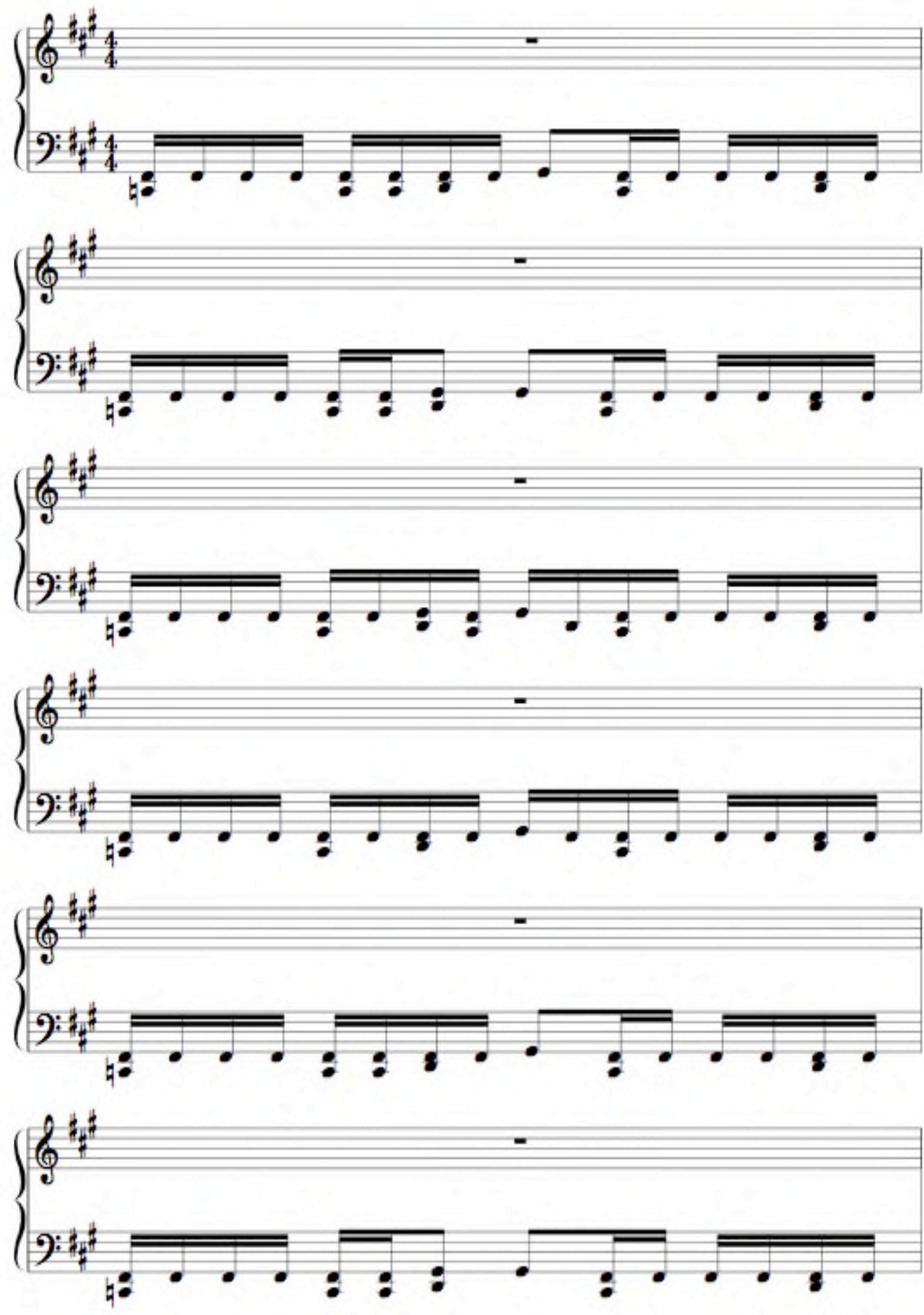

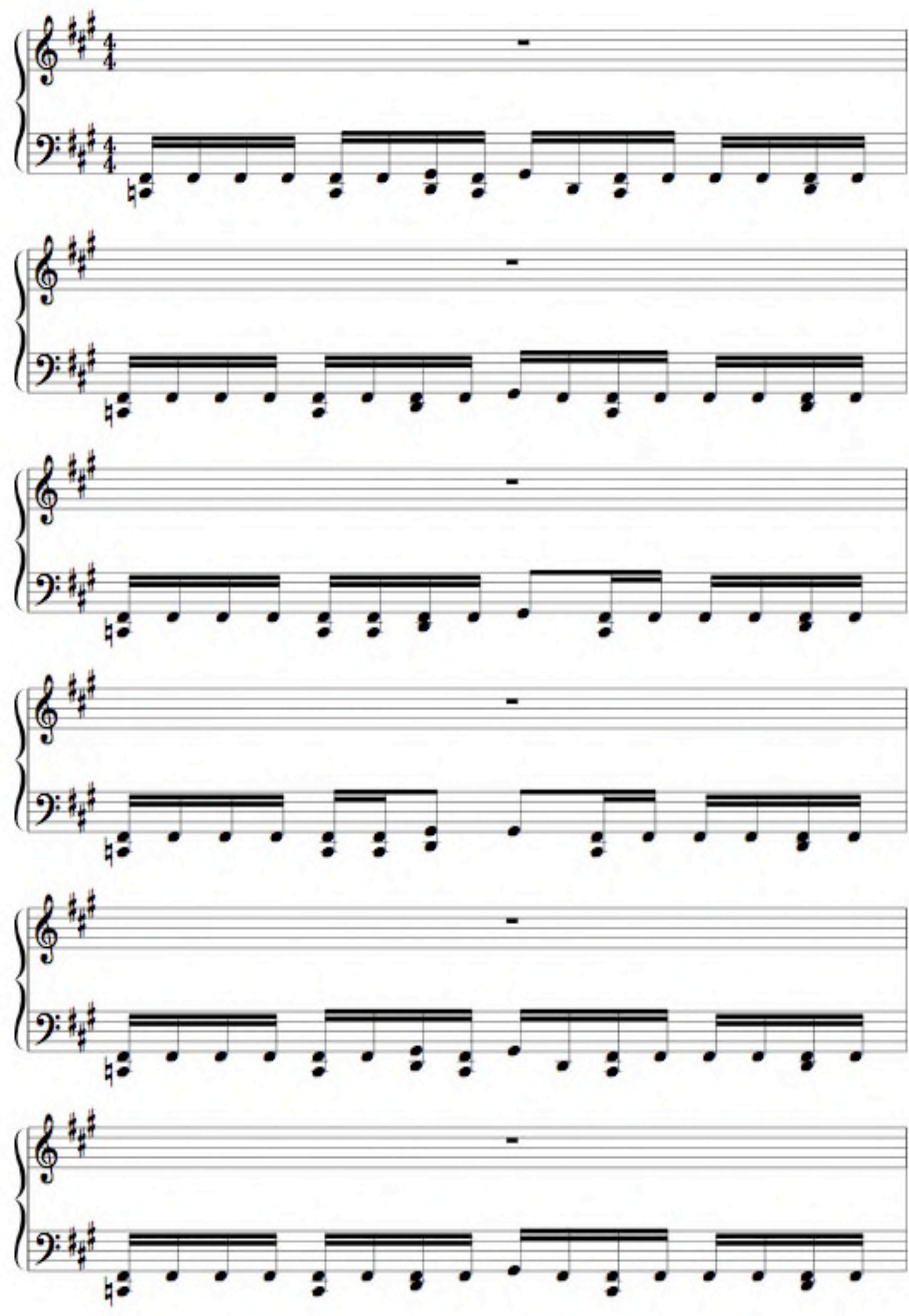

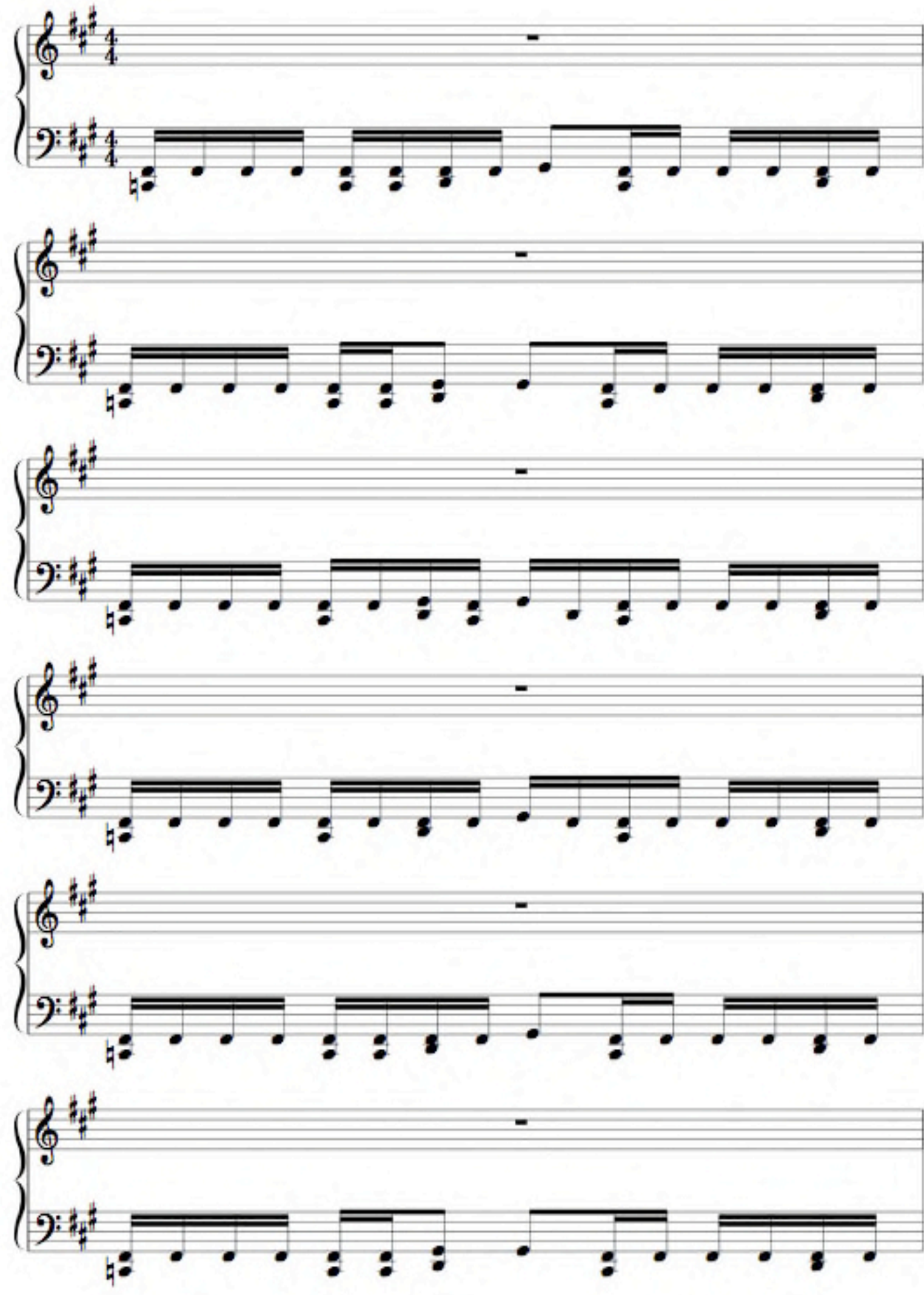

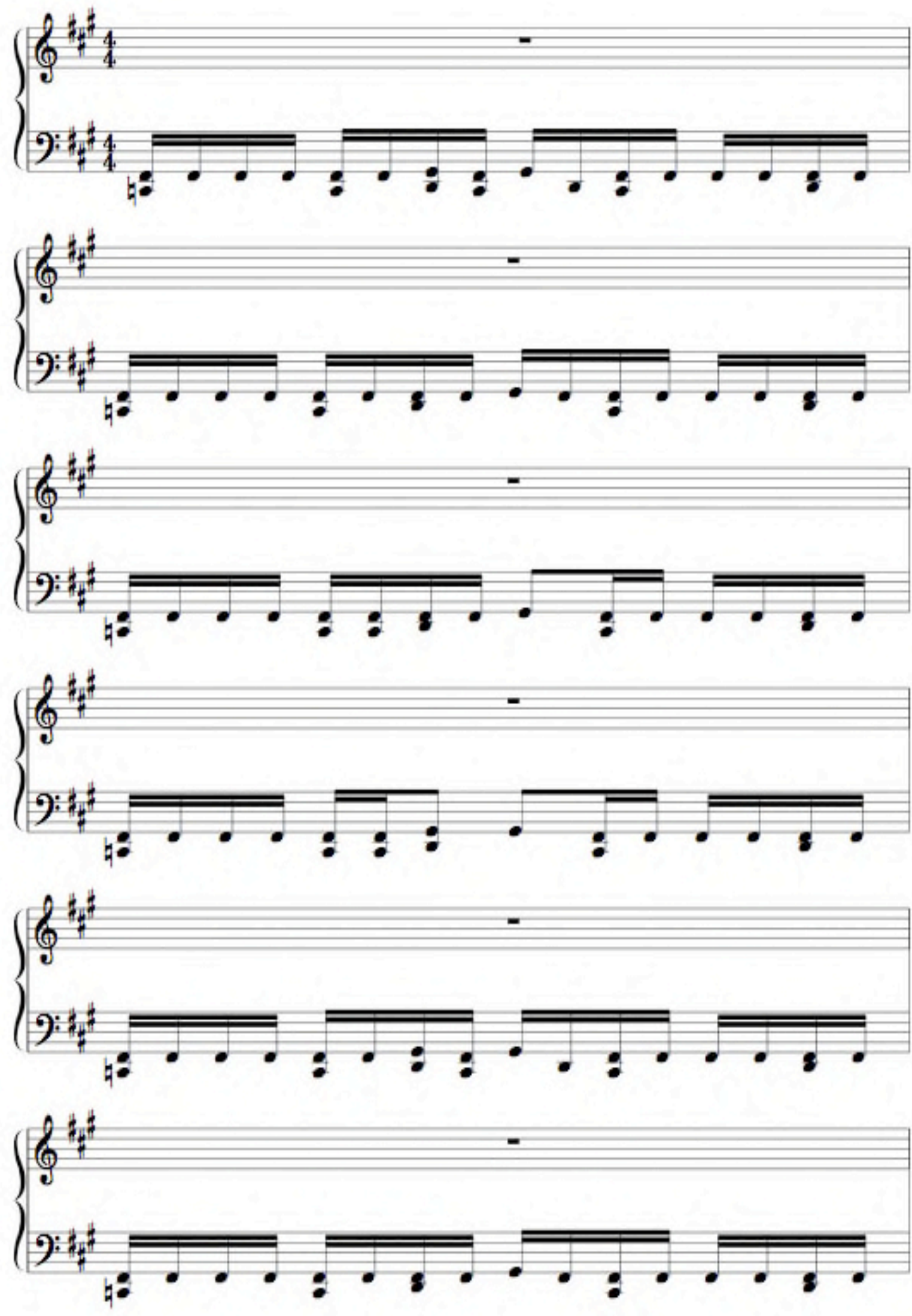

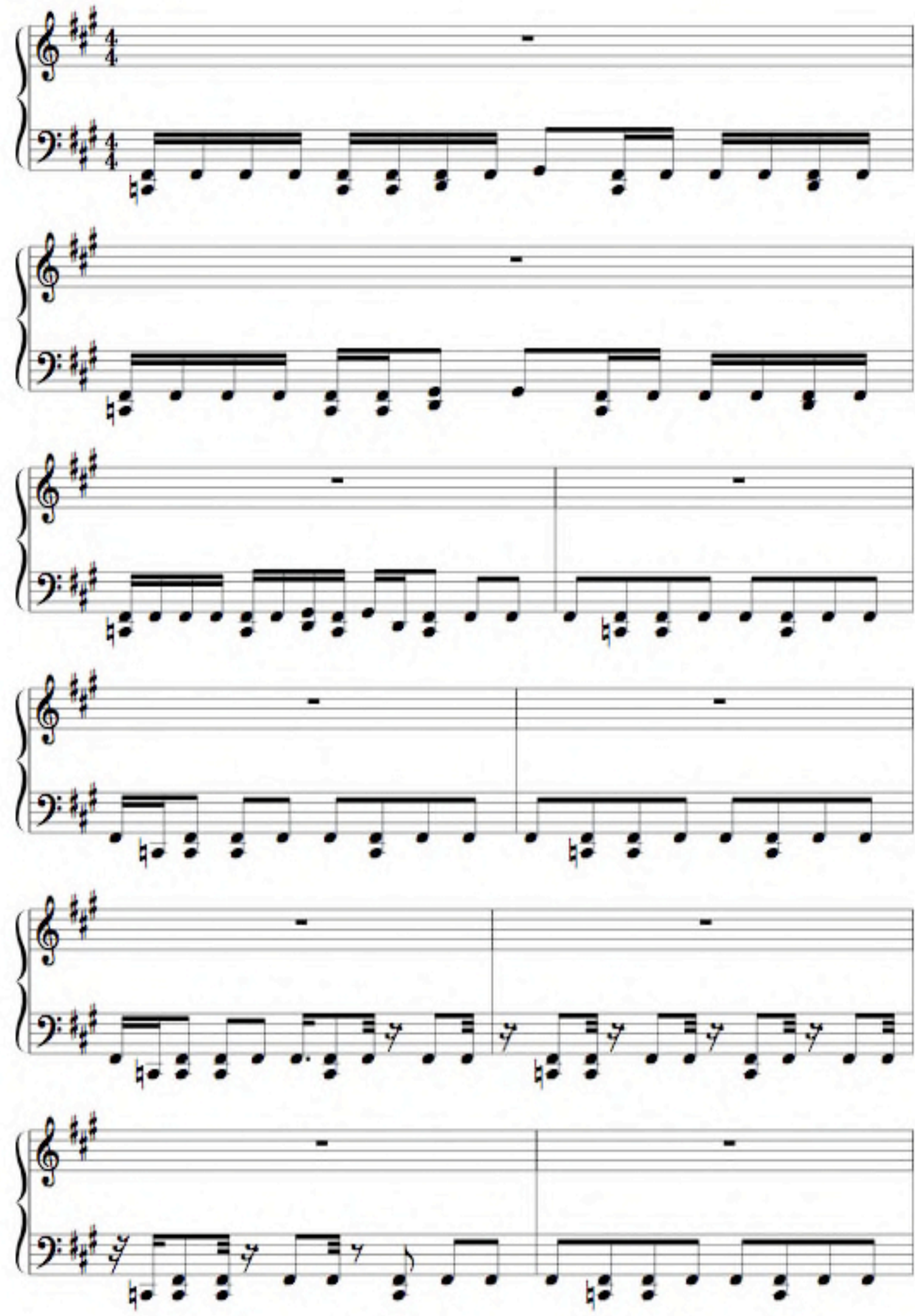

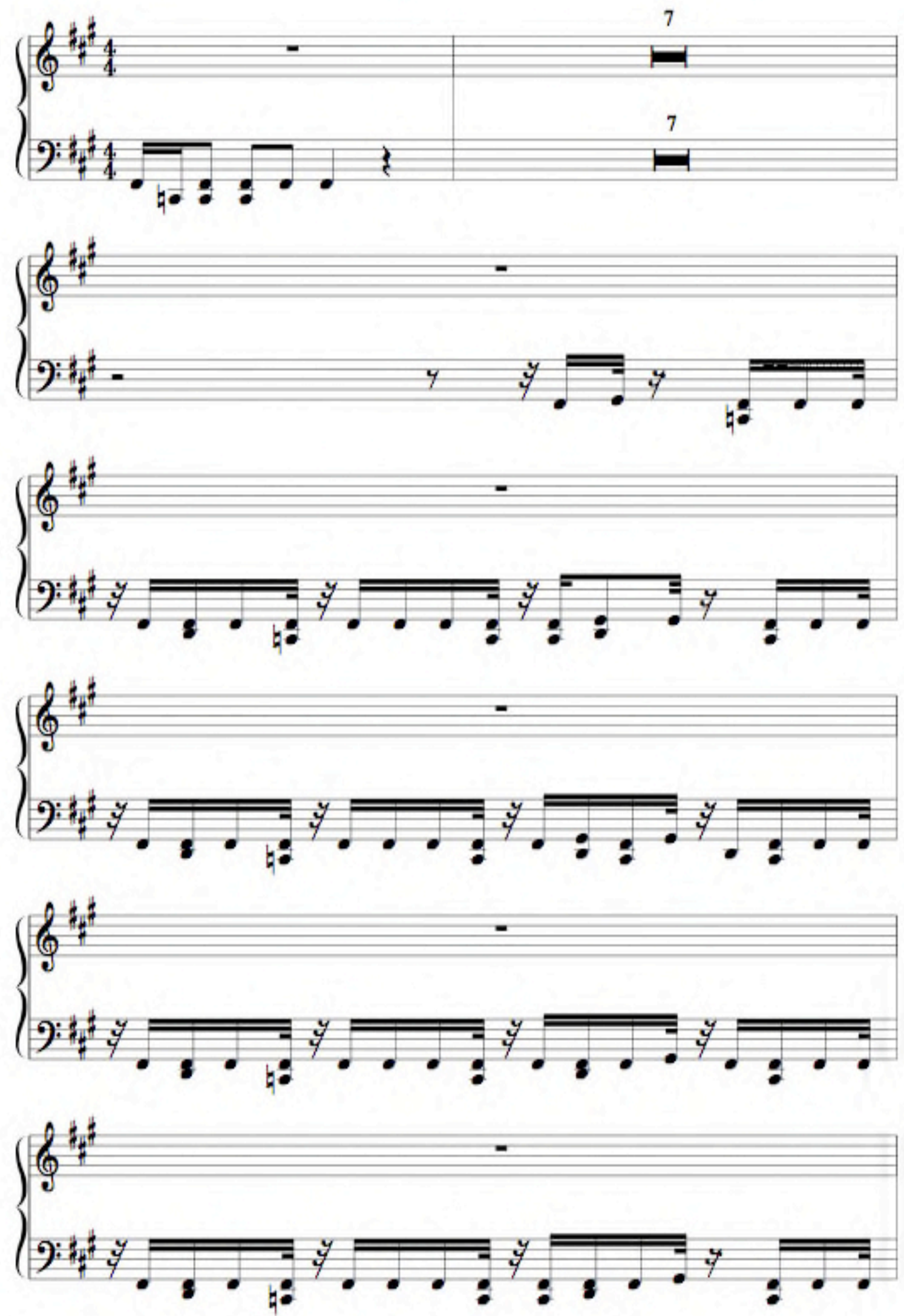

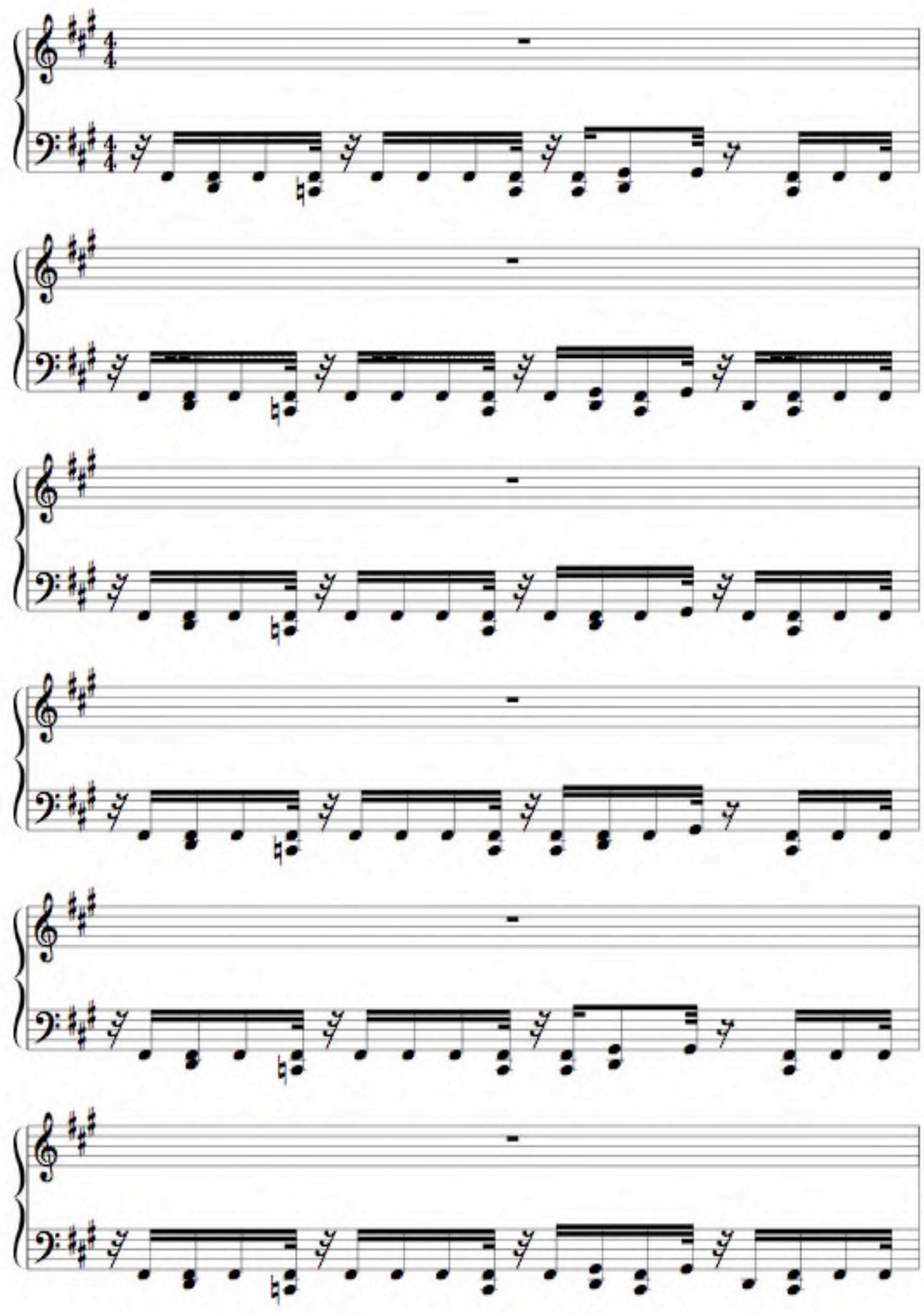

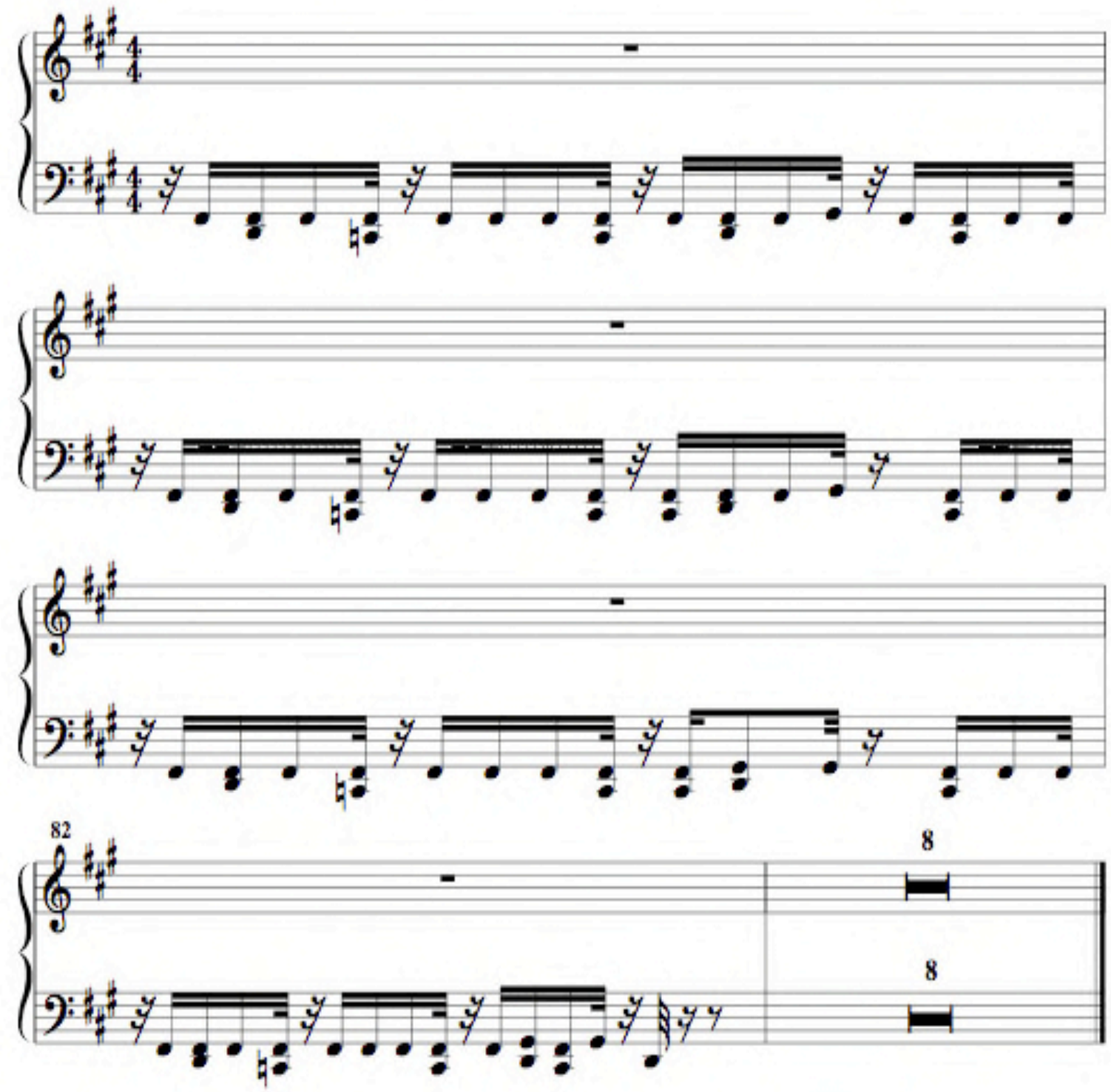


\section{Appendix F: Robert - 'The Journey' - Garageband representation of sequential instrumentation}
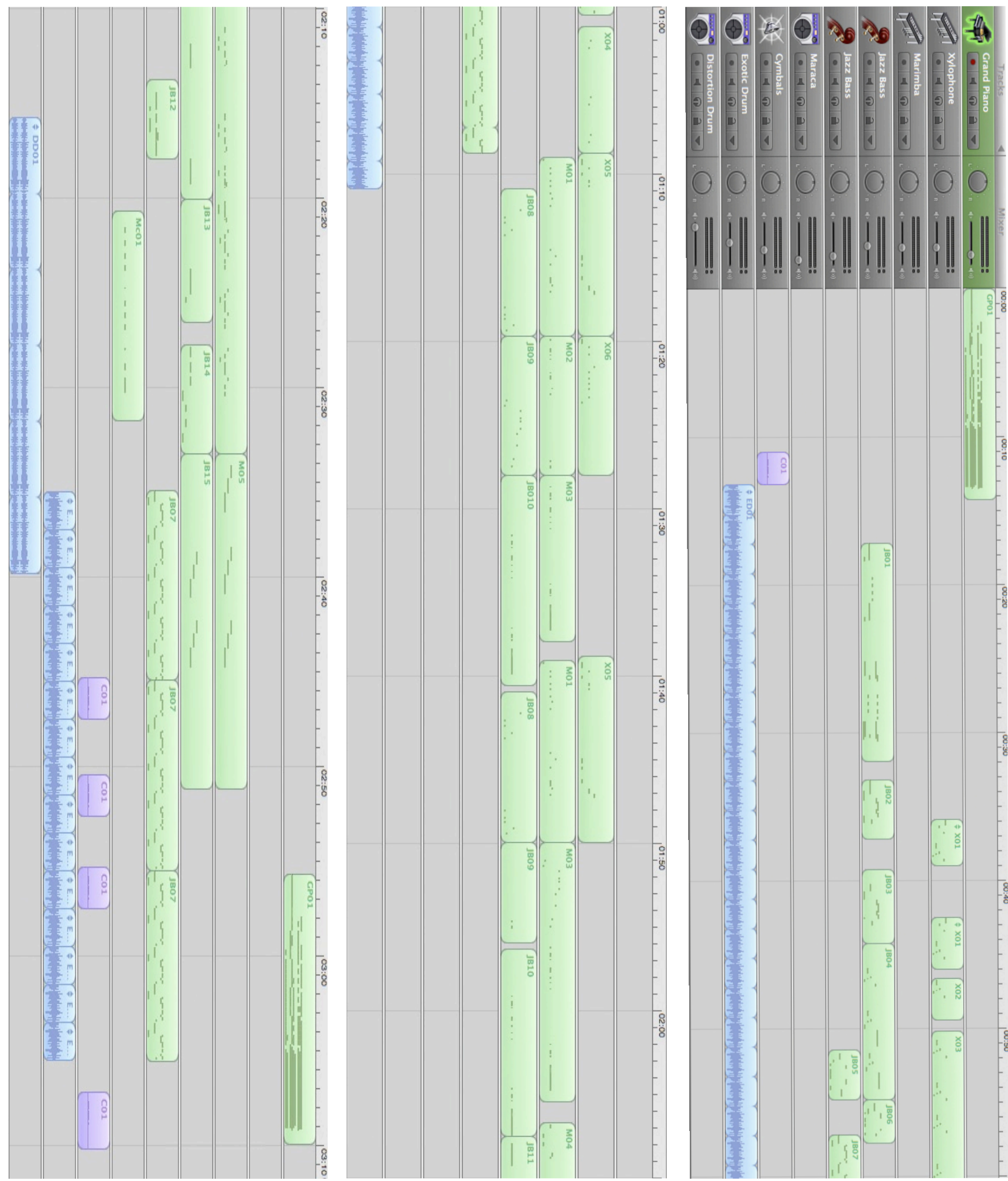
Appendix G: Robert - Grand Piano Score

\title{
The Journey
}

\author{
Grand Piano
}
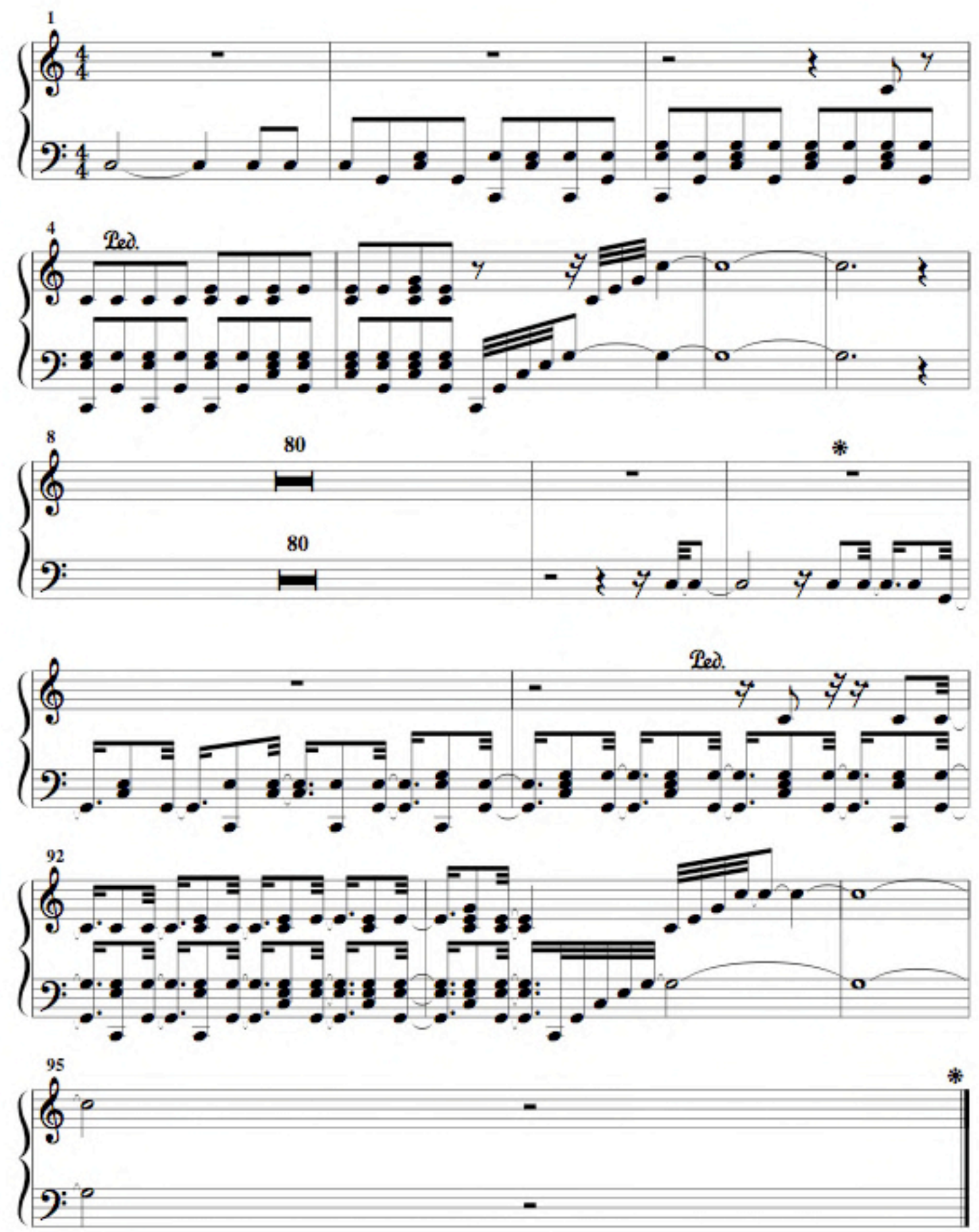


\title{
Appendix H: Robert - Xylophone Score
}

\section{The Journey}

\author{
Xylophone
}
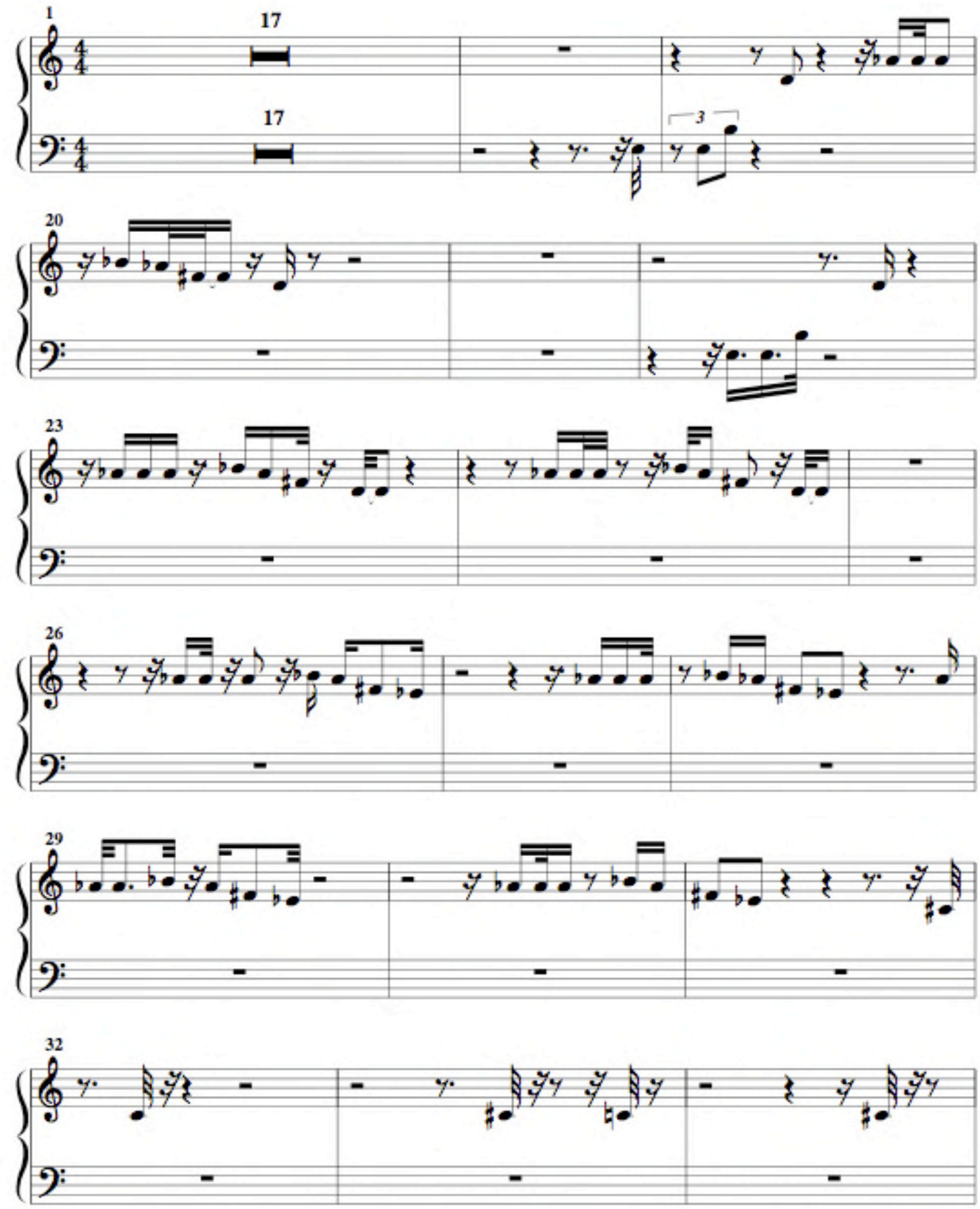

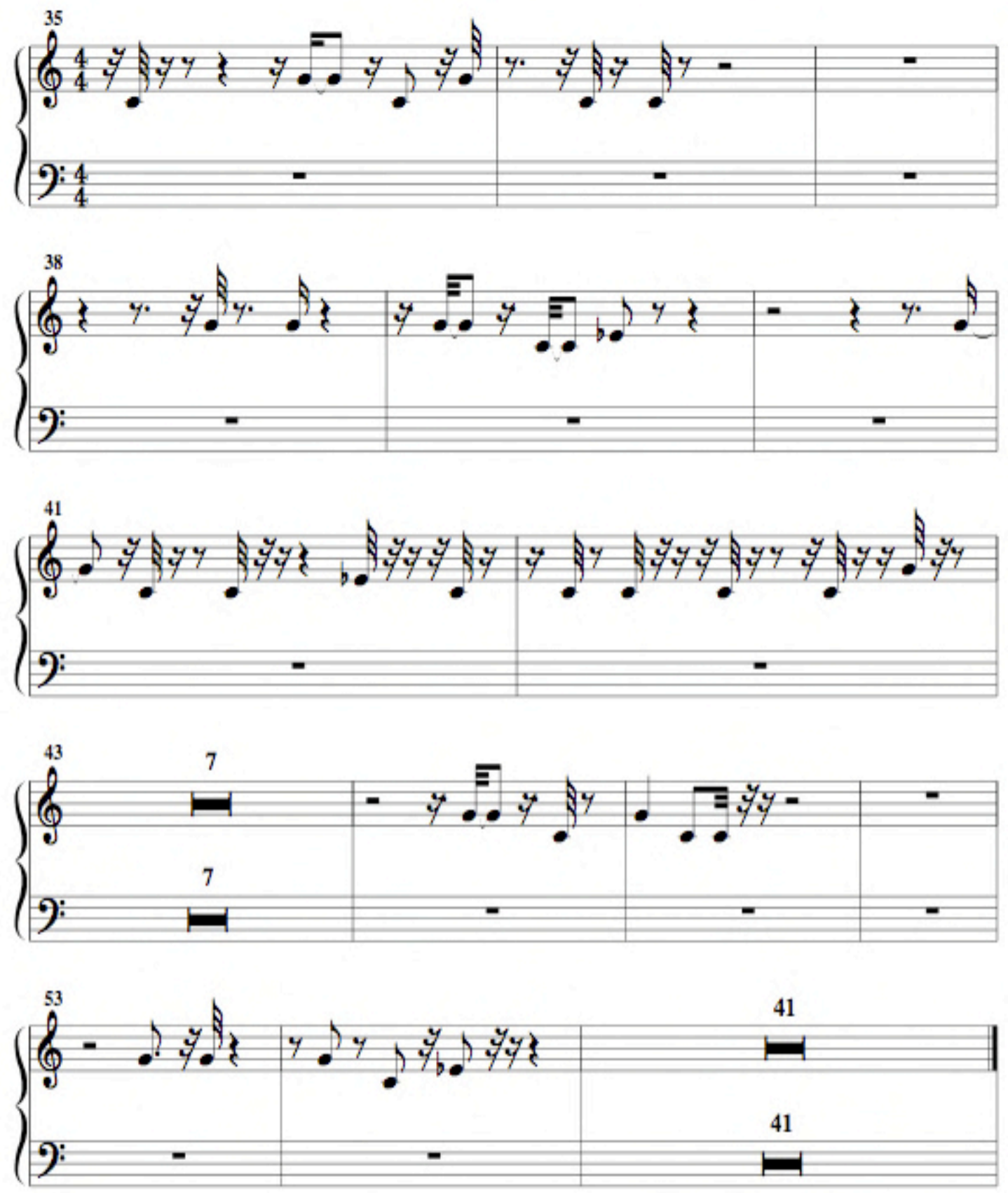
Appendix I: Robert - Marimba Score

\title{
The Journey
}

\author{
Marimba
}
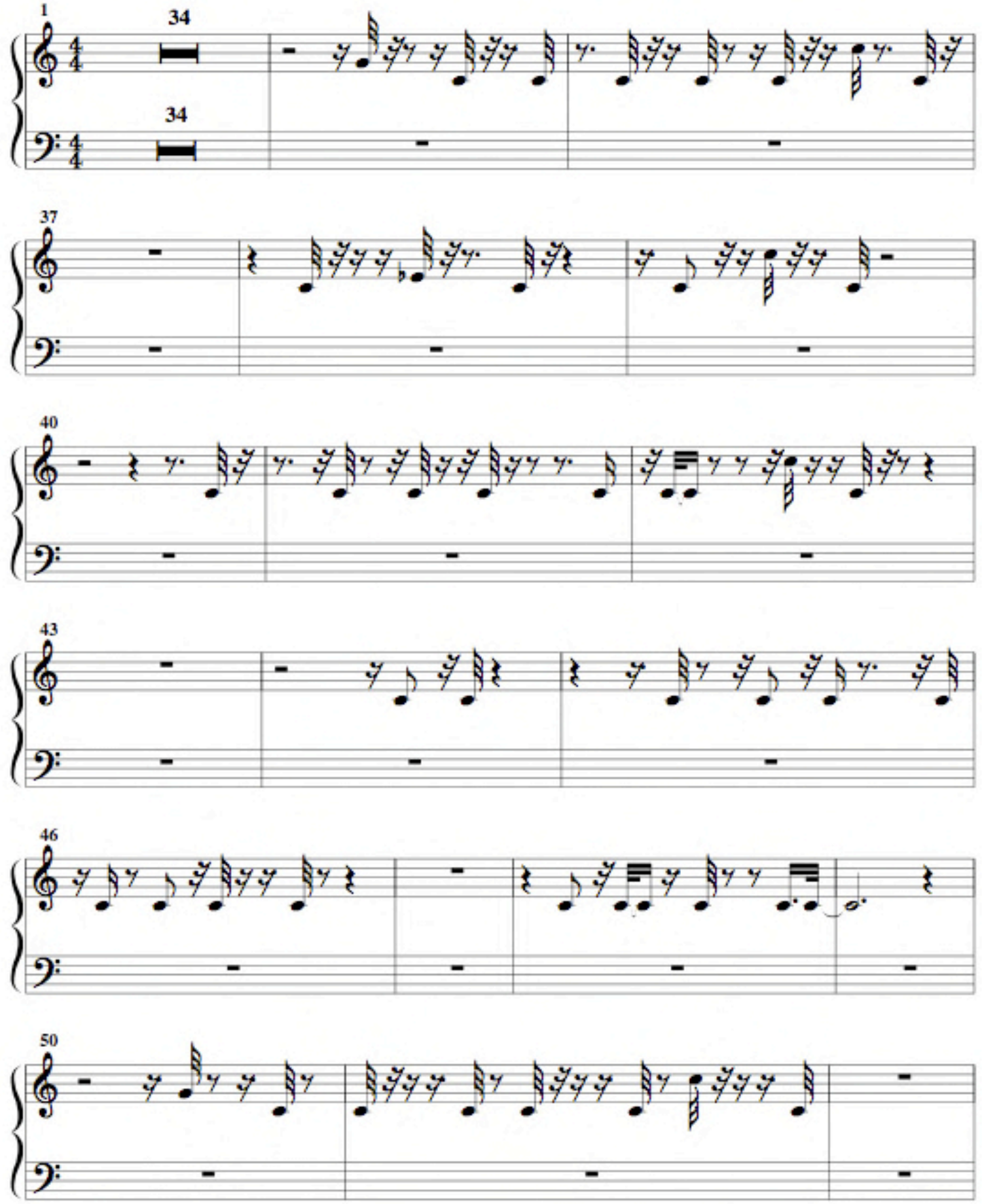

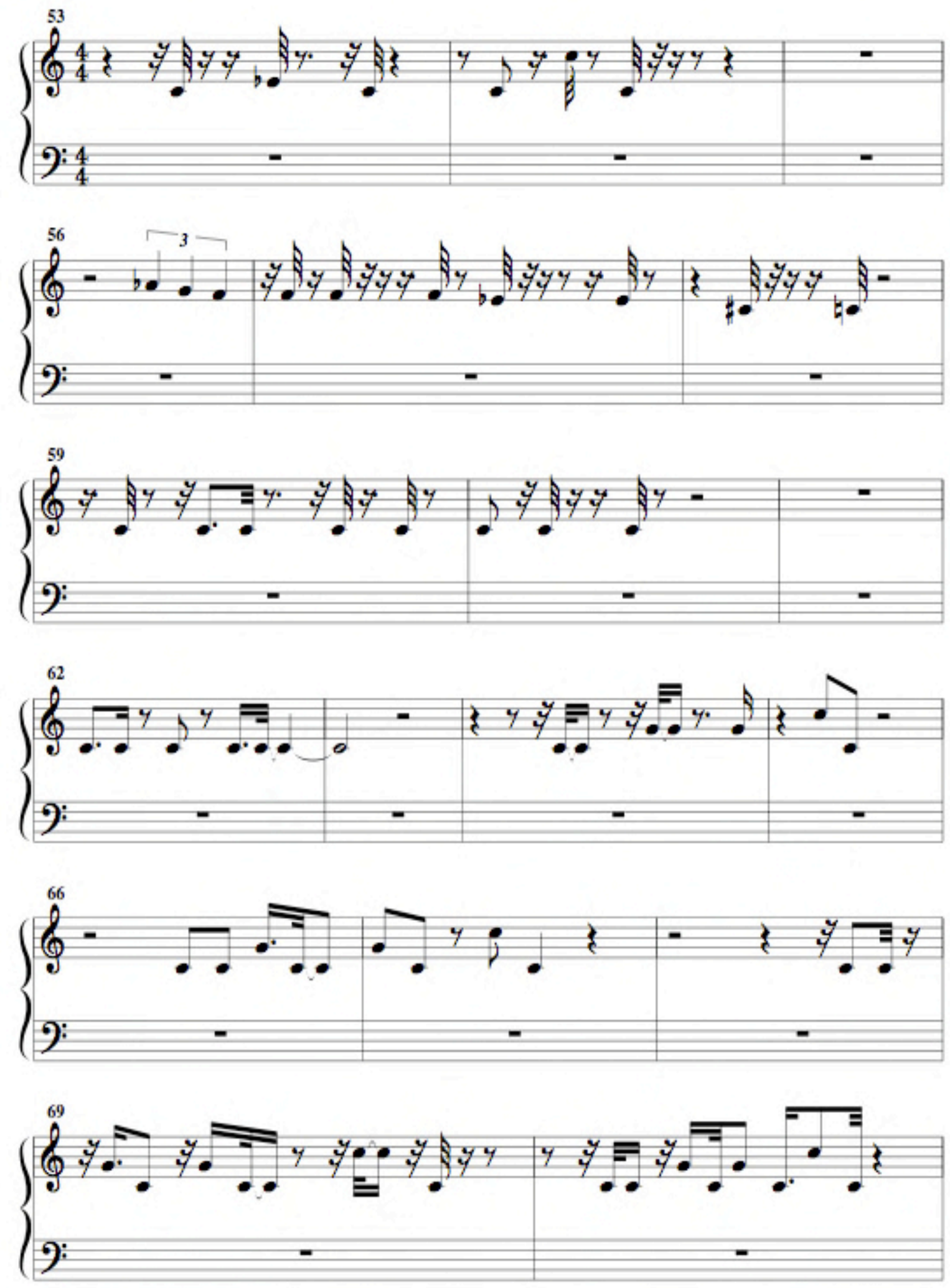

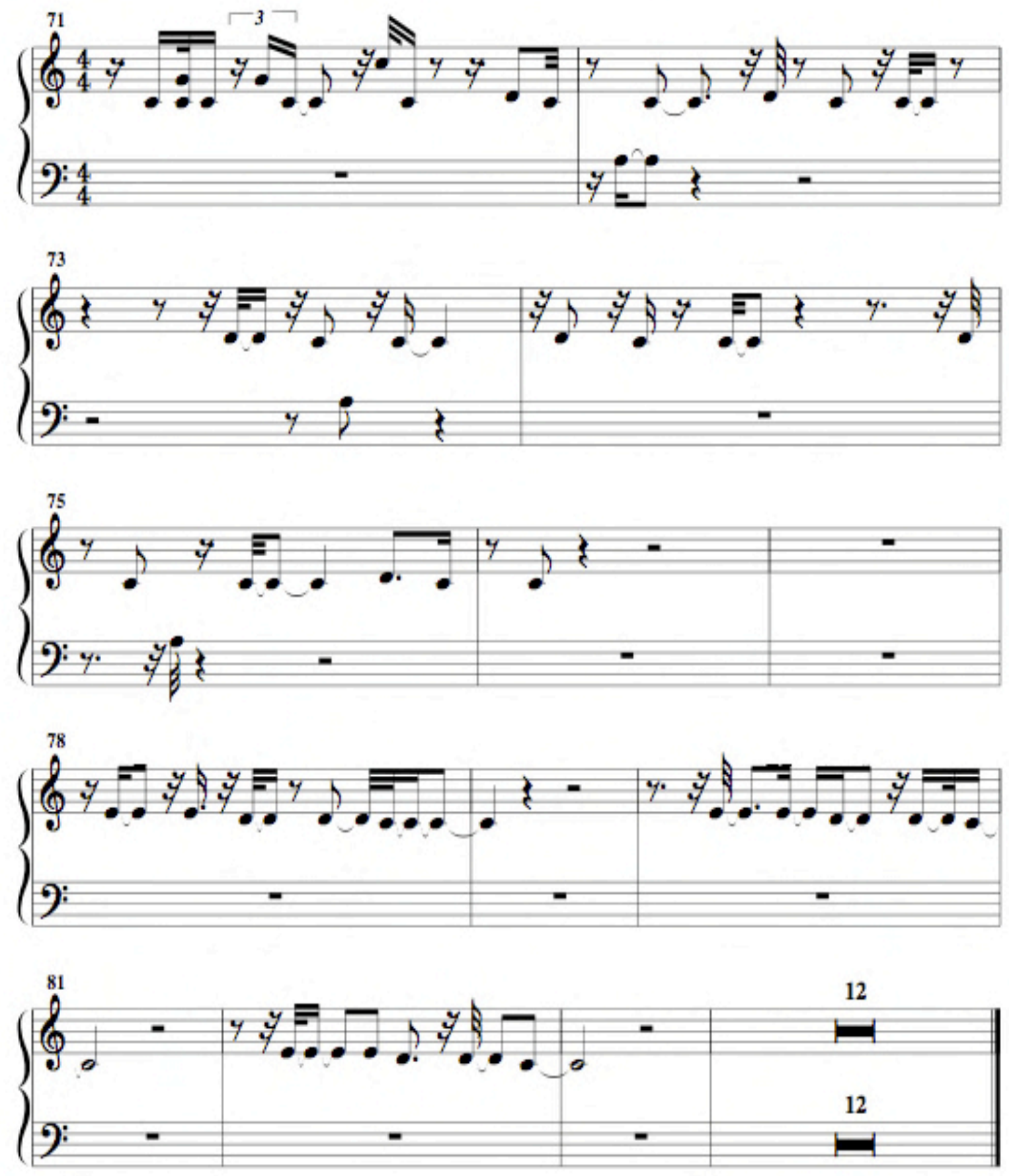
Analysing children's offerings in music therapy

99

Appendix J: Robert - Jazz Bass 1 Score

The Journey

Jazz Bass 1
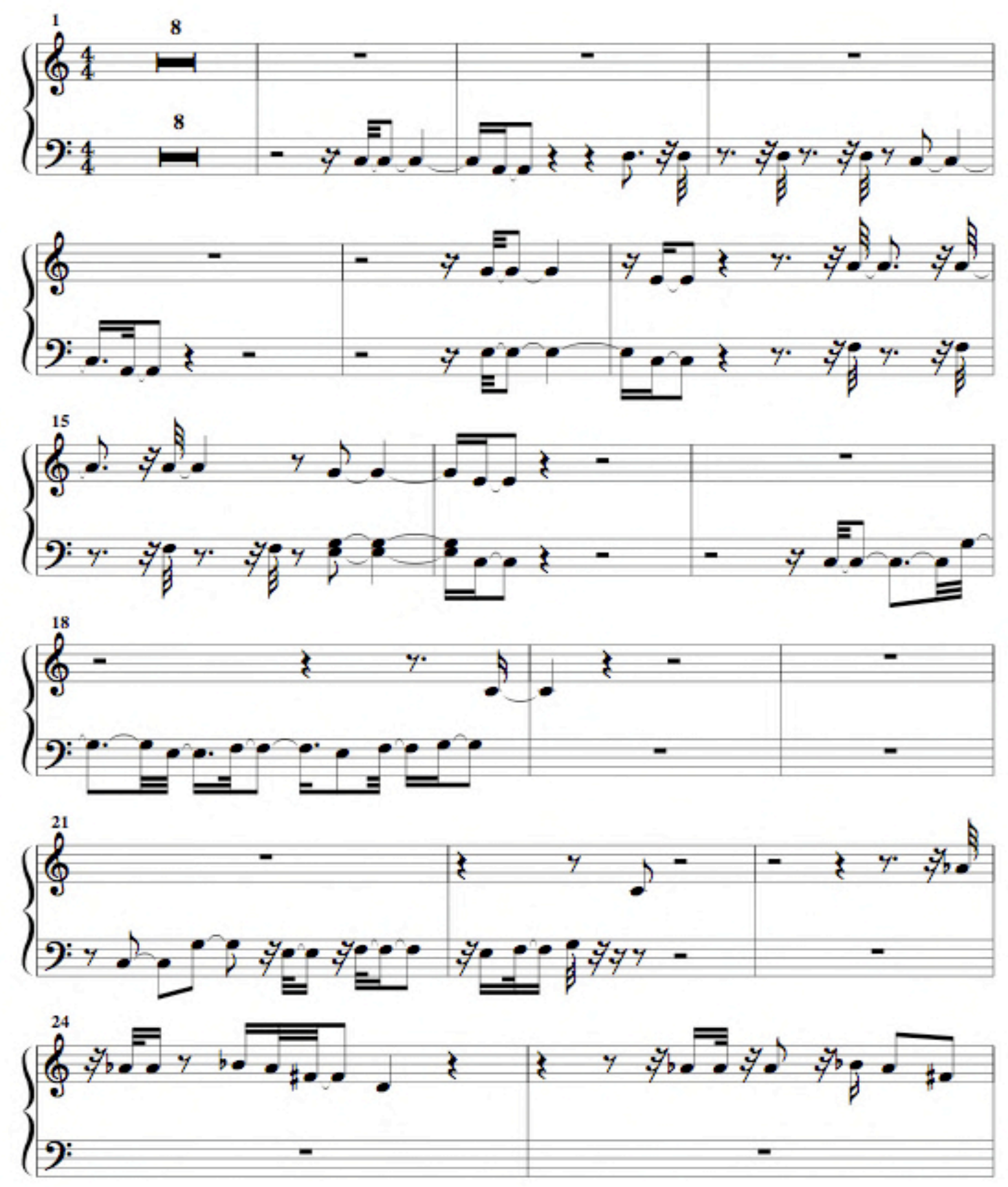

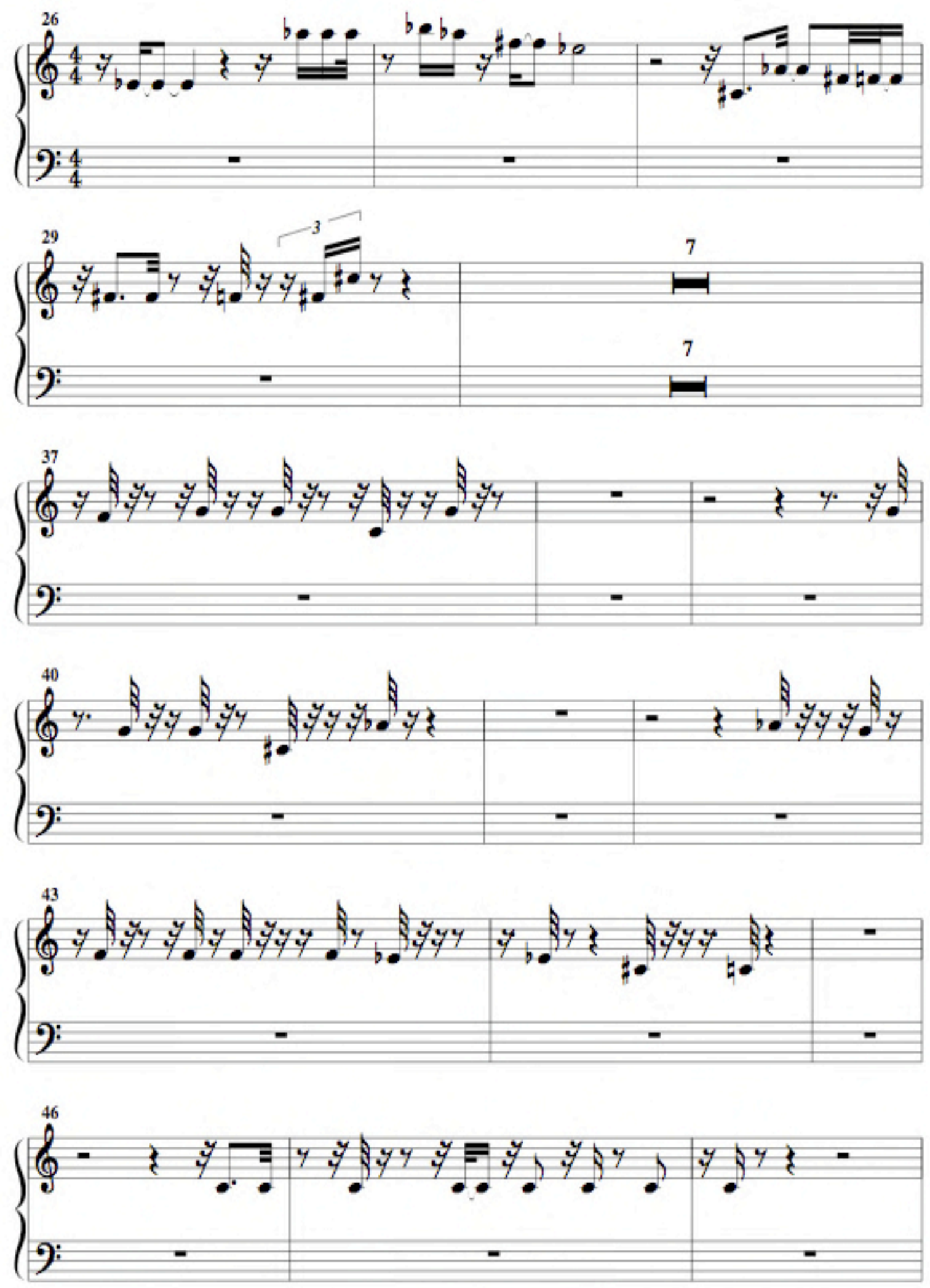

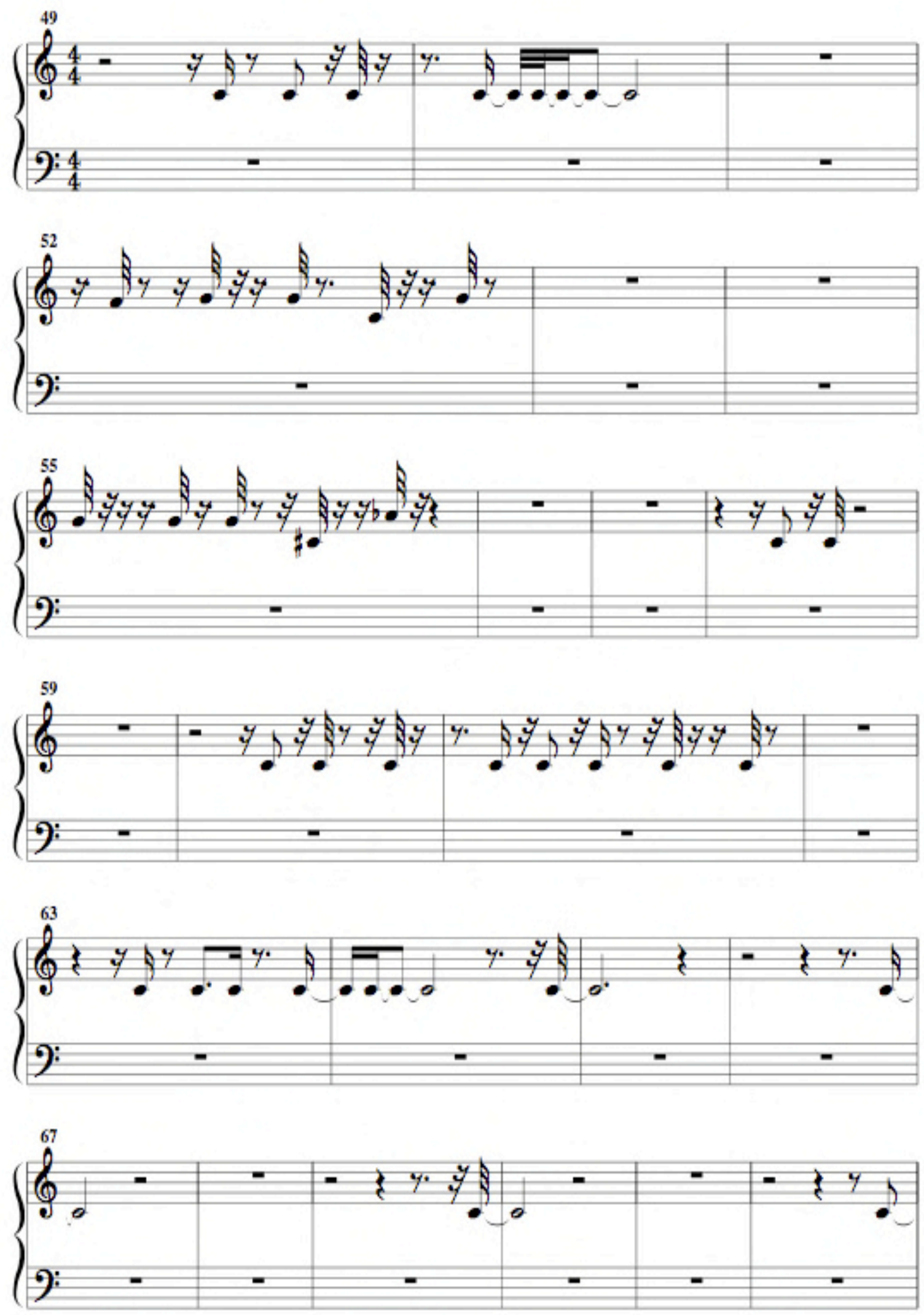

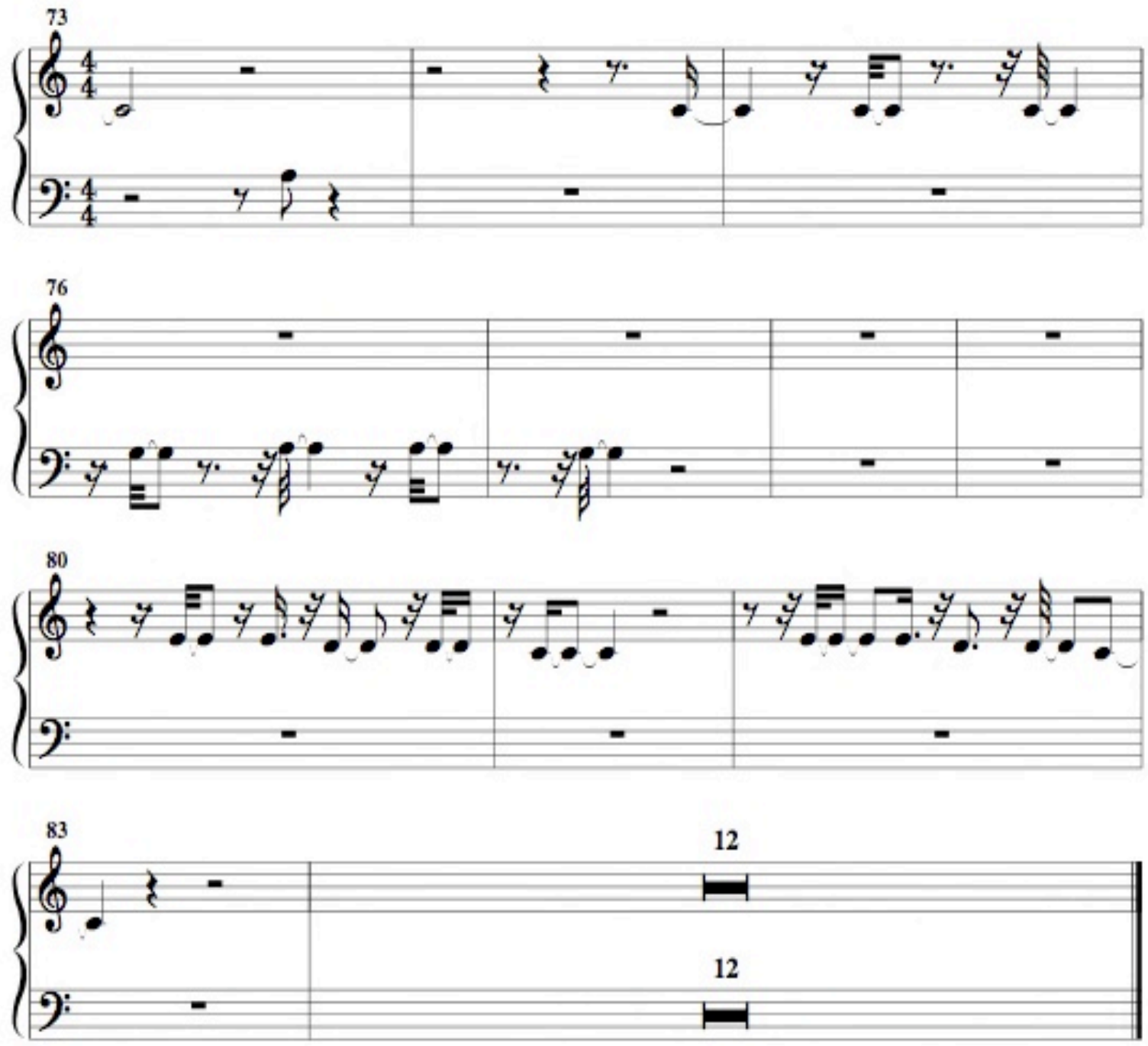
Analysing children's offerings in music therapy

103

Appendix K: Robert - Jazz Bass 2 Score

The Journey

Jazz Bass 2
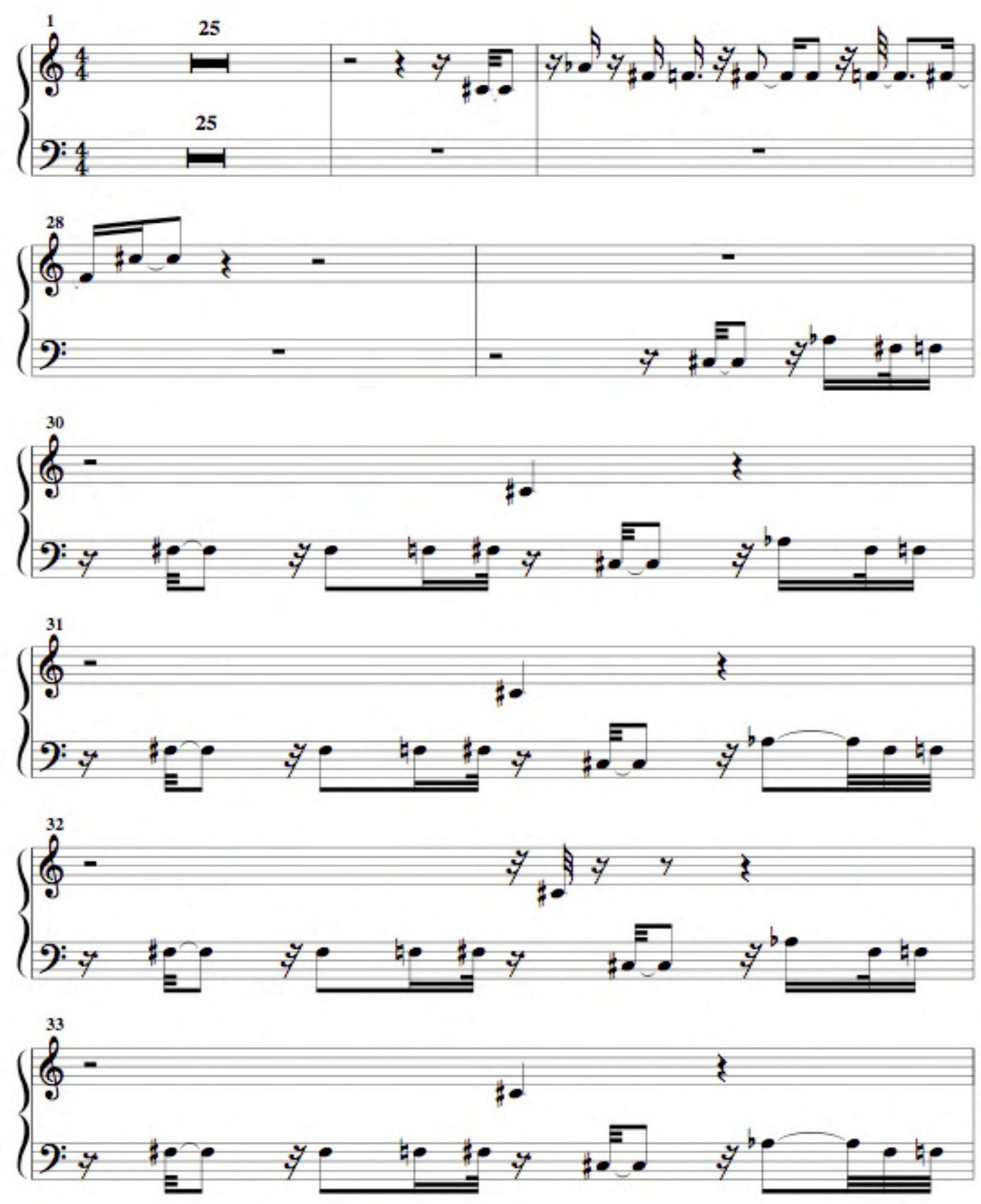

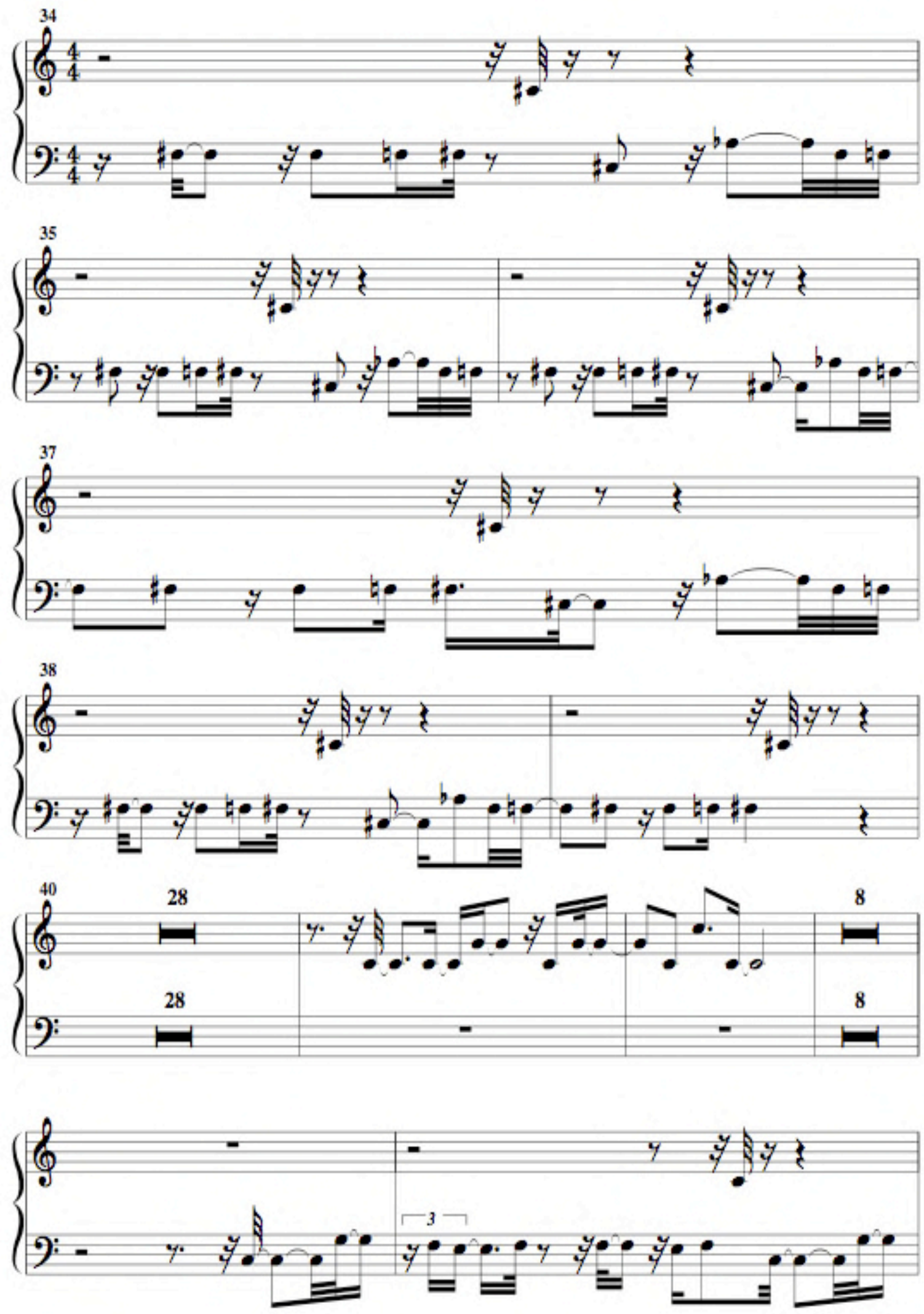

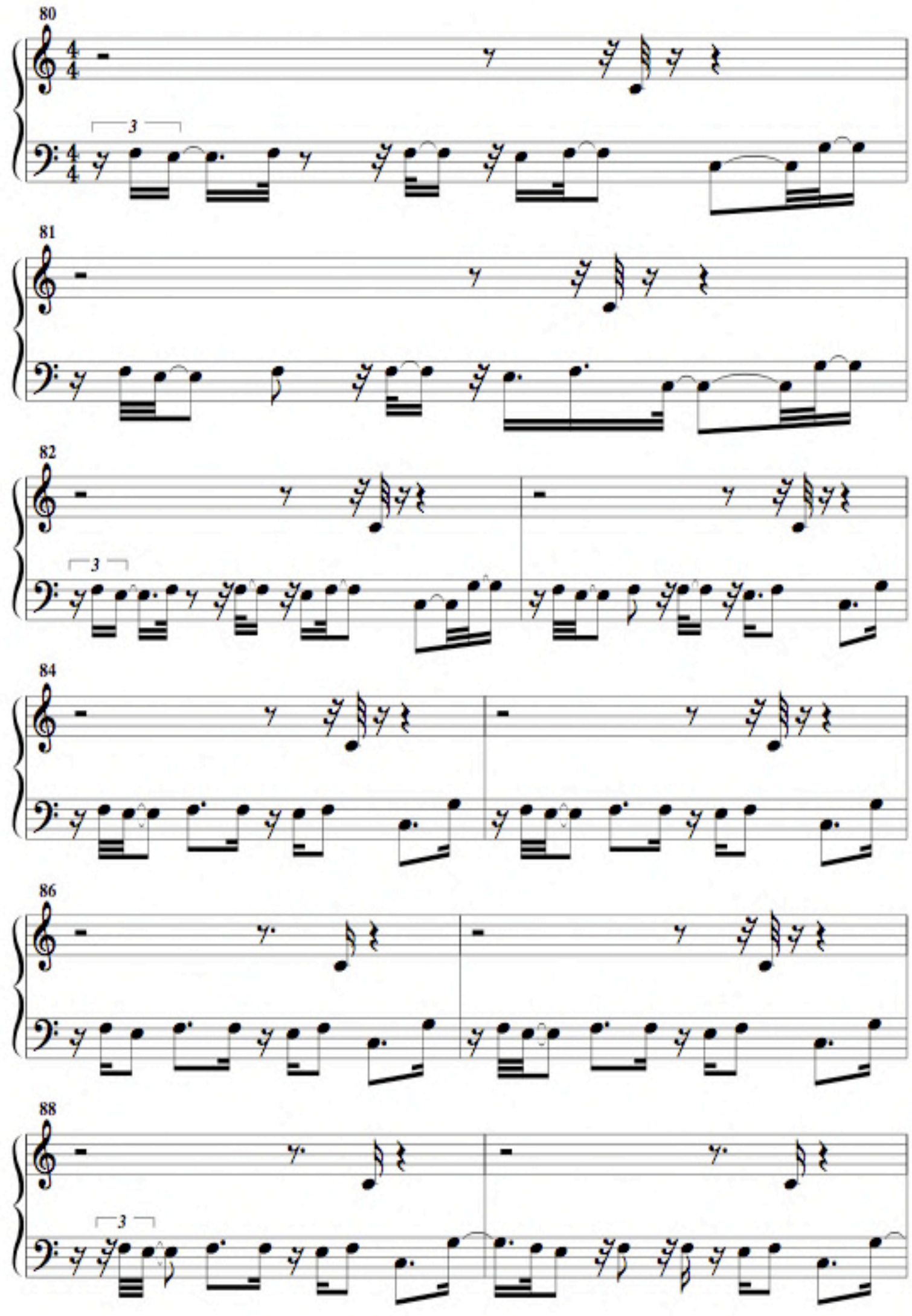

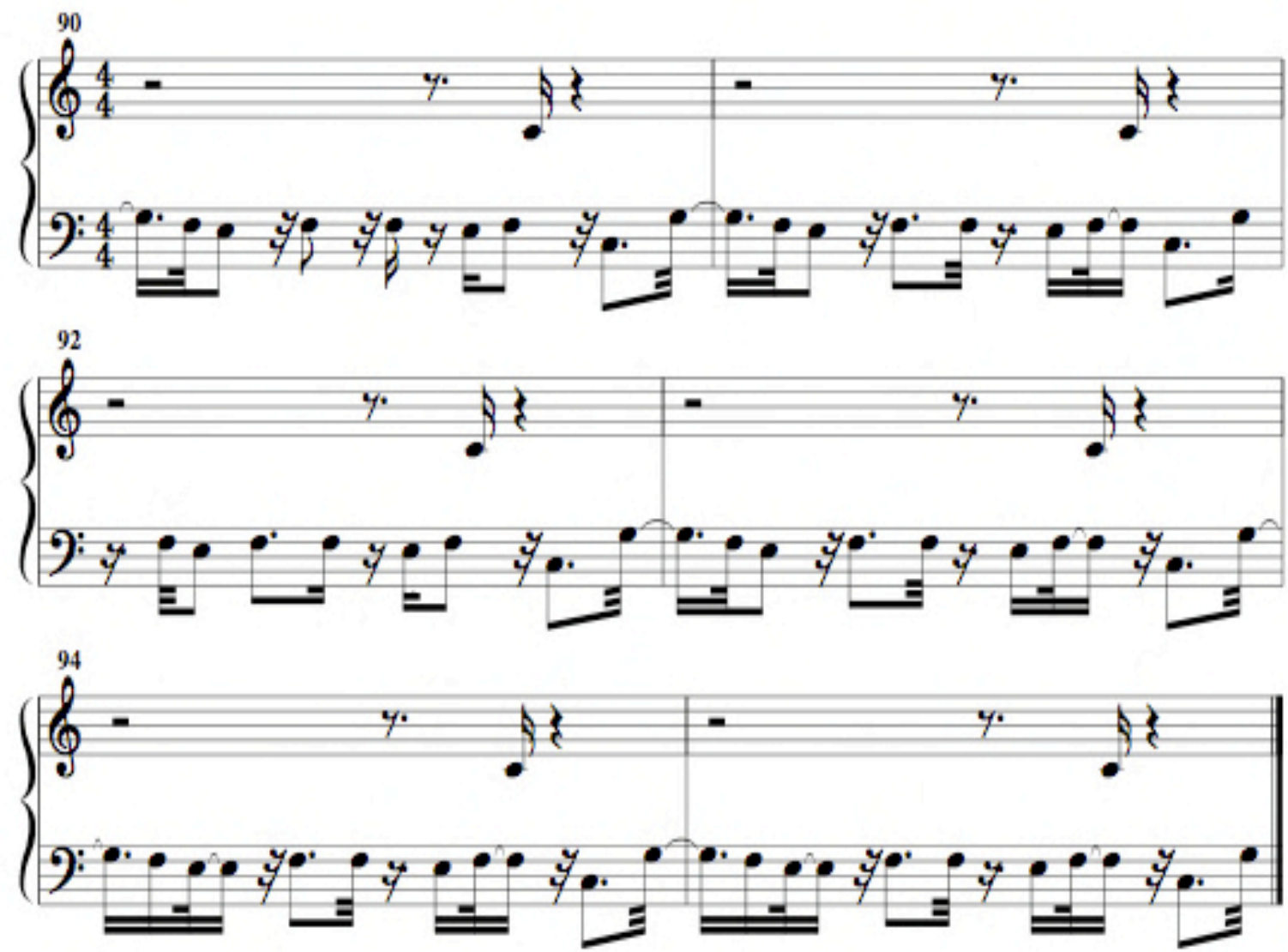


\section{Appendix L: Robert - Maraca Score}

\section{The Journey \\ Maraca}
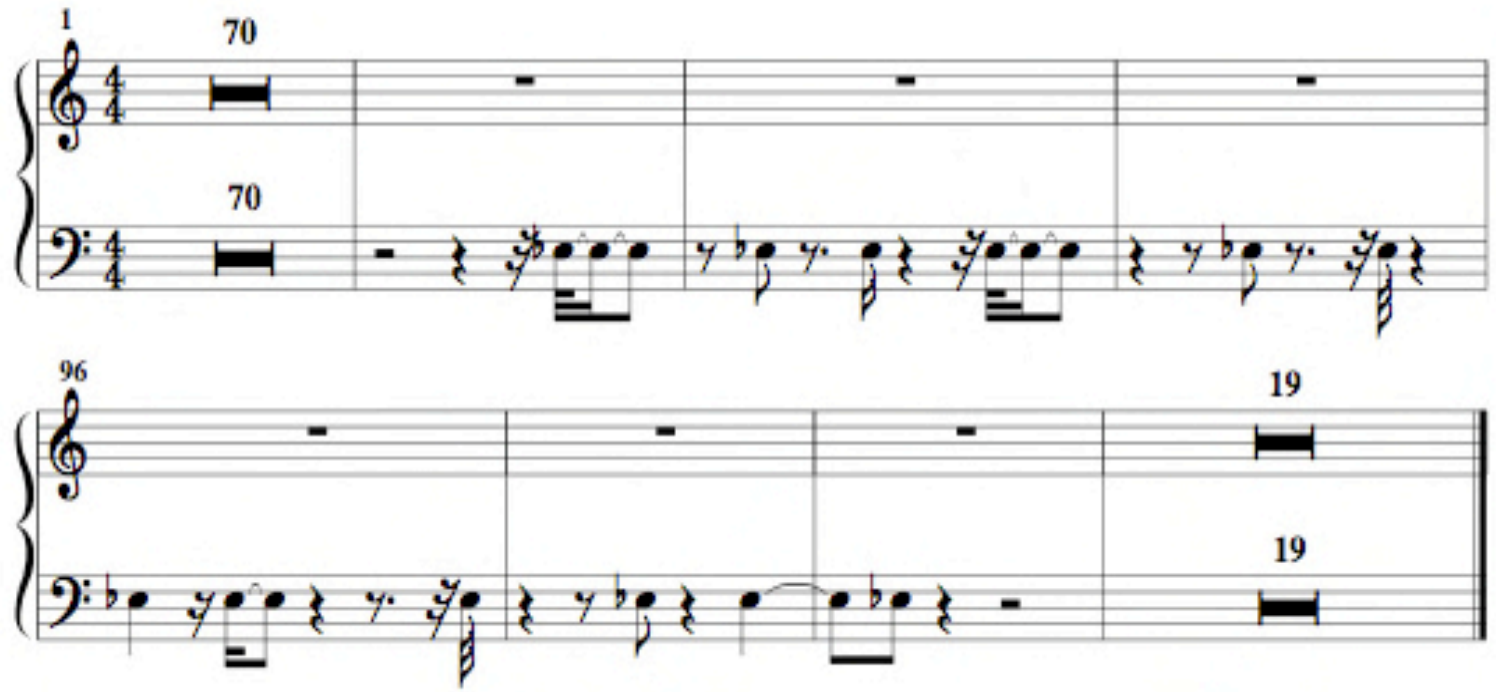
Appendix M: JEX15 - John

\section{JEX15 John}

\section{Voice}
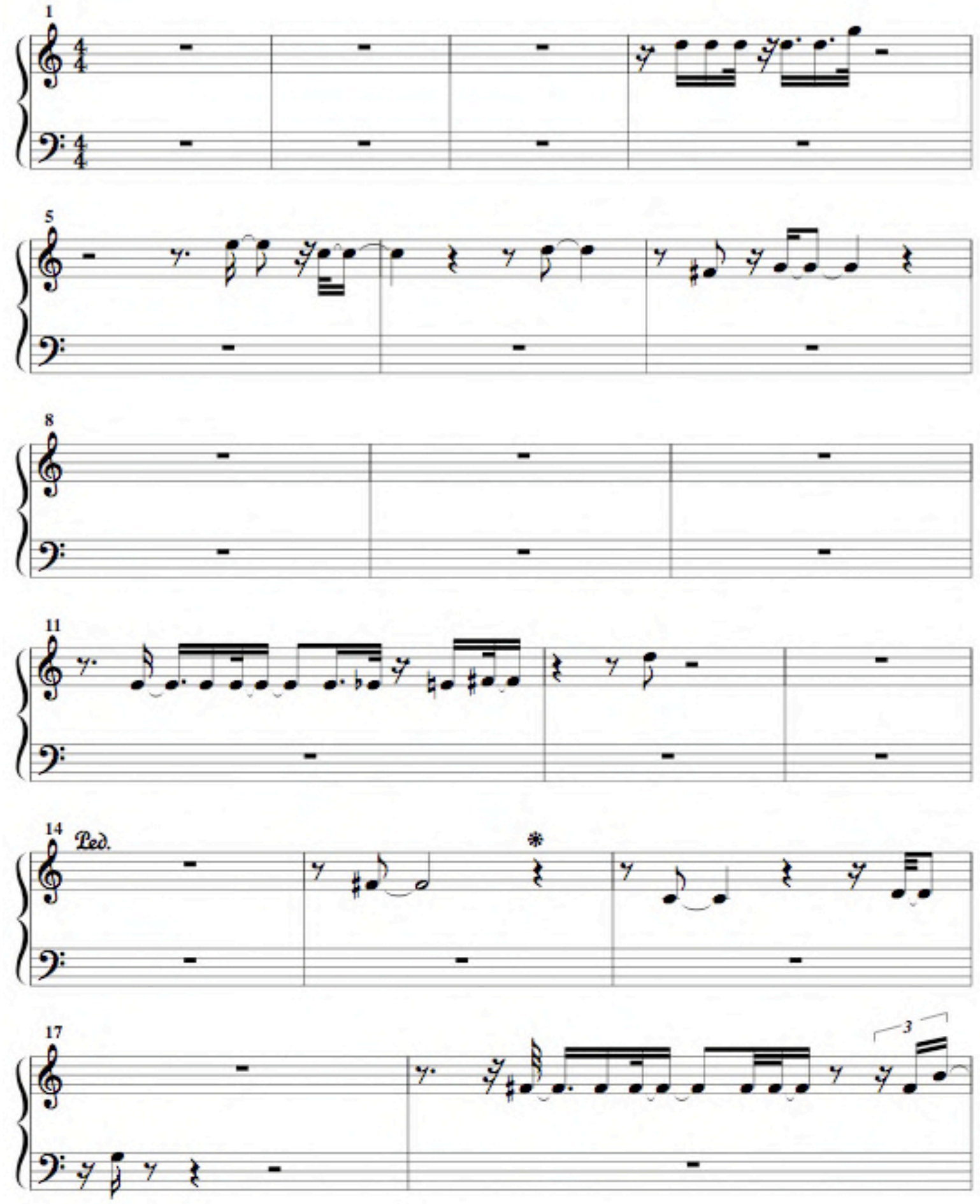

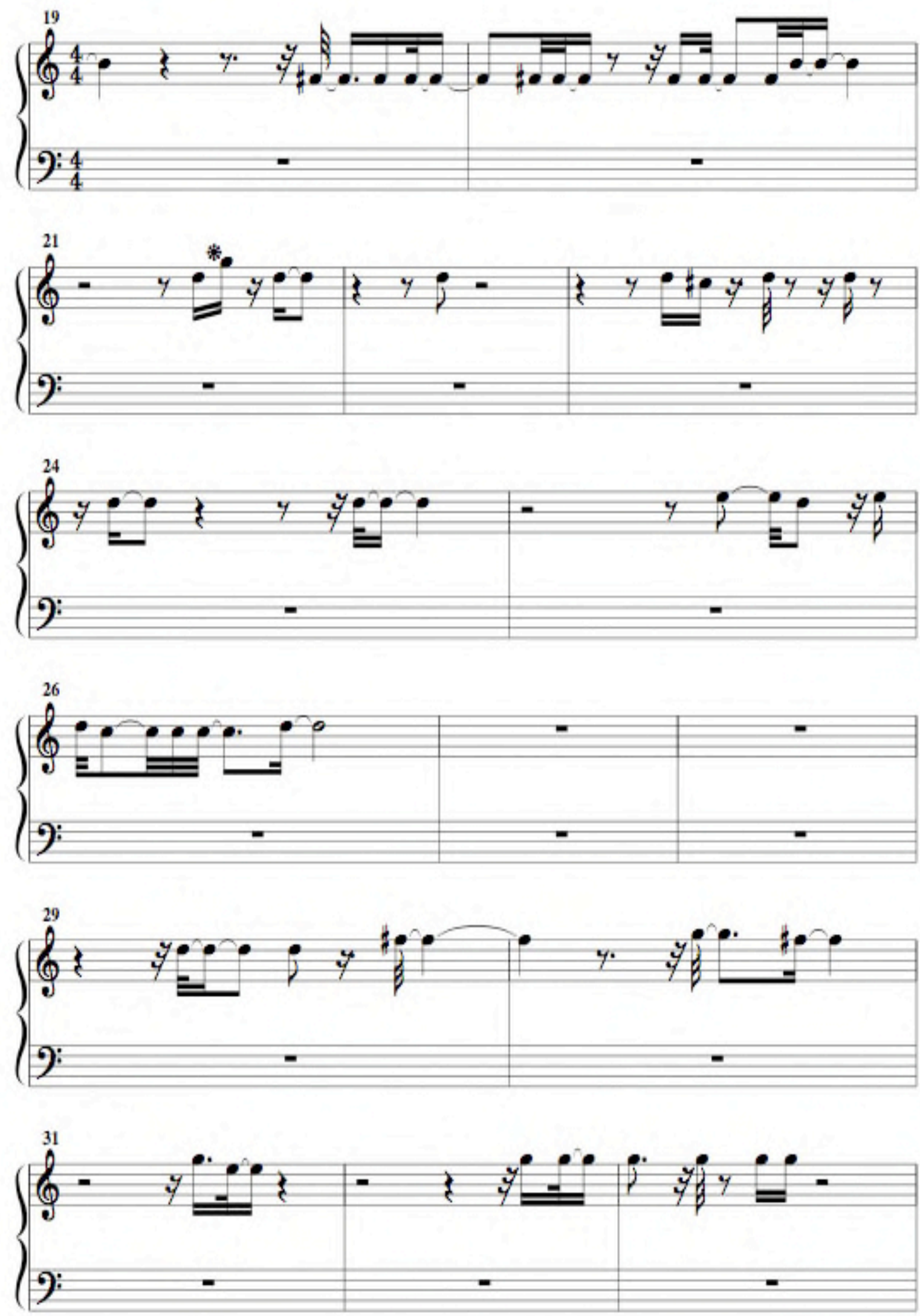

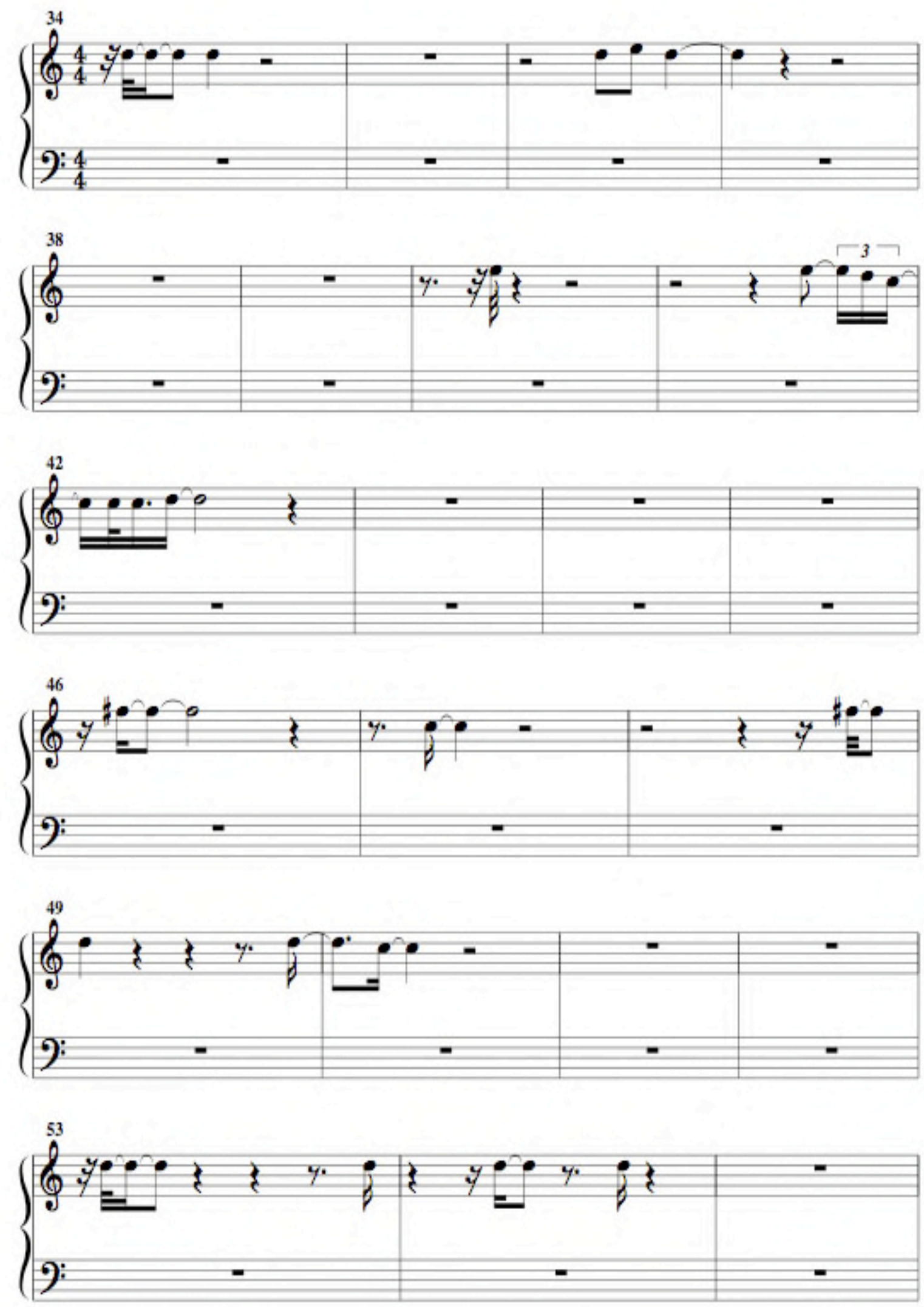
Analysing children's offerings in music therapy 111
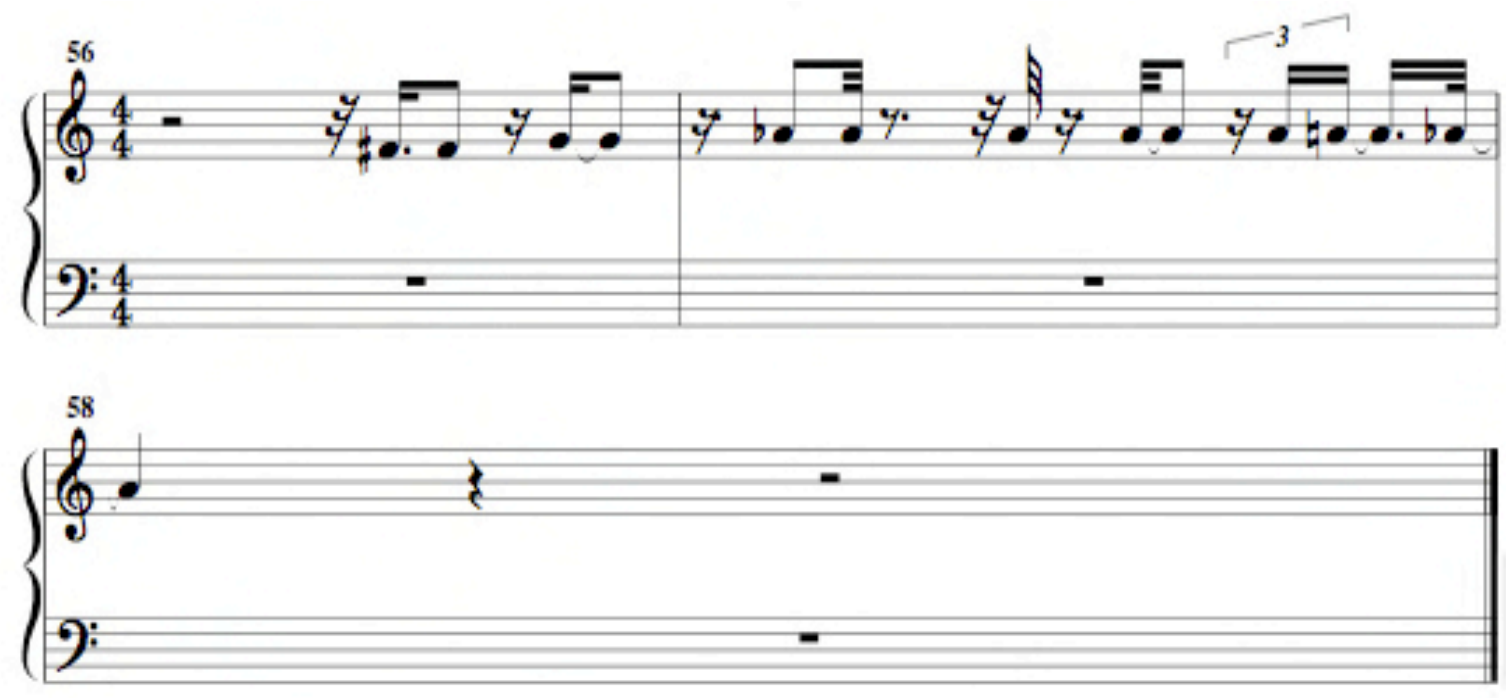
Appendix N: JEX15 - MT

\title{
JEX15 MT
}

\author{
Voice
}
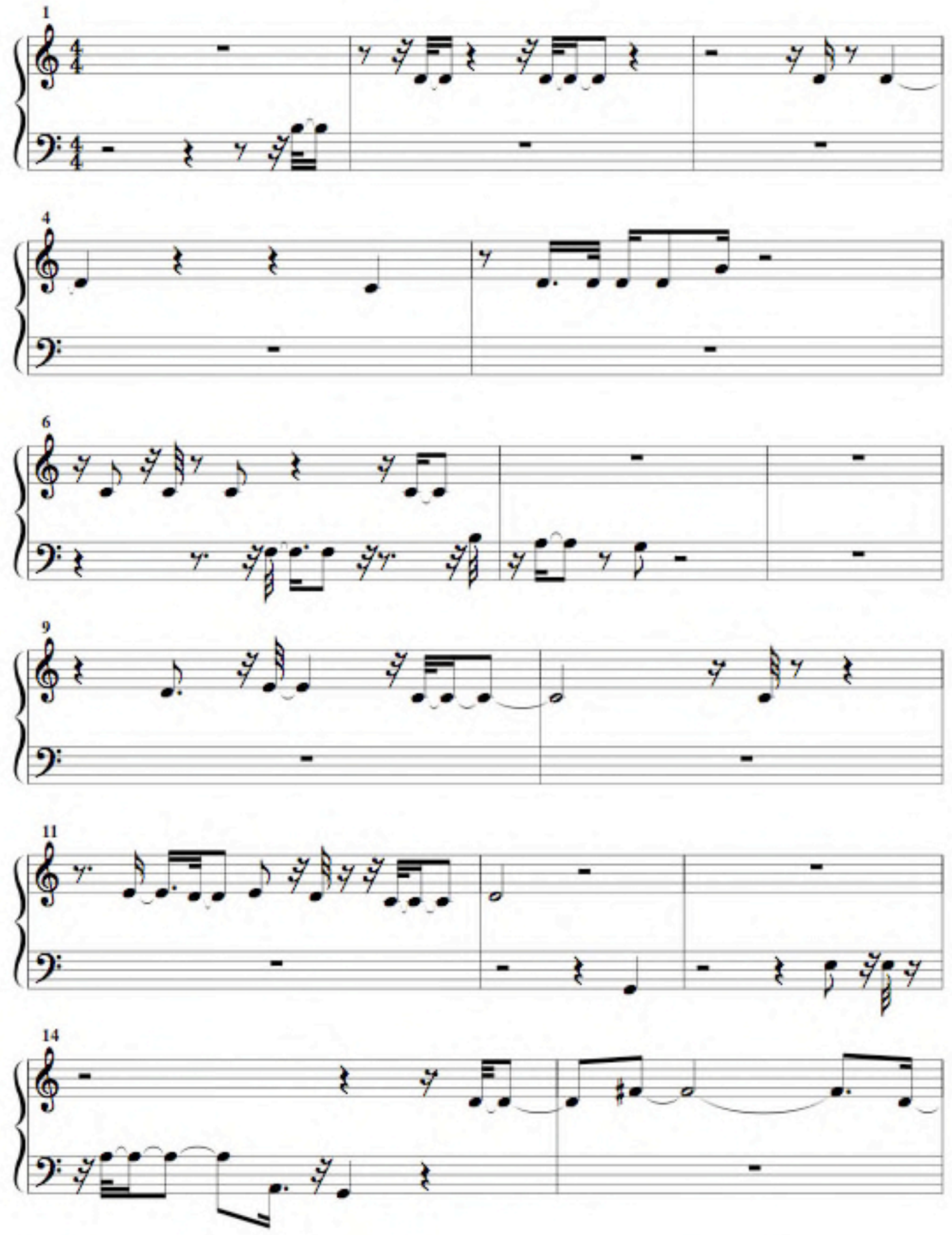

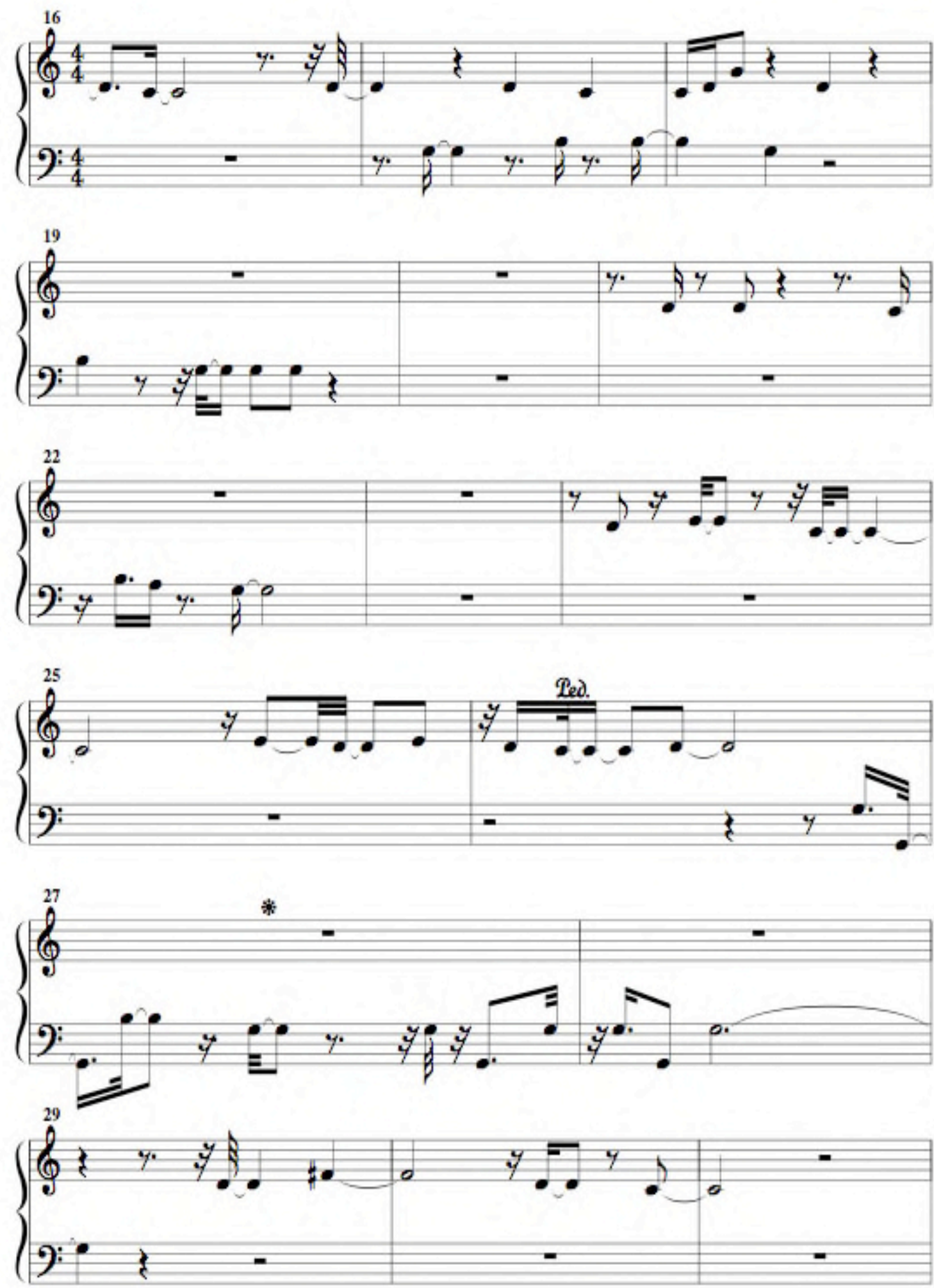

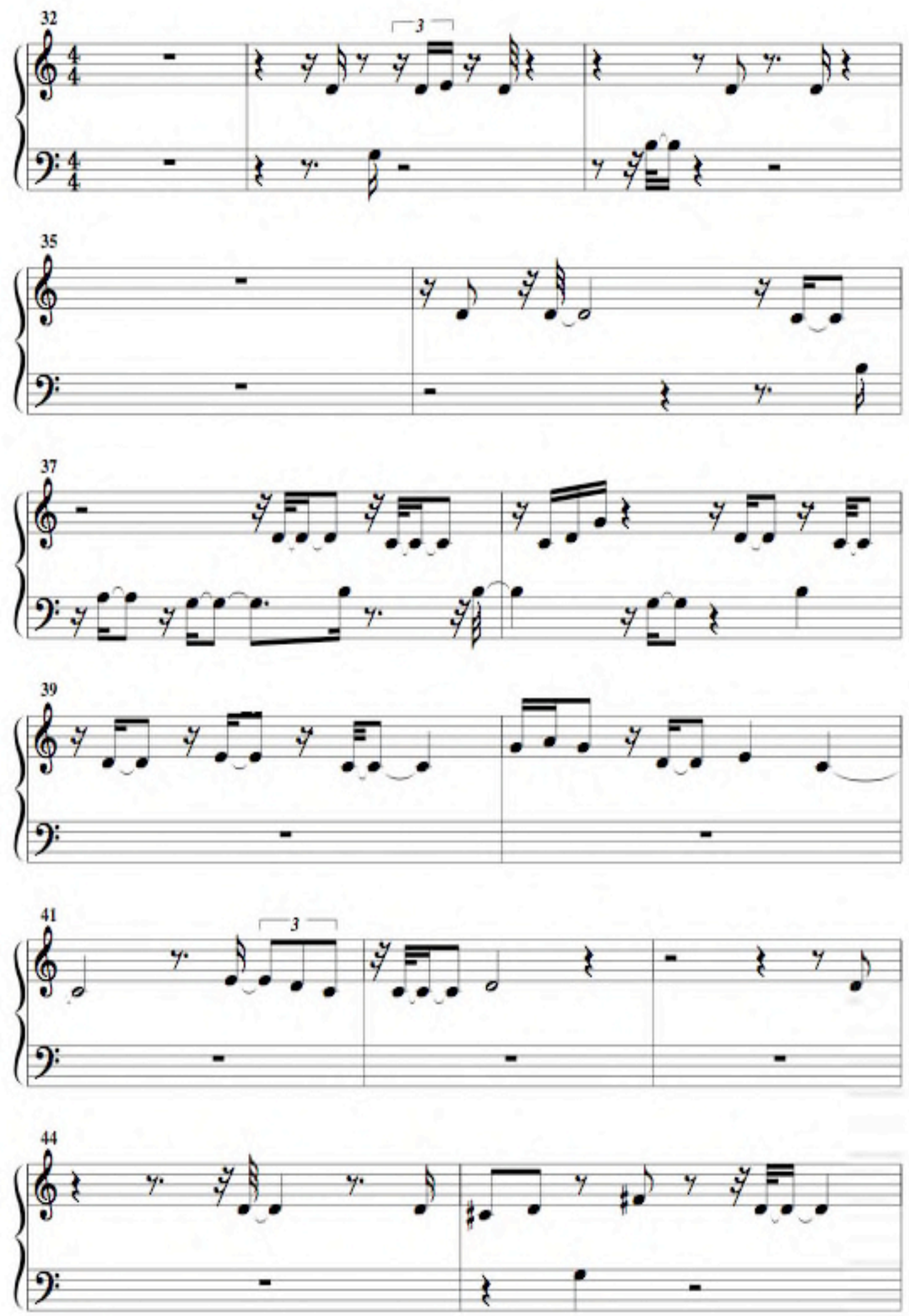

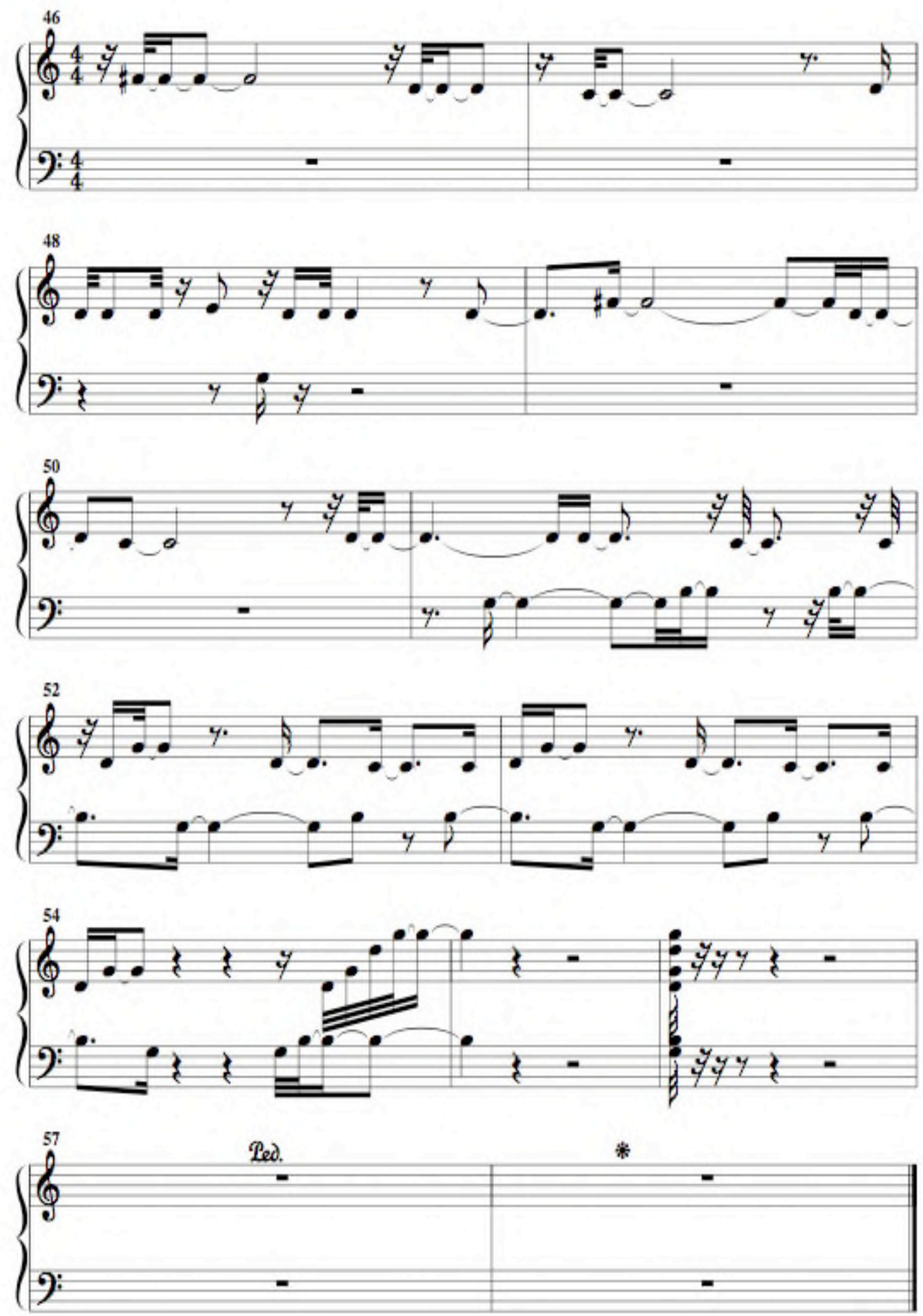
Appendix O: REX06 - Robert - Xylophone

REX06 - Bars 01 - 40

Robert - Xylophone
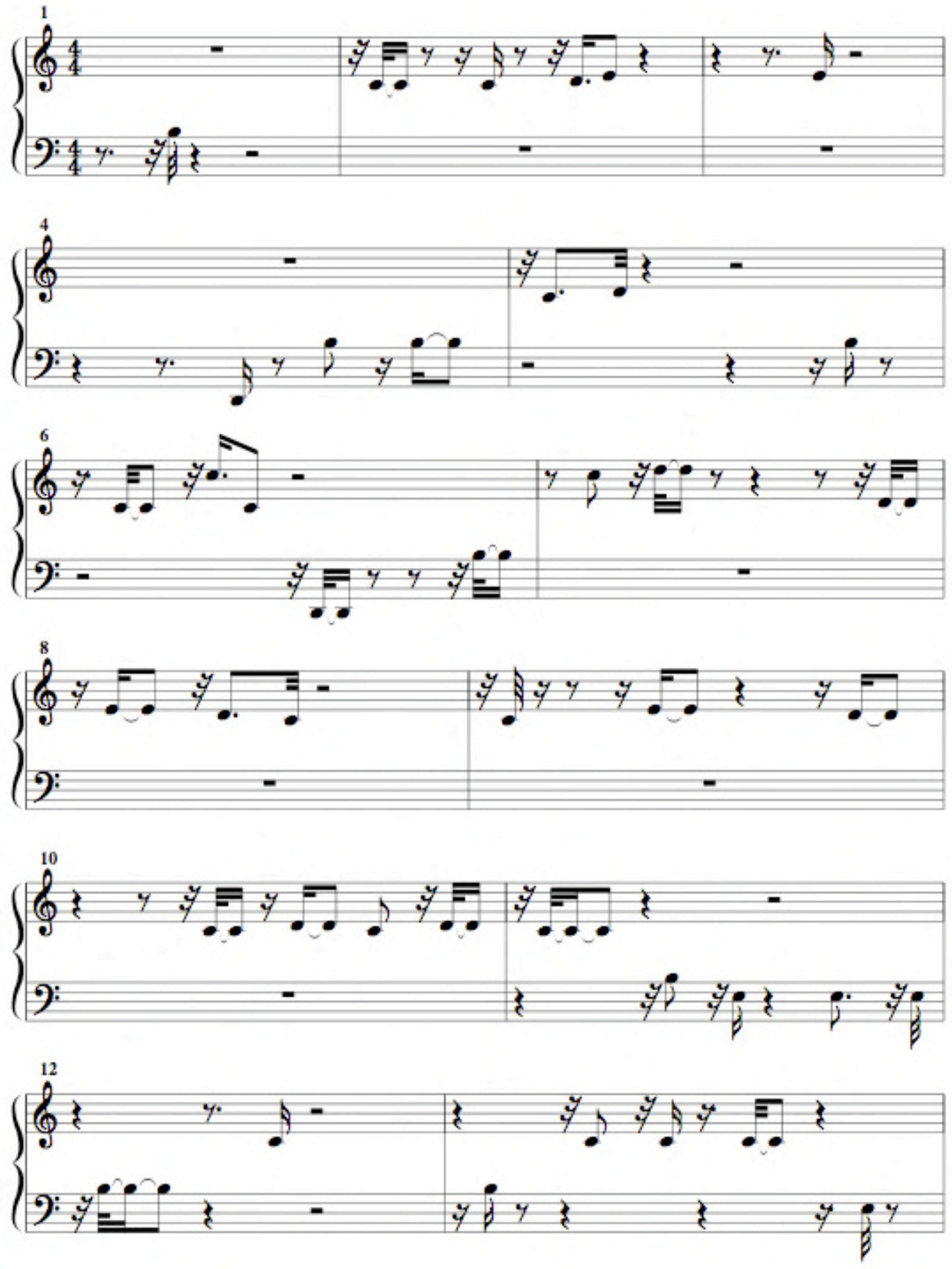

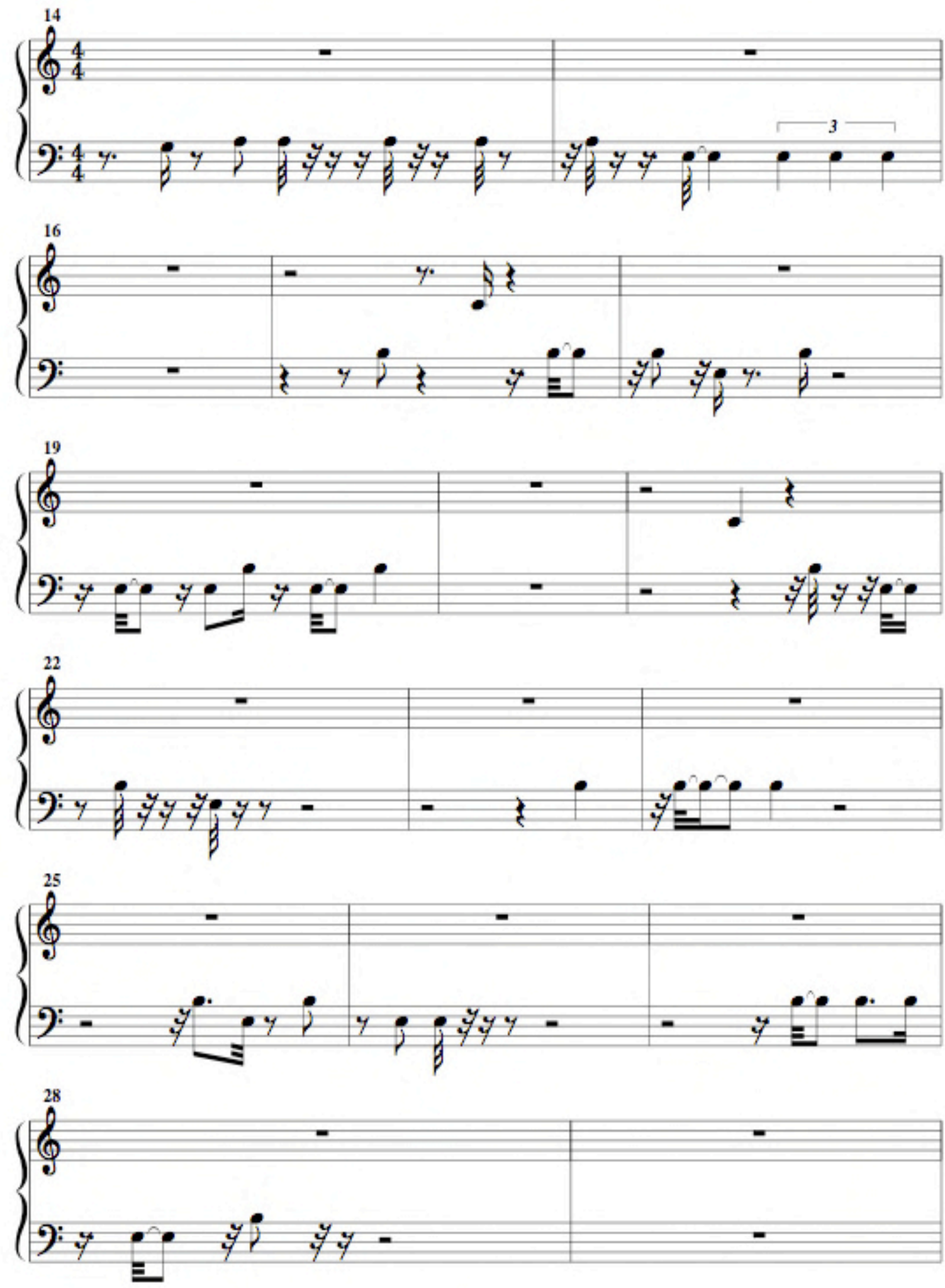
Analysing children's offerings in music therapy 118
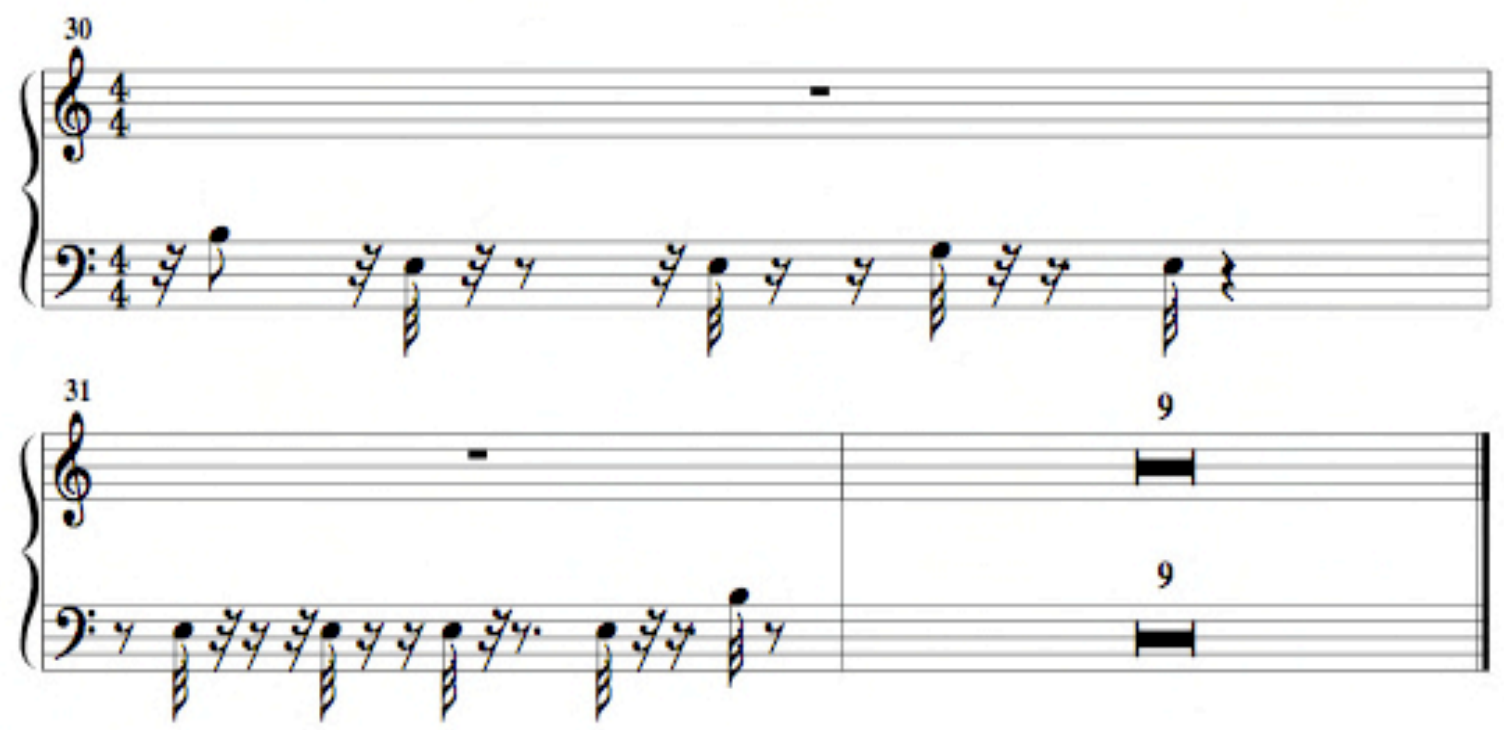
Analysing children's offerings in music therapy

119

Appendix P: REX06 - Robert - Voice

REX06 - Bars 01 - 40

Robert - Voice
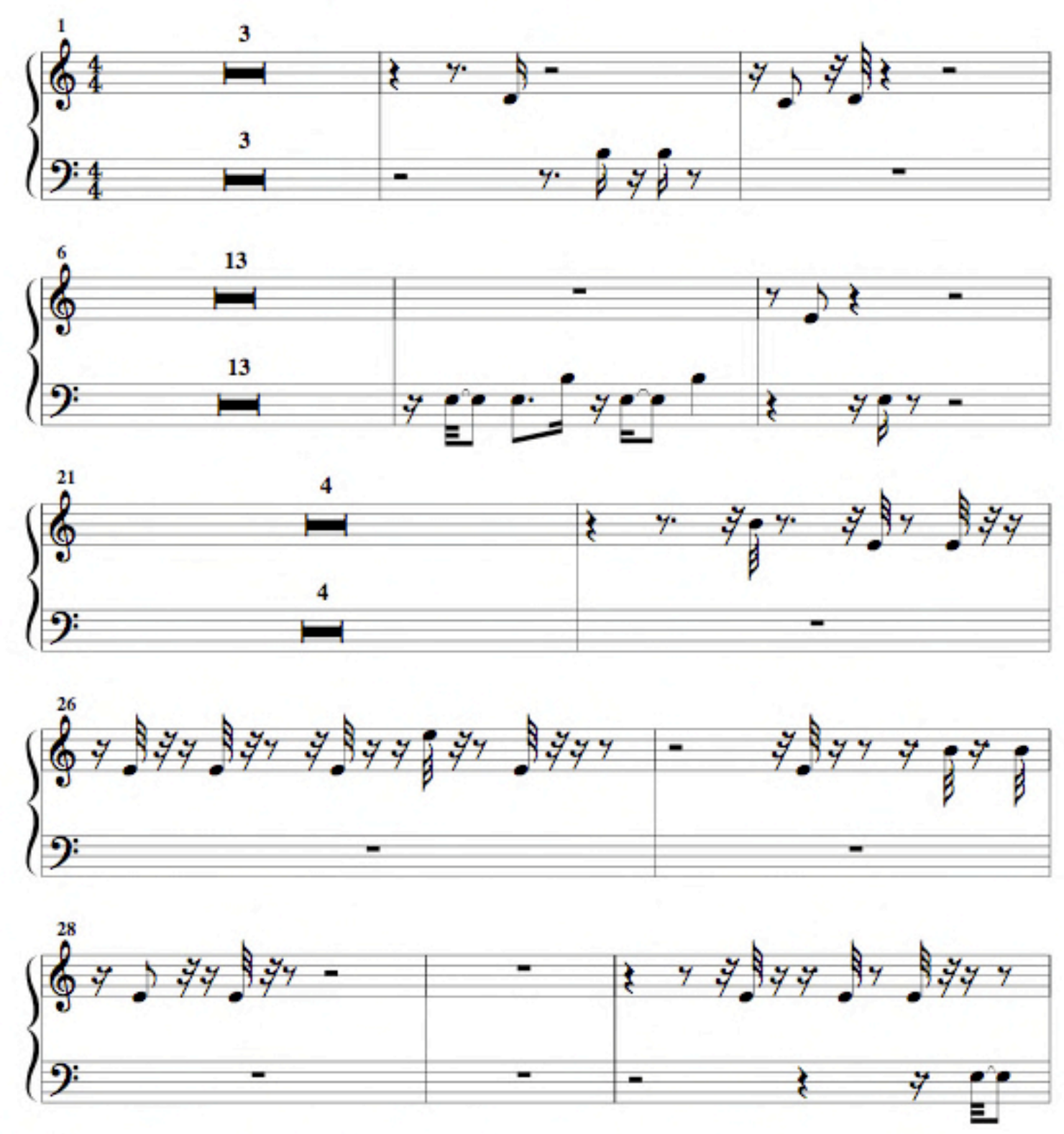

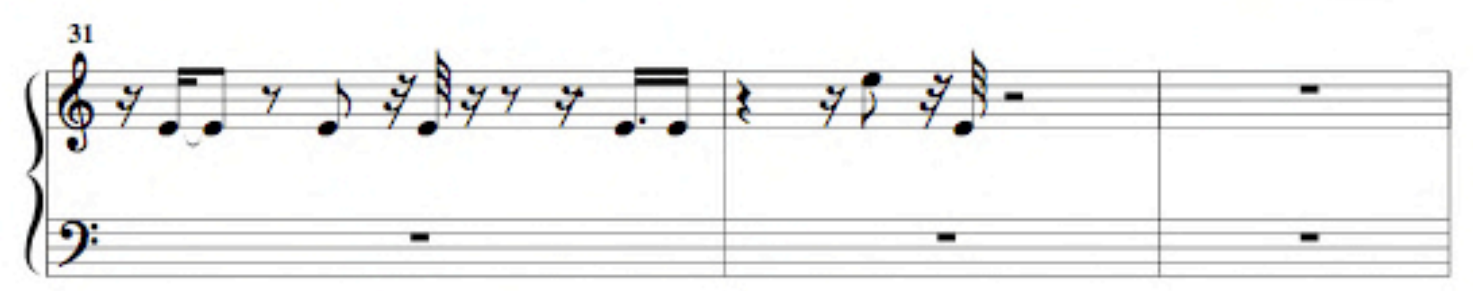



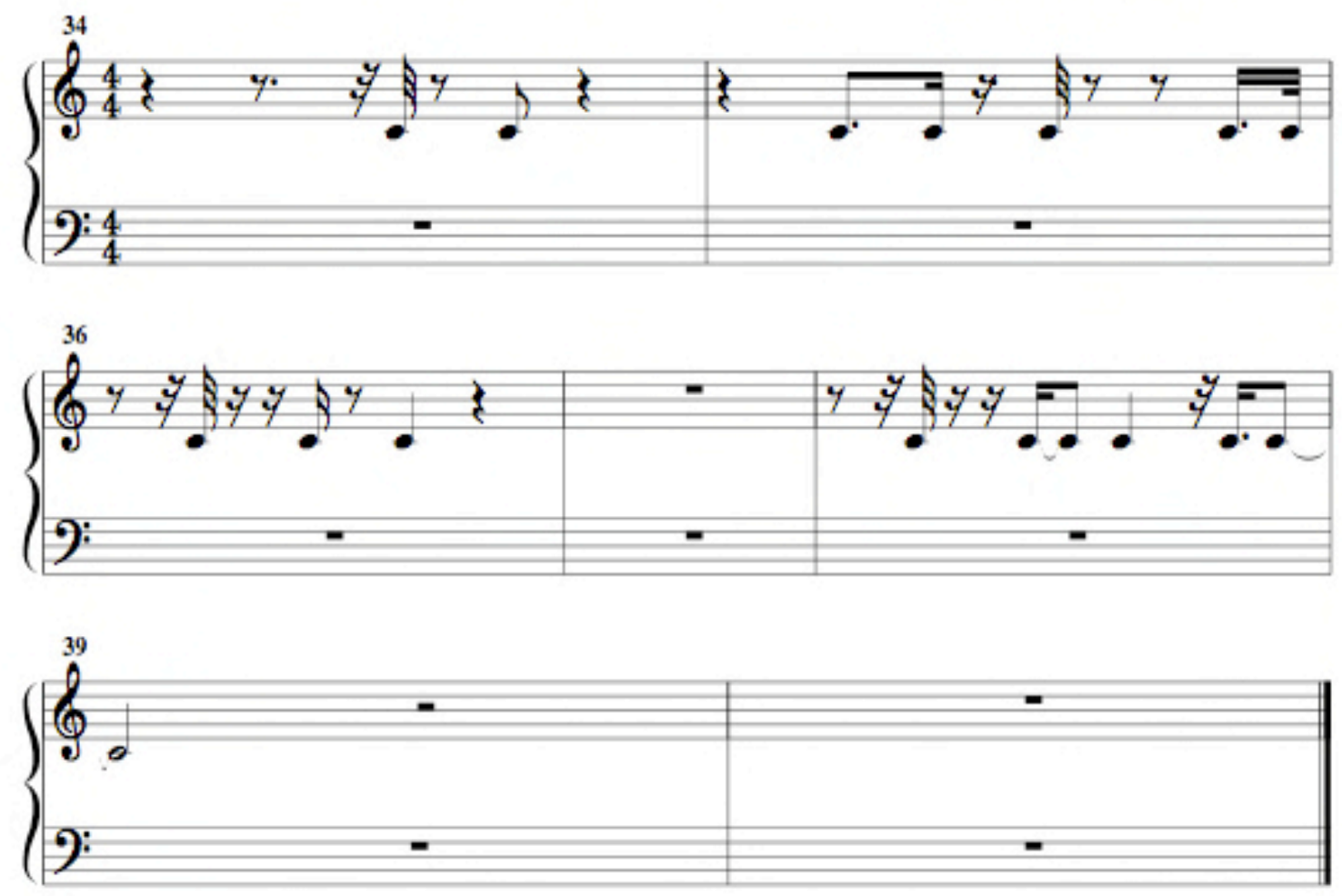


\title{
Appendix Q: REX06 - MT - Xylophone
}

REX06 - Bars 01 - 40

\author{
MT - Xylophone
}
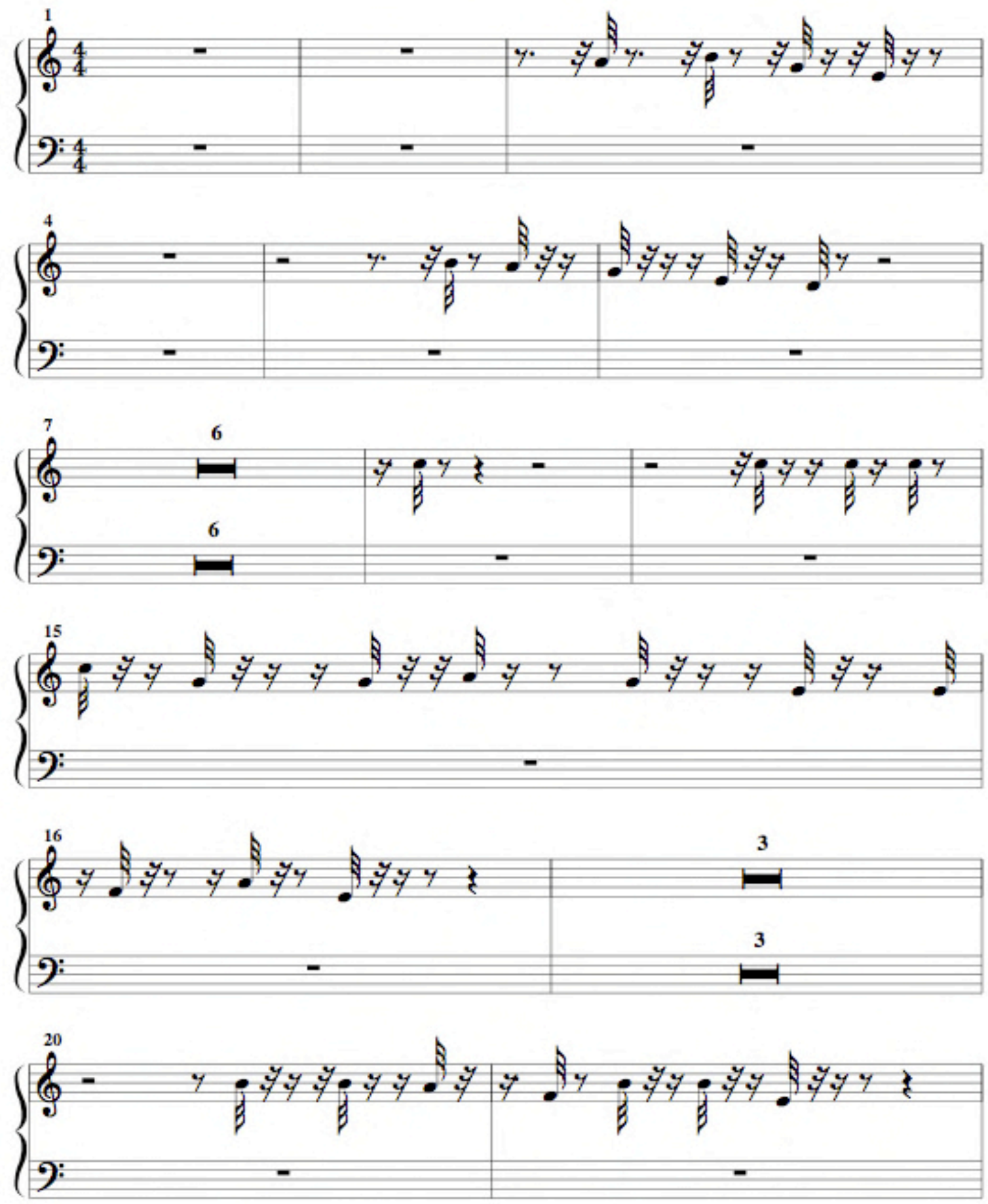

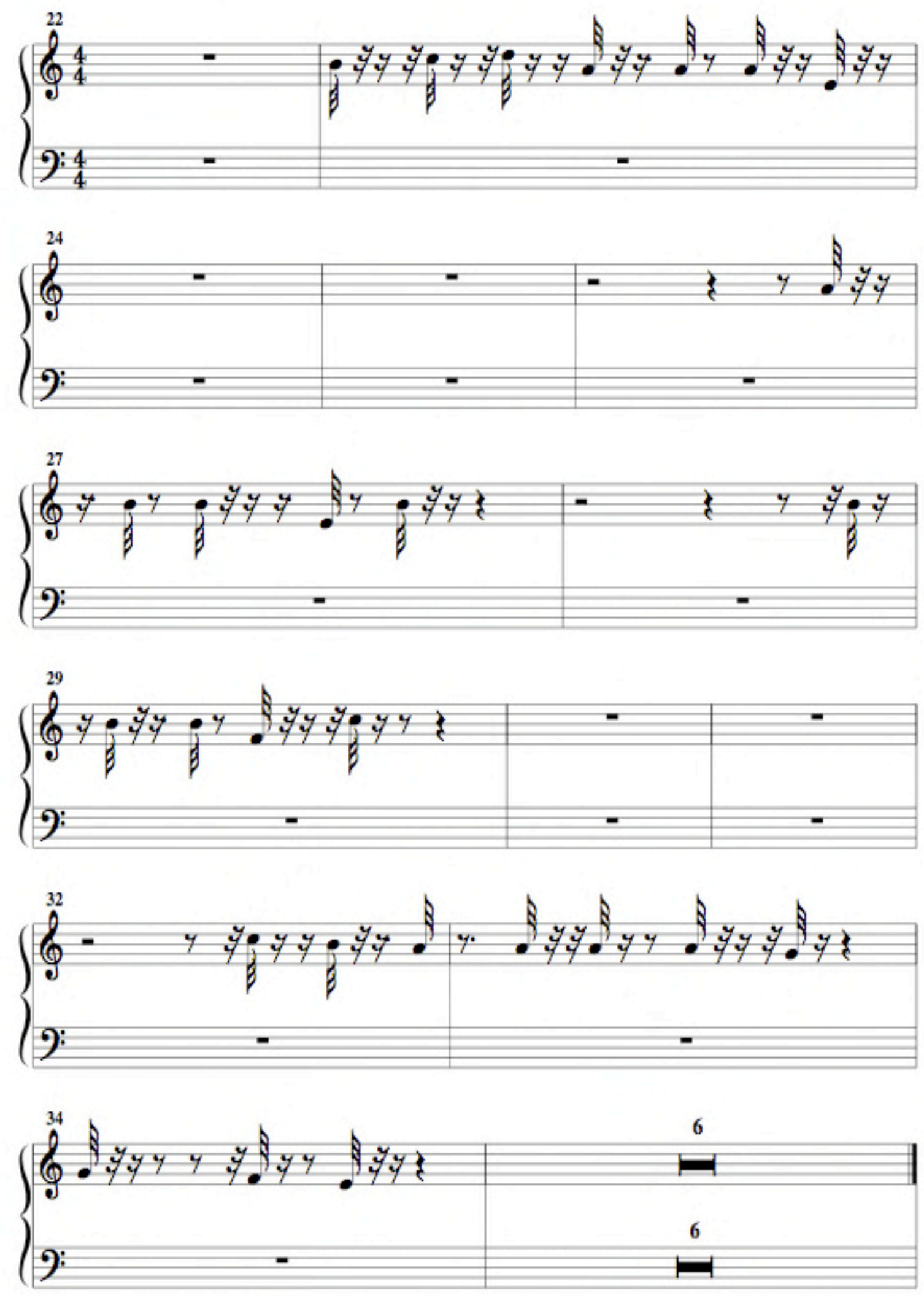
Appendix R: REX06 - MT - Voice

\section{REX06 - Bars 01 - 40 \\ MT - Voice}
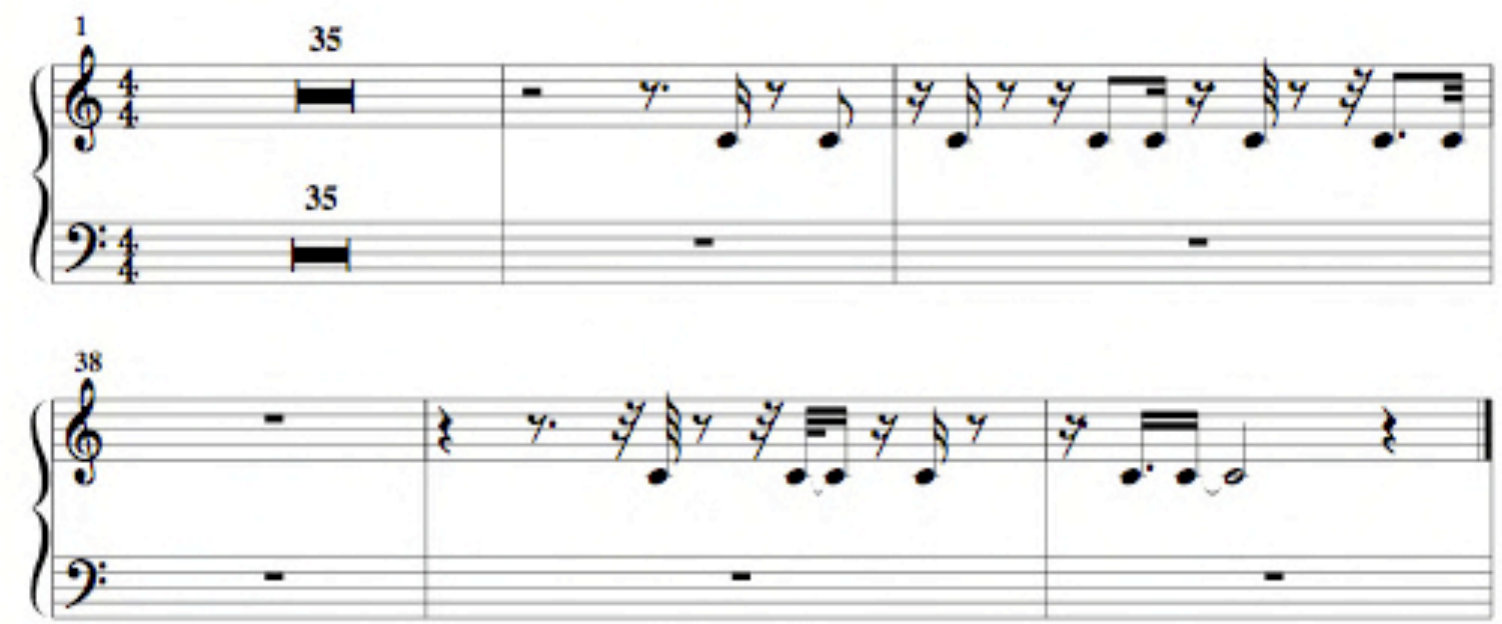


\section{Appendix S: Robert's excerpt chart}

\begin{tabular}{|c|c|c|c|c|}
\hline $\begin{array}{l}\text { Session } \\
\text { Number }\end{array}$ & $\begin{array}{l}\text { Session } \\
\text { Time } \\
\text { stamp }\end{array}$ & $\begin{array}{l}\text { Excerpt } \\
\text { Label }\end{array}$ & Where / Context & $\begin{array}{lc}\text { Excerpt } & * * * \text { Impressionistic } \\
\text { Description } & \text { title }\end{array}$ \\
\hline $\mathrm{S} 1$ & $\begin{array}{l}04: 42- \\
05: 34\end{array}$ & REX01 & $\begin{array}{l}\text { Prior to } \\
\text { starting Old } \\
\text { McDonald }\end{array}$ & $\begin{array}{l}\text { During a pause between activities, } \mathrm{R} \text { starts displaying } \\
\text { agitation. My first reaction is to be agitated! His } \\
\text { teacher aide interjects with explanation on behavioural } \\
\text { issues during the week. R is drawn out of agitation } \\
\text { "pattern' by me starting the next planned activity "Old } \\
\text { McDonald" with a strong rhythm. } \\
* * * \text { Getting lost and found }\end{array}$ \\
\hline
\end{tabular}

S1 00:54 - REX02 In Hello song 1:05

In the 'Hello song', I ask "how are you today?". After a period of silence, I then offer "you OK?" R responds "you OK". Echolalia is debatable, for while R repeats my phrase "you OK", his intonation dropped (00:09), as in what would be expected in an answer.

$* * *$ Speaking the same language?

S1

04:17 - REX03

Prior to

starting an improvisation activity.

In setting up an improvisation activity, I ask R to choose either a 'shaker' or a 'drum'. In retrospect, I didn't phrase the question well, modeling "I want shaker - or - I want drum", which may have confused him - was I talking to him or about myself? However, R's response appears classically echolalic, copying practically every word I said. He did reach for the shaker, but without saying the aimed at phrase - "I want shaker". I ended up stating his choice for him. Perhaps I should have given him more silence / 'space'.

$* * *$ Table tennis

$\begin{array}{lll}\text { S3 22:33 - REX04 } & \begin{array}{l}\text { At the end of } \\ \text { his session }\end{array}\end{array}$

At the end of his session, R's teacher aide turns him to face me and models "Bye Shane"; $R$ responds "Bye Shane". I wasn't totally sure, but felt it was an example of echolalia as immediately afterwards, $R$ began vocalising and turns away - there didn't seem any engagement in his farewell.

*** Parroting away 


\begin{tabular}{|c|c|c|c|}
\hline $\begin{array}{l}10: 02- \\
10: 21\end{array}$ & REX05 & $\begin{array}{l}\text { In xylophone } \\
\text { improvisation }\end{array}$ & $\begin{array}{l}\text { During a xylophone improvisation, I play a glissando } \\
\text { and } \mathrm{R} \text { answers with one or two short notes. This occurs } \\
\text { several times. } \\
* * * \text { Lessons in punctuation }\end{array}$ \\
\hline $\begin{array}{l}14: 42- \\
20: 16\end{array}$ & REX06 & $\begin{array}{l}\text { In xylophone } \\
\text { improvisation } \\
\text { with } \\
\text { vocalisations }\end{array}$ & $\begin{array}{l}0: 00 \text { - Xylo conversation } \\
0: 36 \text { - R adds vocalizations to his xylo } \\
\text { 1:07 - R stops xylo and keeps going vocalizations } \\
\text { 1:24 - I start xylo again (his) with mirror / R continues } \\
\text { with vocal and xylo - quiet } \\
\text { 2:02 - 2:33 R introduces new vocalisation motif, I } \\
\text { mirror } \\
\text { 2:33 - R throws his beaters away; I retrieve them } \\
\text { 3:35 - R brings back the same motif as at } 0: 36 \\
\text { 3:34 - I start guitar containment and sing about R } \\
\text { 4:14 - R starts beating xylophone agressively, so I } \\
\text { match } \\
5: 03 \text { - I start singing to "play with two hands" as he's } \\
\text { putting one of the beaters in his mouth } \\
* * * \text { A journey of discovery through an enchanted } \\
\text { forest }\end{array}$ \\
\hline
\end{tabular}

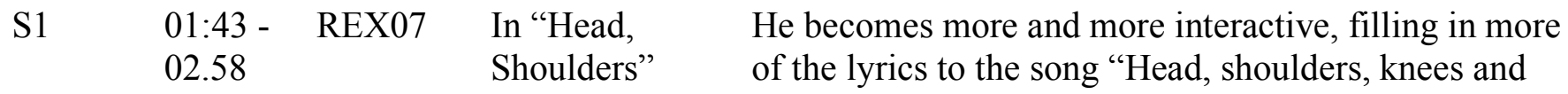

S2 00:05 - REX08 In Hello song toes", singing along with me by the end.

\section{***A quivering, little bunny - slowly gaining confidence to interact.}

$00: 56$

I play his Hello song but this time it's a shortened version with an emphasized off-beat; Ryan plays on the drum in time.

*** Dancing a new rhythm
S2 17:22 - REX09 In "Ryan is 18:02 playing the xylophone" improvisation (me on guitar)
Ryan playing in time to my blues though I had to stop once or twice to get his attention.

S3 20:16- REX10
In Goodbye song, Ryan on xylophone
S4 20:44 - REX11 In Goodbye $21: 10$ song
He starts accompanying on xylophone a little arhythmically, but quickly falls into rhythm.
During 'Goodbye song', Ryan started humming along, with some accuracy in timing and pitch




\begin{tabular}{|c|c|c|c|c|}
\hline S5 & $\begin{array}{l}00: 07- \\
00: 29\end{array}$ & REX12 & In Hello song & $\begin{array}{l}\text { Ryan was playing with a toy in the far corner of the } \\
\text { room. When I beckoned him with my voice, and } \\
\text { started playing his 'Hello song', he stopped vocalizing } \\
\text { and ran and threw himself in front of me. At the first } \\
\text { opportunity for him to participate, he engaged, } \\
\text { stating/singing "sun-ny-day". }\end{array}$ \\
\hline S5 & $\begin{array}{l}05: 35- \\
05: 59\end{array}$ & REX13 & $\begin{array}{l}\text { In Old } \\
\text { McDonald }\end{array}$ & $\begin{array}{l}\text { During "Old McDonald", Ryan suggested an animal, } \\
\text { verbalizing clearly, then followed through with the } \\
\text { appropriate sounds in the correct timing. }\end{array}$ \\
\hline S5 & $\begin{array}{l}08: 10- \\
08: 42\end{array}$ & REX14 & $\begin{array}{l}\text { In Old } \\
\text { McDonald }\end{array}$ & $\begin{array}{l}\text { During "Old McDonald", Ryan suggested an animal, } \\
\text { verbalizing clearly, then followed through with the } \\
\text { appropriate sounds in the correct timing. }\end{array}$ \\
\hline S5 & $\begin{array}{l}15: 25- \\
15: 51\end{array}$ & REX15 & $\begin{array}{l}\text { In "Ryan is } \\
\text { playing the } \\
\text { xylophone" } \\
\text { improvisation } \\
\text { (me on guitar) }\end{array}$ & $\begin{array}{l}\text { Ryan immediately played forte and in time with the } \\
\text { song "Ryan is playing the drum" - } 12 \text { bar blues. }\end{array}$ \\
\hline S5 & $\begin{array}{l}02: 30- \\
03: 39\end{array}$ & REX16 & $\begin{array}{l}\text { In "Head, } \\
\text { Shoulders" }\end{array}$ & $\begin{array}{l}\text { Ryan laughed and engaged the whole song (Head, } \\
\text { shoulders); sang most of the lyrics and pointed at the } \\
\text { correct body parts. }\end{array}$ \\
\hline S6 & $\begin{array}{l}04: 13- \\
05: 24\end{array}$ & REX17 & $\begin{array}{l}\text { In Old } \\
\text { McDonald }\end{array}$ & $\begin{array}{l}\text { Ryan is singing almost every word now, not just the } \\
\text { animal name and sound. His xylophone playing grew } \\
\text { louder when he heard his name (?) }\end{array}$ \\
\hline S6 & $\begin{array}{l}16: 29- \\
16: 55\end{array}$ & REX18 & $\begin{array}{l}\text { In Goodbye } \\
\text { song }\end{array}$ & $\begin{array}{l}\text { During final goodbye song, Ryan plays in time and } \\
\text { moderately loudly and at 00:17, you can hear him sing } \\
\text { "for your" in perfect pitching \& timing. }\end{array}$ \\
\hline $\mathrm{S} 1$ & $\begin{array}{l}00: 23- \\
00: 32\end{array}$ & REX19 & In Hello song & $\begin{array}{l}\text { During his 'Hello Song', I ask through lyrics how he } \\
\text { is. he responds with a tuneful vocalisation. - analyse } \\
\text { his tune line vs. mine } \\
\text { A songbird - not direct mirror, but still an answer }\end{array}$ \\
\hline $\mathrm{S} 2$ & $\begin{array}{l}09: 15- \\
09: 22\end{array}$ & REX20 & $\begin{array}{l}\text { In Old } \\
\text { McDonald }\end{array}$ & $\begin{array}{l}\text { In "Old McDonald", I make a chicken noise and he } \\
\text { 'echoes'? makes his own noise. }\end{array}$ \\
\hline $\mathrm{S} 2$ & $\begin{array}{l}10: 36- \\
10: 46\end{array}$ & REX21 & $\begin{array}{l}\text { In xylophone } \\
\text { improvisation }\end{array}$ & $\begin{array}{l}\text { Non-referential improvisation, Ryan playing high } \\
\text { notes on xylophone ... imitation? }\end{array}$ \\
\hline S4 & $\begin{array}{l}12: 13- \\
12: 22\end{array}$ & REX22 & $\begin{array}{l}\text { In xylophone } \\
\text { improvisation, } \\
\text { echo of motif } \\
\text { in REX06 }\end{array}$ & $\begin{array}{l}\text { During the xylophone improvisation, he vocalizes a } \\
\text { motif that is an echo to one who vocalised in the } \\
\text { previous session. }\end{array}$ \\
\hline S6 & $\begin{array}{l}14: 14- \\
14: 43\end{array}$ & REX23 & $\begin{array}{l}\text { Drum } \\
\text { improvisation }\end{array}$ & $\begin{array}{l}\text { At the end of a drum improvisation exercise, I call an } \\
\text { end to the exercise. Ryan then starts up his own } \\
\text { rhythm with vocalisations. }\end{array}$ \\
\hline
\end{tabular}




\section{Appendix T: Research Information Form for participant's parents}

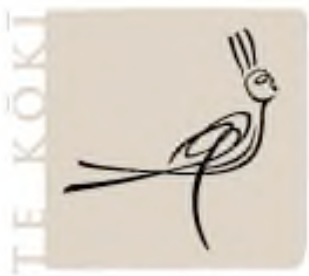

NEW ZEALAND SCHOOL

\section{RESEARCH INFORMATION FOR PARENTS}

\section{Central idea}

Musical interaction is nonverbal communication. I would like to carefully examine the musical material that children produce in music therapy sessions, to help to gain a better understanding of them. Once I have completed the analysis of the music offered by each child and identified the important musical themes, I intend to write songs that contain those themes. Each song can then be viewed as a representation of a particular child's 'voice'.

\section{Research participants}

\section{How I plan to choose which children will participate in the research:}

All children currently involved at $* * * * * * * * * *$ School undergoing music therapy are invited to participate in this research. This information sheet and a consent form will be sent home and parents and children are welcome to ask any questions at any stage of the research process. From the consent forms received back, two children will be randomly picked, using a lottery-based system of 'names in a hat'. I will inform you whether your child is selected or not, and if he / she is not included initially I will keep your consent on file for the duration of the study and will let you know if he / she can be included in the future.

The particular style of research I'm proposing poses no risks to your child; the research data will be drawn from music therapy sessions which would occur with or without the presence of the research study. Your child will not be introduced to anything out of the ordinary, but will be observed via audio recording during their normal music therapy interactions.

\section{Project Procedures}

The data will be held, following the completion of the project, for ten years in a locked cabinet at the New Zealand School of Music, and then destroyed. No real names will be used in the reporting of the data. Pseudonyms will be used to protect the identity of the students and the school where this research is taking place.

The research data will be available for viewing by academic staff (supervisors) at the New Zealand School of Music. The research report may be published more widely, for example presentations or publications. 


\section{Participant's Rights}

You are under no obligation to accept this invitation. If you are happy for your child to participate, you have the right to:

- withdraw him or her from the project at any time without giving reason until the end of the data collection period;

- ask questions about the study at any time during participation;

- provide information on the understanding that you and your child's name will not be used in any reporting of data;

- be given access to a summary of the project findings when it is concluded;

- ask for the audiotape to be turned off at any time during the session.

\section{Ethics}

This study has been reviewed and approved by the Central Regional Ethics Committee, Ministry of Health, New Zealand. If you have any concerns about the conduct of this research that you wish to raise with someone other than the researcher, please contact Daphne Rickson (Research Supervisor) or the Central Regional Ethics Committee. 


\section{Appendix U: Participant Consent Form}

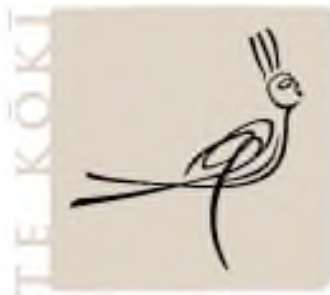

NEW ZEALAND SCHOOL:MUSIC

\section{PARTICIPANT CONSENT}

This consent form will be held for a period of ten (10) years

I have read the Research Information for Parents forms and have had the details of the study explained to me. My questions have been answered to my satisfaction, and I understand that I may ask further questions at any time.

I agree / do not agree to my child taking part in this research project.

I believe that my child would have chosen and consented to participate in this study if he / she had been able to understand the information that I have received and understood.

I understand that music therapy sessions for my child will be audio-recorded for the purposes of this research project.

I wish / do not wish to have the recordings returned to me.

I agree to participate in this study under the conditions set out in the Information Sheet.

Child's full name (please print)

Parent(s) full names (please print) 


\section{Appendix V: CD Track List}

$\begin{aligned} \text { Track \# } & \text { John's Music } \\ 1 & \text { Life is Good } \\ 2 & \text { JEX01 } \\ 3 & \text { JEX02 } \\ 4 & \text { JEX03 } \\ 5 & \text { JEX04 } \\ 6 & \text { JEX05 } \\ 7 & \text { JEX06 } \\ 8 & \text { JEX07 } \\ 9 & \text { JEX08 } \\ 10 & \text { JEX09 } \\ 11 & \text { JEX10 } \\ 12 & \text { JEX11 } \\ 13 & \text { JEX12 } \\ 14 & \text { JEX13 } \\ 15 & \text { JEX14 } \\ 16 & \text { JEX15 } \\ 17 & \text { JEX16 } \\ 18 & \text { JEX17 } \\ 19 & \text { JEX18 } \\ 20 & \text { JEX19 } \\ 21 & \text { JEX20 } \\ 22 & \text { JEX21 } \\ 23 & \text { JEX22 } \\ 24 & \text { JEX23 } \\ 25 & \text { JEX24 } \\ 26 & \text { JEX25 } \\ 27 & \text { JEX26 } \\ 28 & \text { JEX38 } \\ 29 & \text { JEX28 } \\ 30 & \text { JEX29 } \\ 31 & \text { JEX30 } \\ 32 & \text { JEX31 } \\ 33 & \text { JEX32 } \\ 34 & \text { JEX33 } \\ 35 & \text { JEX34 } \\ 36 & \text { JEX35 } \\ 37 & \text { JEX36 } \\ 38 & \text { JEX37 } \\ 39 & \text { JEX38 }\end{aligned}$

$\begin{aligned} \text { Track \# } & \text { Robert's Music } \\ 40 & \text { The Journey } \\ 41 & \text { REX01 } \\ 42 & \text { REX02 } \\ 43 & \text { REX03 } \\ 44 & \text { REX04 } \\ 45 & \text { REX05 } \\ 46 & \text { REX06 } \\ 47 & \text { REX07 } \\ 48 & \text { REX08 } \\ 49 & \text { REX09 } \\ 50 & \text { REX10 } \\ 51 & \text { REX11 } \\ 52 & \text { REX12 } \\ 53 & \text { REX13 } \\ 54 & \text { REX14 } \\ 55 & \text { REX15 } \\ 56 & \text { REX16 } \\ 57 & \text { REX17 } \\ 58 & \text { REX18 } \\ 59 & \text { REX19 } \\ 60 & \text { REX20 } \\ 61 & \text { REX21 } \\ 62 & \text { REX22 } \\ 63 & \text { REX23 }\end{aligned}$

